NBER WORKING PAPER SERIES

\title{
INPUT AND TECHNOLOGY CHOICES IN REGULATED INDUSTRIES: EVIDENCE FROM THE HEALTH CARE SECTOR
}

\author{
Daron Acemoglu \\ Amy Finkelstein \\ Working Paper 12254 \\ http://www.nber.org/papers/w12254
NATIONAL BUREAU OF ECONOMIC RESEARCH
1050 Massachusetts Avenue
Cambridge, MA 02138
May 2006

We are grateful to David Autor, David Cutler, Jon Gruber, Jerry Hausman, Rob Huckman, Paul Joskow, Nolan Miller, Joe Newhouse, Joshua Rauh, Nancy Rose, Catherine Wolfram, and seminar participants at the MIT public finance and industrial organization lunches, the NBER Productivity conference, the NBER IO conference, the International Industrial Organization Conference, the Harvard-MIT-BU health seminar, and Chicago GSB for helpful comments. We also thank Adam Block, Amanda Kowalski, Matthew Notowidigdo, Erin Strumpf, and Heidi Williams for excellent research assistance. The views expressed herein are those of the author(s) and do not necessarily reflect the views of the National Bureau of Economic Research.

(C2006 by Daron Acemoglu and Amy Finkelstein. All rights reserved. Short sections of text, not to exceed two paragraphs, may be quoted without explicit permission provided that full credit, including $(\odot)$ notice, is given to the source. 
Input and Technology Choices in Regulated Industries: Evidence From the Health Care Sector Daron Acemoglu and Amy Finkelstein

NBER Working Paper No. 12254

May 2006

JEL No. H51, I18, L50, L51, O31, O33

\begin{abstract}
This paper examines the implications of regulatory change for the input mix and technology choices of regulated industries. We present a simple neoclassical framework that emphasizes the change in relative factor prices associated with the regulatory change from full cost to partial cost reimbursement, and investigate how this affects firms' technology choices through substitution of (capital embodied) technologies for tasks previously performed by labor. We examine these implications empirically by studying the change from full cost to partial cost reimbursement under the Medicare Prospective Payment System (PPS) reform, which increased the relative price of labor faced by U.S. hospitals. Using the interaction of hospitals' pre-PPS Medicare share of patient days with the introduction of these regulatory changes, we document a substantial increase in capital-labor ratios and a large decline in labor inputs associated with PPS. Most interestingly, we find that the PPS reform seems to have encouraged the adoption of a range of new medical technologies. We also show that the reform was associated with an increase in the skill composition of these hospitals, which is consistent with technology-skill or capital-skill complementarities.

Daron Acemoglu

Department of Economics

MIT, E52-380B

50 Memorial Drive

Cambridge, MA 02142-1347

and NBER

daron@mit.edu

Amy Finkelstein

Department of Economics

MIT, E52-262F

50 Memorial Drive

Cambridge MA 02142

and NBER

afink@mit.edu
\end{abstract}




\section{Introduction}

There is broad agreement that differences in technology are essential for understanding productivity differences across nations, industries and firms. Despite this agreement, we know relatively little about the empirical determinants of technology choices and of adoption of capital goods embodying new technologies. The lack of empirical knowledge is even more pronounced when we turn to regulated industries, such as health care, electricity and telecommunications, which are not only important for their sizable contributions to total GDP, but have been at the forefront of technological advances over the past several decades. In this paper, we investigate how input and technology choices respond to changes in regulation regime.

Starting in the mid-1980s, a number of different industries in a variety of countries experienced a change in regulation regime away from full cost reimbursement towards some type of "price cap". 1 These new regulation regimes often entailed a mixture of "partial cost reimbursement" and "partial price cap". Under this mixed regime - which we refer to hereafter as "partial cost reimbursement" - only expenditures on capital inputs are reimbursed, while labor expenses are supposed to be covered by the fixed price paid per unit of output. Consequently, a change from full cost to partial cost reimbursement increases the relative price of labor inputs, among other things.

Despite many examples of this type of partial cost reimbursement, including the Medicare Prospective Payment System (PPS) reform in the United States which we study in this paper, partial cost reimbursement has received little theoretical or empirical attention. For example, in his recent survey, Joskow (2005, p. 36) notes:

"Although it is not discussed too much in the empirical literature, the development of the parameters of price cap mechanisms .... have typically focused primarily on operating costs only, with capital cost allowances established through more traditional utility planning and cost-of-service regulatory accounting methods".

To investigate the implications of changes in regulation away from full cost reimbursement, we develop a simple neoclassical model of firm behavior under regulation. The most common approaches to regulation are the optimal regulation models, for example as in Laffont and

\footnotetext{
${ }^{1}$ Examples include the telecommunications sector in the United States and United Kingdom, gas, electric and water utilities in the United Kingdom, New Zealand, Australia, and parts of Latin America (see, for example, Laffont and Tirole 1993, Armstrong, Cowen and Vickers, 1994, Joskow, 2005) and the Medicare Prospective Payment System for US hosptials which is the focus of this paper.
} 
Tirole (1993), and the rate of return regulation of Averch and Johnson (1962) and Baumol and Klevorick (1970). Neither is appropriate as a framework for guiding empirical work in this setting, however, for at least two reasons. First, cost reimbursement regulation, both in general and in the health care sector in particular, does not have the screening structure posited in the optimal regulation models, nor does cost reimbursement in the health care sector regulate the rate of return on capital as in the Averch and Johnson model. Second, neither of these two approaches provides a framework for analyzing the impact of regulation regime on technology adoption (though it may be possible to extend these approaches to do so).

Our neoclassical framework is similar to Averch and Johnson, but focuses on cost reimbursement rather than rate of return regulation. It links the input and technology choices of firms to the relative factor prices they face, which are themselves determined by the regulation regime. $^{2}$ We show that under fairly mild assumptions, a change in regulation regime from full cost to partial cost reimbursement will be associated with an increase in capital-labor ratios.

The implications of the change in regulation for the overall level of labor and capital inputs (and the scale of activity) are ambiguous and depend on the generosity of the partial price cap that replaces cost reimbursement. In the context of the Medicare PPS reform, existing qualitative and empirical evidence suggests a relatively low price cap. We present evidence that the reform is associated with a decline in overall labor inputs and in the Medicare share of hospital activity, both of which would be predicted by our framework if the level of the price cap is sufficiently low. Despite the decline in labor inputs, our simple framework shows that capital expenditures can increase, and perhaps more surprisingly, the firm may be induced to adopt more advanced technologies. This configuration is more likely when there are decreasing returns to capital and labor (or technology and labor) and the elasticity of substitution between these factors is high. Intuitively, the increased relative price of labor induces the firm to substitute technology and capital embodying new technologies for tasks previously performed by labor. This result also has implications for the famous labor push theory of innovation suggested by Hicks (1932) and Habakkuk (1962), which claims that higher wages encourage innovation. Although this result is not possible under competitive markets and constant returns to capital and labor, we derive conditions under which such a result might obtain. ${ }^{3}$

The bulk of the paper empirically investigates the impact of the Medicare Prospective

\footnotetext{
${ }^{2}$ In contrast, in the Averch and Johnson model, as in the modified model we present in Appendix B, input choices are not directly affected by relative prices, but are chosen in order to satisfy various regulatory constraints faced by firms.

${ }^{3}$ Strictly speaking, the labor push theory of innovation refers to the case in which the only change is an increase in the price of labor. In the theory section, we derive the conditions under which such a change in the price of labor will encourage technology adoption (or capital deepening). However, in our empirical setting, the introduction of PPS is associated with both an increase in the price of labor and some increase in the price of output (increased reimbursement for health services provided to Medicare patients). Our empirical results on the effect of PPS on technology adoption therefore do not provide direct evidence for the labor push theory.
} 
Payment System (PPS) in the United States. PPS, introduced in October 1983, changed reimbursement for hospital inpatient expenses of Medicare patients from full cost to partial cost reimbursement, resulting in significant changes in the relative factor prices faced by hospitals. The motivation behind the reform was to reduce the level and growth of hospital spending, which had been rising rapidly (as a share of GDP) for several decades.

The PPS reform provides an attractive setting for studying the impact of regulatory change on firm input and technology choice for several reasons. First, the health care industry is one of the most technologically-intensive and dynamic sectors in the United States. Indeed, rapid technological change is believed to be the major cause of both the dramatic increase in health spending as a share of GDP and the substantial health improvements experienced over the last half century (Newhouse, 1992, Fuchs, 1996, Cutler, 2003). Understanding the determinants of technological progress in the health care sector, and the role played by government policy, is therefore of substantial interest in its own right. Second, government regulation is ubiquitous in this industry. Finally, because of substantial differences in the importance of Medicare patients for different hospitals, there is an attractive source of variation to determine the effects of such a regulatory reform on input and technology choices.

Our empirical strategy is to exploit the interaction between the introduction of PPS and the pre-PPS share of Medicare patient days (Medicare share for short) in hospitals. We document that before the introduction of PPS, hospitals with different Medicare shares do not display systematically different trends in their input or technology choices. In contrast, following PPS, hospitals with different Medicare share show significantly different trends.

Consistent with the predictions of our motivating theory, there is a significant and sizable increase in the capital-labor ratio of higher Medicare share hospitals associated with the change from full cost to partial cost reimbursement. This change in the capital-labor ratio is made up of a decline in the labor inputs of high-Medicare share hospitals, with approximately constant capital inputs. Perhaps most interestingly, we find that the introduction of PPS is associated with a significant increase in the adoption of a range of new health care technologies. We document this pattern both by looking at the total number of different technologies used by hospitals, and also by estimating hazard models for a number of specific high-tech technologies that are in our sample throughout. ${ }^{4}$ The increase in technology adoption and the decline in labor inputs associated with the increase in the relative price of labor also suggests that there is a relatively high degree of substitution between technology and labor. We present suggestive evidence of one possible mechanism for this substitution; the introduction of PPS

\footnotetext{
${ }^{4}$ As we discuss below, increased technology adoption, combined with more or less constant overall capital expenidtures, suggests that there was likely a decline in some other type of capital expenditures, such as structures.
} 
is associated with a decline in length of stay, which may represent substitution of high-tech capital equipment for relatively labor-intensive hospital stays.

Finally, we present evidence that the introduction of PPS is associated with an increase in the skill composition of hospital nurses. This pattern buttresses our results on increased capital-labor ratios and technology adoption, since the consensus view in the literature is that skilled labor is complementary to capital and/or technology (e.g., Griliches, 1956, Berman et al. 1994, Autor et al. 1998, Krusell et al., 2000, Acemoglu, 2002).

We consider a number of alternative interpretations for our findings and conclude that the evidence for them is not compelling. We therefore interpret our finding of PPS-induced changes in input mix and technology adoption in the health care sector to be a response to the changes in relative factor prices induced by the change in regulation regime. Consequently, to our knowledge, this makes ours the first paper to document that technology adoption in the health care sector is affected by relative factor prices. ${ }^{5}$

It is also noteworthy that our findings run counter to the general expectation that PPS would slow the growth of expensive technology diffusion (see, for example, Sloan et al., 1988, Weisbrod, 1991, and the discussion of initial expectations in Coulam and Gaumer, 1991). However, most prior analyses of PPS have conceived of it as a move from full cost reimbursement to full price cap reimbursement and have overlooked the fact that it was only a partial price cap on non-capital expenditures; both our theoretical and empirical results show the importance of the increase in the relative price of labor resulting from the partial price cap structure. ${ }^{6}$

The rest of the paper proceeds as follows. In Section 2, we develop a simple neoclassical framework to investigate the implications of the change in regulation regime on input and technology choices. Section 3 reviews the relevant institutional background on Medicare reimbursement. Section 4 describes the data and presents some descriptive statistics. The econometric framework is presented in Section 5. Our main empirical results are presented in Section 6, while Section 7 shows that they are robust to a number of alternative specifications. Section 8 concludes. Appendix A contains the proofs from Section 2, and Appendix B discusses a number of further theoretical issues.

\footnotetext{
${ }^{5}$ In this respect, our paper is related to Newell et al. (1999) who study the effect of energy price increases on the energy efficiency of a variety of appliances. See also Greenstone (2002) on the effect of environmental regulations on plant level investment. In the hospital sector, past work has suggested that hospital technology adoption appears to increase in response to traditional fee-for-service health insurance (Finkelstein, 2005) and to slow in response to managed care organizations (Cutler and Sheiner, 1998, Baker, 2001, Baker and Phibbs, 2002). In the context of the health sector more generally, the rate of pharmaceutical innovation appears to increase in response to increased (expected) market size (Acemoglu and Linn, 2004, Finkelstein, 2004) or to tax subsidies for R\&D (Yin, 2005).

${ }^{6}$ The literature on PPS is reviewed in Section 3.
} 


\section{Motivating Theory}

There are many conceptual difficulties in modeling both the demand for and supply of health care; the demand for health care is often determined by the technologies and the diagnoses that are available, and neither the supply nor the demand for health care can be separated from various private and social insurance policies and government regulation. Our purpose here is not to present a comprehensive model of the health care market, but rather to develop an organizing framework for the empirical work, and also to provide a number of simple insights that are applicable to other industries regulated by full cost or partial cost reimbursement.

\subsection{A Neoclassical Model of Regulation}

\subsubsection{Environment}

Four simplifying assumptions in our approach are worth highlighting at the outset. The first is that hospitals maximize profits. Clearly, non-profit or public hospitals have other objectives as well, but starting with the profit-maximizing case is a useful benchmark. It is also consistent with a large empirical literature that finds essentially no evidence of differential behavior across for-profit and non-profit hospitals (see Sloan, 2000, for a recent review of this literature). Second, we assume that, at least at the margin, there is considerable fungibility between labor and capital inputs used for Medicare purposes and labor and capital inputs used for nonMedicare purposes; descriptions of how Medicare reimbursement operates in practice suggest that this is a realistic assumption (OTA, 1984, CBO, 1988). This allows us to model Medicare input reimbursement as taking a simple form in which hospital $i$ is reimbursed for a fraction $m_{i}$ of its capital and labor costs, where $m_{i}$ is the "Medicare share" of this hospital. Appendix $\mathrm{B}$ shows that the basic implications of our analysis of the impact of a change in regulation regime continue to hold without fungibility. Third, we assume that hospitals are price takers in the input markets, facing a wage rate of $w$ per unit of labor and a cost of capital equal to $R$ per unit of capital. ${ }^{7}$ Finally, we assume that hospitals are price takers for Medicare patients. ${ }^{8}$

Suppose that hospital $i$ has a production function for total health services given by

$$
\tilde{F}\left(A_{i}, L_{i}, K_{i}, z_{i}\right)
$$

\footnotetext{
${ }^{7}$ In practice, some hospitals might have monopsony power for some component of their labor demand. For example, Staiger et al. (1999) find evidence of hospital monopsony power in the market for registered nurses. Incorporating any such monopsony power would have no effect on our main results.

${ }^{8}$ In practice, unlike in the standard model of perfectly competitive firms, hospitals may not be able to choose the total number of Medicare patients. Either a hospital is the only one in the area, thus facing an essentially constant demand for Medicare services, or it may be competing with other hospitals in the area, in which case, the number of Medicare patients will depend on the quality of service. This would require a more involved analysis where the firm chooses both quantity and quality, and there is quality competition. Although we believe this is an important area for theoretical analysis, it falls outside the scope of our paper.
} 
where $L_{i}$ and $K_{i}$ are total labor and capital hired by this hospital, $z_{i}$ is some other input, such as managerial effort (or doctors, who are not directly hired and paid by hospitals themselves), and $A_{i}$ is a productivity term, which may differ across hospital, for example because of their technology choices or other reasons. We assume that $\tilde{F}$ is increasing in all of its inputs and twice continuously differentiable for positive levels of inputs.

For simplicity, we will interpret (1) as the production function of the hospital, though equivalently, it could be interpreted as its revenue function (with the price substituted in as a function of quantity). We also assume that $z_{i}$ is fixed, and, without loss of any generality, we normalize it to $z_{i}=1$, and begin with the case in which $A_{i}$ is exogenous. This gives:

$$
F\left(A_{i}, L_{i}, K_{i}\right) \equiv \tilde{F}\left(A_{i}, L_{i}, K_{i}, z_{i}=1\right)
$$

which we assume exhibits decreasing returns to scale in capital and labor (for example, because the original production function $\tilde{F}$ exhibited constant returns to scale). Since $\tilde{F}$ is increasing in its inputs and twice continuously differentiable for positive inputs, so is $F$, and we denote the partial derivatives by $F_{L}$ and $F_{K}$ (and the second derivatives by $F_{L L}, F_{K K}$ and $\left.F_{L K}\right)$. Moreover, we make the standard Inada type assumption that $\lim _{L_{i} \rightarrow 0} F_{L}\left(A_{i}, L_{i}, K_{i}\right)=$ $\lim _{K_{i} \rightarrow 0} F_{K}\left(A_{i}, L_{i}, K_{i}\right)=\infty$ and $\lim _{L_{i} \rightarrow \infty} F_{K}\left(A_{i}, L_{i}, K_{i}\right)=\lim _{K_{i} \rightarrow \infty} F_{K}\left(A_{i}, L_{i}, K_{i}\right)=0$. In addition, we will often look at the cases in which $F\left(A_{i}, L_{i}, K_{i}\right)$ is homothetic or homogeneous in $L_{i}$ and $K_{i}$, or in $A_{i}$ and $L_{i} \cdot{ }^{9}$

\subsubsection{Full Cost Reimbursement Regulation}

Under the original regulation, which we refer to as full cost reimbursement, each hospital receives reimbursement for some fraction of its labor and capital used for Medicare purposes. ${ }^{10}$ It also receives a copayment from Medicare patients as well as revenues from non-Medicare patients (where the hospital might have some market power, which we are incorporating into the $F$ function). Denoting the total price per unit of health care services under the cost reimbursement regulation system by $q>0$, the maximization problem of the hospital is

$$
\max _{L_{i}, K_{i}} \pi^{f}(i)=q F\left(A_{i}, L_{i}, K_{i}\right)-\left(1-m_{i} s_{L}\right) w L_{i}-\left(1-m_{i} s_{K}\right) R K_{i}
$$

where $s_{L}<1$ and $s_{K}<1$ are constants capturing the relative generosity of labor and capital Medicare reimbursement and $m_{i} \in[0,1]$ is the Medicare share of the hospital, which we take

\footnotetext{
${ }^{9}$ If $F\left(A_{i}, L_{i}, K_{i}\right)$ is homothetic in $L_{i}$ and $K_{i}$, then $F_{K}\left(A_{i}, L_{i}, K_{i}\right) / F_{L}\left(A_{i}, L_{i}, K_{i}\right)$ is only a function of $K_{i} / L_{i}$. Alternatively, homotheticity in $L_{i}$ and $K_{i}$ is equivalent to $F\left(A_{i}, L_{i}, K_{i}\right) \equiv H_{1}\left(A_{i}\right) H_{2}\left(\phi\left(L_{i}, K_{i}\right)\right)$, where $H_{1}(\cdot)$ and $H_{2}(\cdot)$ are increasing functions, and $\phi$ is increasing in both of its arguments and exhibits constant returns to scale. If $F\left(A_{i}, L_{i}, K_{i}\right)$ is homogeneous of degree $\alpha$ in $L_{i}$ and $K_{i}$, then $F_{K}\left(A_{i}, L_{i}, K_{i}\right) / F_{L}\left(A_{i}, L_{i}, K_{i}\right)$ is again only a function of $K_{i} / L_{i}$, but in addition $F\left(A_{i}, L_{i}, K_{i}\right) \equiv H_{1}\left(A_{i}\right) \phi\left(L_{i}, K_{i}\right)^{\alpha}$, where $\phi$ is increasing in both of its arguments and exhibits constant returns to scale.

${ }^{10}$ As discussed in Section 3, under the pre-PPS system, Medicare-related capital and labor expenses were reimbursed in proportion to Medicare's share of patient days or charges (see Newhouse, 2002, p. 22).
} 
as given for now and endogenize in subsection 2.2. ${ }^{11}$

The first-order conditions of this maximization problem are

$$
\begin{gathered}
q F_{L}\left(A_{i}, L_{i}^{f}, K_{i}^{f}\right)=\left(1-m_{i} s_{L}\right) w, \text { and } \\
q F_{K}\left(A_{i}, L_{i}^{f}, K_{i}^{f}\right)=\left(1-m_{i} s_{K}\right) R,
\end{gathered}
$$

for labor and capital, respectively, where the superscript $f$ refers to full cost reimbursement.

The Inada and the differentiability assumptions imply that these first-order conditions are necessary, and the decreasing returns (strict joint concavity) of $F$ implies that they are sufficient. Taking the ratio of these two first-order conditions we have

$$
\frac{F_{K}\left(A_{i}, L_{i}^{f}, K_{i}^{f}\right)}{F_{L}\left(A_{i}, L_{i}^{f}, K_{i}^{f}\right)}=\frac{\left(1-m_{i} s_{K}\right) R}{\left(1-m_{i} s_{L}\right) w}
$$

which shows that the relative input choices of the hospital will be similar to that of an unregulated firm (hospital) with the same production technology, except for the relative generosity of capital and labor reimbursements. Equation (6) combined with the decreasing returns assumption on $F$ implies that an increase in $s_{K} / s_{L}$, which corresponds to capital reimbursements becoming more generous relative to labor reimbursements, will increase $K_{i} / L_{i}$. Similarly, a decrease in the relative price of capital, $R / w$, will increase $K_{i} / L_{i}$. The impact of changes in $m_{i}$ on $K_{i} / L_{i}$ will depend on whether $s_{K}$ is greater or less than $s_{L}$. In the former case, capital is favored relative to labor, so higher $m_{i}$ will be associated with greater capital intensity.

\subsubsection{Partial Cost Reimbursement Regulation}

Our main interest is to compare the full cost reimbursement regulation regime described above, which is a stylized description of the regulation policy before PPS, to the partial cost reimbursement that came with PPS. As described above, under this new regime, capital continues to be reimbursed as before, but labor reimbursements cease, and instead, hospitals receive additional payments from Medicare for health services provided to Medicare patients. We model this as an increase in $q$ to $\left(1+\theta m_{i}\right) q$, where $\theta>1$ incorporates the fact that the extent to which a hospital receives the subsidy is also a function of its Medicare share. ${ }^{12}$

\footnotetext{
${ }^{11}$ The assumption that $s_{L}<1$ and $s_{K}<1$ ensures that, at the margin, labor and capital costs are always positive for the hospital. In fact, all we need is that $m_{i} s_{L}<1$ and $m_{i} s_{K}<1$, so in practice when $m_{i} \leq \bar{m}$ for some $\bar{m}<1$, we can have $s_{L}>1$ and $s_{K}>1$. The case in which there is true cost plus reimbursement whereby the hospital makes money by hiring more inputs is discussed in Appendix B.

${ }^{12}$ In practice, the price subsidy under PPS is a function of Medicare (diagnosis-adjusted) admissions. Modeling it as a function of the Medicare share, $m_{i}$ - which corresponds roughly to Medicare share of total output (see Section 2.2) - is a simplifying assumption, with no major effect on our theoretical results.
} 
Now the maximization problem of hospital $i$ is

$$
\max _{L_{i}, K_{i}} \pi^{p}(i)=\left(1+\theta m_{i}\right) q F\left(A_{i}, L_{i}, K_{i}\right)-w L_{i}-\left(1-m_{i} s_{K}\right) R K_{i} .
$$

The first-order necessary and sufficient conditions are

$$
\begin{gathered}
\left(1+\theta m_{i}\right) q F_{L}\left(A_{i}, L_{i}^{p}, K_{i}^{p}\right)=w, \text { and } \\
\left(1+\theta m_{i}\right) q F_{K}\left(A_{i}, L_{i}^{p}, K_{i}^{p}\right)=\left(1-m_{i} s_{K}\right) R,
\end{gathered}
$$

where the superscript $p$ refers to partial cost reimbursement. (8) and (9) jointly imply

$$
\frac{F_{K}\left(A_{i}, L_{i}^{p}, K_{i}^{p}\right)}{F_{L}\left(A_{i}, L_{i}^{p}, K_{i}^{p}\right)}=\frac{\left(1-m_{i} s_{K}\right) R}{w} .
$$

Comparison of (10) to (6) immediately yields the following result (proof in Appendix A):

Proposition 1 Suppose $F\left(A_{i}, L_{i}, K_{i}\right)$ is homothetic in $L_{i}$ and $K_{i}$. Then, the move from full cost reimbursement to partial cost reimbursement increases capital-labor ratio, i.e.,

$$
\frac{K_{i}^{p}}{L_{i}^{p}}>\frac{K_{i}^{f}}{L_{i}^{f}} .
$$

Moreover, this effect is stronger for hospitals with greater Medicare share, i.e.,

$$
\partial\left(\frac{K_{i}^{p} / L_{i}^{p}}{K_{i}^{f} / L_{i}^{f}}\right) / \partial m_{i}>0 .
$$

This proposition is the starting point for our empirical work. It shows that the move from full to partial cost reimbursement should be associated with an increase in capital-labor ratios. Moreover, equation (12) provides an empirical strategy to investigate this effect by comparing hospitals with different Medicare shares (from the pre-reform period).

Next, we would like to know the impact of the change in regulation regime on the level of inputs and the total amount of health services. It is clear that the results here will depend on the generosity of the price subsidy (price cap) $\theta>0$. We can obtain more insights by focusing on the case where the price cap, $\theta$, is sufficiently low. This case is particularly relevant, since it is consistent with the existing evidence, ${ }^{13}$ and because the empirical work below will show that the price cap appears to have been less than sufficient to overturn the effects of decreased cost subsidies.

Let us consider the extreme case with $\theta=0$ (clearly, by continuity, the same results apply when $\theta$ is sufficiently small around zero). In this case, we can analyze the effect of the change

\footnotetext{
${ }^{13}$ Qualitative descriptions of the PPS suggest a relatively low level of the price cap, particularly after the first year of the program (Coulam and Gaumer, 1991). The empirical evidence reviewed by Cutler and Zeckhauser (2000) and Coulam and Gaumer (1991) indicates that the introduction of PPS was associated with a decline in hospital profit margins, which is also consistent with a relatively low level of the price cap.
} 
in the cost reimbursement regime as comparative statics of $s_{L}$; a reduction in $s_{L}$ from positive to zero is equivalent to a change in regulation regime from full cost reimbursement the partial cost reimbursement.

Proposition 2 Suppose that $\theta=0$, and let $L_{i}\left(s_{L}\right)$ and $K_{i}\left(s_{L}\right)$ be the optimal choices for hospital $i$ at labor subsidy rate $s_{L}$. Then

$$
\frac{d L_{i}\left(s_{L}\right)}{d s_{L}}=\frac{-m_{i} F_{K K}}{F_{L L} F_{K K}-\left(F_{L K}\right)^{2}}>0
$$

Moreover, let $F\left(A_{i}, L_{i}, K_{i}\right)$ be homogeneous of degree $\alpha<1$ in $L_{i}$ and $K_{i}$, i.e., $F\left(A_{i}, L_{i}, K_{i}\right)=$ $H_{1}\left(A_{i}\right) \phi\left(L_{i}, K_{i}\right)^{\alpha}$, with $\phi(\cdot, \cdot)$ exhibiting constant returns to scale. Let the (local) elasticity of substitution between capital and labor of the $\phi(\cdot, \cdot)$ function be $\sigma_{\phi}$. Then

$$
\frac{d K_{i}\left(s_{L}\right)}{d s_{L}} \lesseqgtr 0 \text { if and only if } \frac{1}{1-\alpha} \lesseqgtr \sigma_{\phi} \text {. }
$$

This proposition, which is also proved in Appendix A, shows that when the price cap is not very generous, the firm will respond to the switch from full to partial cost reimbursement by reducing its labor input, i.e., $d L_{i}\left(s_{L}\right) / d s_{L}>0$.

Nevertheless, it is noteworthy that even in this case, capital inputs may increase, i.e., $d K_{i}\left(s_{L}\right) / d s_{L} \leq 0$ is possible. Whether they do so or not depends on the amount of "decreasing returns" to labor and capital, which is measured by the $\alpha$ parameter, and the elasticity of substitution, $\sigma_{\phi}$. If $\sigma_{\phi}<1$, so that labor and capital are gross complements in the $\phi$ function, capital will always decline as well. Similarly, if $\alpha=1$, so that there are constant returns to scale to capital and labor jointly, again, capital will always decline. However, if $\alpha<1$ and there is sufficient substitution between labor and capital, i.e., $\sigma_{\phi}>1$, the firm can (partially) make up for the decline in its labor demand by increasing its capital inputs.

This is an important result both for understanding the response of capital inputs to an increase in the cost of labor in general, and for our specific case. The general relevance of this result stems from the labor push theory of innovation suggested by Hicks (1932) and Habakkuk (1962) as discussed in the Introduction. Despite a lengthy literature on this subject, there is still no agreement on the relevance of these ideas, especially since in the standard neoclassical growth model with constant returns to scale, this can never happen. ${ }^{14}$ Proposition 2 shows that this result is possible when there are diminishing returns (either in terms of production technology or revenues) and when capital and labor are sufficiently substitutable.

\footnotetext{
${ }^{14}$ This is obvious in Proposition 2, because of constant returns to scale, i.e., $\alpha=1$. Alternatively, with constant returns to scale in labor and capital, the Euler theorem implies that $F_{L K}>0$, so (14) immediately yields $d K_{i}\left(s_{L}\right) / d s_{L}>0$.
} 


\subsubsection{Technology Choices}

The overall amount of capital inputs used by the hospital is a combination of capital embodying new technologies and other types of capital, such as structures (e.g., buildings). These different types of capitals may respond differentially to the change in regulation. To study how technology will respond to the regulation regime, we now model technology choices.

Suppose that technology is always embodied in capital, and it can be measured by a real number, i.e., $A_{i} \in \mathbb{R}_{+}$, as specified by the production functions in (1) or (2). In particular, let us posit that there is a large number of (perfectly substitutable) technologies, each indexed by $x \in[0, \infty)$. Technology $x$ requires a capital outlay of $\kappa(x) \cdot{ }^{15}$ We rank technologies such that $\kappa(x)$ is increasing. Furthermore, to simplify the analysis, let us assume that $\kappa(\cdot)$ is continuously differentiable. Since the productivity of the hospital depends only on how many of these technologies are adopted, i.e., only on $A_{i}$, it will adopt low $x$ technologies before high $x$ technologies, i.e., there will exist a cutoff level $x_{i}^{*}$ such that hospital $i$ adopts all technologies $x \leq x_{i}^{*}$, and moreover, clearly $x_{i}^{*} \equiv A_{i}$. Hence the capital cost of technology for hospital $i$ when it adopts technology $A_{i}$ it is

$$
K_{a, i} \equiv \int_{0}^{A_{i}} \kappa(x) d x
$$

which is in addition to its capital costs for structures. Note from (15) that the marginal cost of adopting technology $A_{i}$ is $\kappa\left(A_{i}\right)$, and moreover, since $\kappa(x)$ is increasing, this marginal cost is increasing in $A_{i}$. Other differences in productivity across hospitals are ignored for simplicity.

Since we now allow for the adoption of new technologies embodied in capital, the remaining capital is interpreted as "structures" capital and denoted by $K_{s, i}$. Hence, we write

$$
F\left(A_{i}, L_{i}, K_{s, i}\right)=\psi\left(A_{i}, L_{i}\right)^{\beta} K_{s, i}^{\eta}
$$

where $\eta \in[0,1-\beta)$ and $\psi$ exhibits constant returns to scale, which imposes homogeneity of degree $\beta<1$ between $A_{i}$ and $L_{i}$. The rest of the setup is unchanged.

Once again, since for arbitrary $\theta$ 's, total output (health services) and inputs can increase or decrease, we focus on the case of $\theta=0$. We have (proof in Appendix A):

Proposition 3 Suppose that $\theta=0$ and the production function is given by (16) with $\psi(\cdot, \cdot)$ exhibiting constant returns to scale. let $L_{i}\left(s_{L}\right), A_{i}\left(s_{L}\right), K_{a, i}\left(s_{L}\right)$ and $K_{s, i}\left(s_{L}\right)$ be the optimal

\footnotetext{
${ }^{15}$ In practice, new technologies may differ in their productivity and may also require both capital and labor inputs for their adoption and operation. In the latter case, changes in the relative prices of capital and labor will also affect which technologies are more likely to be adopted. We do not model these issues explicitly both to simplify the analysis and also because we cannot measure the relative capital intensity of technologies in our empirical work.
} 
choices for hospital $i$ at labor subsidy rate $s_{L}$. Let $\varepsilon_{\psi}$ be the (local) elasticity of substitution between $L_{i}$ and $A_{i}$ in the function $\psi(\cdot, \cdot)$. Then we have

$$
\frac{d L_{i}\left(s_{L}\right)}{d s_{L}}>0 \text { and } \frac{d K_{s, i}\left(s_{L}\right)}{d s_{L}}>0 .
$$

and

$$
\frac{\partial K_{a, i}\left(s_{L}\right)}{\partial s_{L}} \lesseqgtr 0 \text { and } \frac{\partial A_{i}\left(s_{L}\right)}{\partial s_{L}} \lesseqgtr 0 \text { if and only if } \frac{1-\eta}{1-\beta-\eta} \lesseqgtr \varepsilon_{\psi} \text {. }
$$

This proposition generalizes Proposition 2 to an environment with labor, capital and technology choices, and is the starting point of our empirical analysis of technology choices. It indicates that the same kind of comparison between the elasticity of substitution and returns to scale also guides whether or not technology adoption will be encouraged by the change in the regulation regime. In this case, the comparison is between the elasticity of substitution between technology (or capital embodying the new technology) and labor, $\varepsilon_{\psi}$, and a composite term capturing both decreasing returns to labor and technology and to the structures capital. In particular, when $\eta=0$, the condition in (18) is equivalent to that in (14), but when $\eta>0$, this condition would be harder to satisfy for a given level of $\beta$, because structures capital also adjusts, leaving less room for technology adjustment (though naturally in practice a higher $\eta$ would correspond to a lower $\beta) .{ }^{16}$ Nevertheless, the qualitative insights are similar, and indicate that the essence of the labor push theory will apply with sufficient decreasing returns and a sufficiently large degree of substitution between technology and labor.

The important implication for our empirical work is that even if the price cap under the partial regulation regime is not very generous, so that overall labor inputs decline, technologylabor substitution may induce further technology adoption. Naturally, technology and capital expenditures on technology are more likely to increase when $\theta$ is positive (i.e., with $\theta>0$, they may increase even when $\varepsilon_{\psi}<(1-\eta) /(1-\beta-\eta)$; see also footnote 29$)$. Nevertheless Proposition 3 gives a useful benchmark and highlights the importance of substitutability between labor and technology (or capital). ${ }^{17}$

Another interesting implication of Proposition 3 is that we could have a configuration in which expenditures on technology (and overall technology adoption) increase with the switch

\footnotetext{
${ }^{16}$ In practice, the condition $\varepsilon_{\psi} \geq(1-\eta) /(1-\beta-\eta)$ in $(18)$ may not be too restrictive since, in addition to the structures capital, doctors' labor is excluded from the $\psi$ function. Thus if we think of doctors as included in the factor $z$ in terms of the original production function $\tilde{F}$, the parameter $\beta$ would correspond to the share of technology (equipment capital) and nurse and custodian labor, while $\eta$ is the share of structures capital. If, for example, $\beta$ is approximately 0.5 and $\eta$ is about 0.1 , the condition $\varepsilon_{\psi} \geq(1-\eta) /(1-\beta-\eta)$ would be satisfied if the elasticity of substitution between technology and labor is greater than 2.5.

${ }^{17}$ In the health services sector, there is a natural substitution between technology and labor, which takes place by varying the length of stay in hospital. Use of more high-tech equipment may save on labor by allowing patients to leave earlier, which amounts to substituting technology for labor. We investigate this issue empirically below.
} 
from full cost reimbursements to PPS, while total capital expenditures may decrease or remain unchanged, because they also include the component on structures expenditure. This is relevant for interpreting the empirical results below.

\subsubsection{Skill Composition of Employment}

Finally, in our empirical work we also look at changes in the composition of the workforce, in particular, of nurses. To do this, the production function can be generalized to

$$
F\left(A_{i}, U_{i}, S_{i}, K_{i}\right)
$$

where $U_{i}$ denotes unskilled labor (nurses) while $S_{i}$ denotes skilled labor (nurses). An increase in capital/labor ratio and technology adoption will increase the ratio of skilled to unskilled labor as long as technology and/or capital is more complementary to skilled than to unskilled labor. To state the result here in the simplest possible form, suppose that $A_{i}$ is fixed, so that the main effect of the change in regulation will work through an increase in the capital stock overall (including equipment as well as structures capital). We have (proof omitted):

Proposition 4 Suppose that $F\left(A_{i}, U_{i}, S_{i}, K_{i}\right)$ is homothetic in $U_{i}, S_{i}$ and $K_{i}$, and denote the (local) elasticity of substitution between $U_{i}$ and $K_{i}$ by $\sigma_{U}$ and the elasticity of substitution between $S_{i}$ and $K_{i}$ by $\sigma_{S}$. Then

$$
\frac{S_{i}^{p}}{U_{i}^{p}} \gtreqless \frac{S_{i}^{f}}{U_{i}^{f}} \text { if and only if } \sigma_{S} \lesseqgtr \sigma_{U} .
$$

This proposition therefore shows that when capital is more complementary to skilled than unskilled labor, the removal of the implicit subsidy to labor involved in the change from full cost reimbursements to partial cost reimbursement will increase the skill composition of hospitals. A similar proposition could be stated for the case in which the main margin of adjustment is technology (embodied in capital), which would correspond to technology-skill complementarity rather than capital-skill complementarity.

\subsection{Choice of Medicare Share}

We now briefly discuss how the Medicare share of hospital $i, m_{i}$, can be endogenized. Suppose that the hospital produces two distinct "products," Medicare health services and non-Medicare health services (the latter may also include outpatient Medicare, which is reimbursed differently). Let the production functions for these two products be

$$
F_{m}\left(A_{m, i}, L_{m, i}, K_{m, i}\right) \text { and } F_{n}\left(A_{n, i}, L_{n, i}, K_{n, i}\right)
$$


with respective prices $q_{m}$ and $q_{n}$, and exogenous technology terms $A_{m, i}$ and $A_{n, i}$, and let

$$
m_{i}=\frac{F_{m}\left(A_{m, i}, L_{m, i}, K_{m, i}\right)}{F_{m}\left(A_{m, i}, L_{m, i}, K_{m, i}\right)+F_{n}\left(A_{n, i}, L_{n, i}, K_{n, i}\right)},
$$

be the Medicare share of total output. Alternatively, we could have defined $m_{i}$ as the Medicare share of total operating expenses, $m_{i}=L_{m, i} /\left(L_{m, i}+L_{n, i}\right)$, or the Medicare share of capital expenses, $m_{i}=K_{m, i} /\left(K_{m, i}+K_{n, i}\right)$, in both cases with identical results.

The maximization problem of the hospital under full cost reimbursement is:

$$
\begin{aligned}
\max _{\substack{L_{m, i}, K_{m, i}, L_{n, i}, K_{n, i}, m_{i}}} \pi^{m}(i)= & q_{m} F_{m}\left(A_{m, i}, L_{m, i}, K_{m, i}\right)+q_{n} F_{n}\left(A_{n, i}, L_{n, i}, K_{n, i}\right) \\
& -\left(1-m_{i} s_{L}\right) w\left(L_{m, i}+L_{n, i}\right)-\left(1-m_{i} s_{K}\right) R\left(K_{m, i}+K_{n, i}\right),
\end{aligned}
$$

subject to $(20)$.

This maximization problem can be broken into two parts. First, maximize $q_{m} F_{m}\left(A_{m, i}, L_{m, i}, K_{m, i}\right)+q_{n} F_{n}\left(A_{n, i}, L_{n, i}, K_{n, i}\right)$ with respect to $L_{m, i}, K_{m, i}, L_{n, i}$ and $K_{n, i}$ for given $m_{i}$ and subject to (20) and to the constraints that $L_{i}=L_{m, i}+L_{n, i}$ and $K_{i}=K_{m, i}+K_{n, i}$. Define the value of the solution to this problem as $F\left(L_{i}, K_{i}, m_{i}\right)$, which only depends on the total amount of labor $L_{i}=L_{m, i}+L_{n, i}$ and total amount of capital $K_{i}=K_{m, i}+K_{n, i}$. Once this first step of maximization is carried out, the solution to the maximization under full cost reimbursement in (21) can be obtained from

$$
\max _{L_{i}, K_{i}, m_{i}} \tilde{\pi}^{m}(i)=F\left(L_{i}, K_{i}, m_{i}\right)-\left(1-m_{i} s_{L}\right) w L_{i}-\left(1-m_{i} s_{K}\right) R K_{i} .
$$

Similarly, with the same assumptions as in subsection 2.1, the maximization problem under the partial cost reimbursement regulation regime (with $\theta=0$ ) can be written as

$$
\max _{L_{i}, K_{i}, m_{i}} \tilde{\pi}^{p}(i)=F\left(L_{i}, K_{i}, m_{i}\right)-w L_{i}-\left(1-m_{i} s_{K}\right) R K_{i}
$$

This implies that the analysis in subsection 2.1 can be carried out as before, with the only addition that now $m_{i}$ is also a choice variable. The following proposition generalizes Proposition 1 to this case (proof in Appendix A):

Proposition 5 Let the Medicare shares with full and partial cost reimbursement be, respectively, $m_{i}^{f}$ and $m_{i}^{p}$, then as long as

$$
\frac{m_{i}^{f}-m_{i}^{p}}{m_{i}^{f}\left(1-m_{i}^{p}\right)}<\frac{s_{L}}{s_{K}},
$$

the move from full the partial cost reimbursement regulation increases the capital-labor ratio, i.e.,

$$
\frac{K_{i}^{p}}{L_{i}^{p}}>\frac{K_{i}^{f}}{L_{i}^{f}} .
$$


Notice that (22) is automatically satisfied if $m_{i}^{f} \leq m_{i}^{p}$, and we obtain the same results as in subsection 2.1 in this extended model with endogenous Medicare share. However, a similar analysis to the one in subsection 2.1 establishes that since $\theta=0$, we should have $m_{i}^{f}>m_{i}^{p}$. The additional implication for the empirical work is that the Medicare share should decline after the introduction of PPS. This implication provides a consistency check for the other results suggesting that the price cap under PPS was not very generous. It is also useful to note that even when $m_{i}^{f}>m_{i}^{p}$, (22) is not very restrictive, so empirically we expect the capital-labor ratio to increase after the introduction of PPS even if the Medicare share is observed to decline.

\section{Overview of Medicare Reimbursement Policies}

The Medicare Prospective Payment System (PPS) was introduced in October 1983 (fiscal year 1984) in an attempt to slow the rapid growth of health care costs and Medicare spending. Under the original (pre-PPS) system of cost reimbursement, Medicare reimbursed hospitals for a share of their capital and labor inpatient expenses, where the share was proportionate to Medicare's share of patient days in the hospital (OTA, 1984, Newhouse, 2002, p. 22). By contrast, under PPS, hospitals are reimbursed a fixed amount for each patient based on his diagnosis, but not on the actual expenditures incurred on the patient. At a broad level, this reform can be thought of as a change from cost reimbursement to fixed price cap reimbursement, and indeed, it is often described in these terms (e.g., Cutler, 1995).

However, an important but largely overlooked feature of the original PPS system - and a central part of our analysis - is that initially only the treatment of inpatient operating costs was changed to a prospective reimbursement basis. For the first eight years of PPS, capital costs continued to be fully passed back to Medicare under the old cost-based reimbursement system, and capital reimbursement only became fully prospective in 2001. Thus for almost its first 20 years, the Medicare Prospective Payment System continued to reimburse capital costs at least partly on the margin. ${ }^{18}$ The reason for the differential treatment of operating and capital costs, both in this case and more generally in other regulated industries, appears to be the greater difficulty in designing a prospective payment system for capital (CBO, 1988, Cotterill, 1991, Joskow, 2005).

The PPS reform is thus an example of a switch from full cost reimbursement to partial cost

\footnotetext{
${ }^{18}$ The original legislation specified that the treatment of capital costs would be unchanged for the first three years of PPS (i.e. through October 1, 1986), and instructed the Department of Health and Human Services to study potential methods by which capital costs might be incorporated into a prospective payment system. In practice, a series of eleventh-hour delays postponed any change in Medicare's reimbursement for capital costs until October 1, 1991, at which point a 10-year transition to a fully prospective payment system for Medicare's share of inpatient capital costs began (GAO, 1986, CBO, 1988, Cotterill, 1991).
} 
reimbursement, as described in Section 2. To our knowledge, this feature of PPS has received no theoretical or empirical attention, even though almost all empirical examinations of the impact of PPS focus on the initial PPS period when partial cost reimbursement was in effect.

Coulam and Gaumer (1991) and Cutler and Zeckhauser (2000) review the extensive empirical literature on the effects of PPS. Broadly speaking, this literature concludes that PPS was associated with declines in hospital spending and in Medicare utilization (both admissions and length of stay), but not with substantial adverse health outcomes. However, most of this literature is based on simple pre-post (time-series) comparisons. Important exceptions include Feder et al.'s (1987) study of the impact of PPS on spending, and Staiger and Gaumer (1990) and Cutler's (1995) studies of the impact of PPS on health outcomes. Staiger and Gaumer (1990) pursue an empirical approach similar to our strategy below, which exploits the interaction between the introduction of PPS and hospital-level variation in the importance of Medicare patients. Our empirical findings below are consistent with the time-series evidence from this literature that there has been a decrease in hospital expenditures and in utilization associated with PPS. To our knowledge, our work is the first to investigate the impact of PPS on labor and capital inputs and the skill composition of the workforce.

Finally, there is a small empirical literature, again using pre-post comparisons, to study the impact of PPS on technology adoption, which finds little conclusive evidence of any effect of PPS (Prospective Payment Assessment Commission, 1988, 1990, Sloan et al., 1988). To our knowledge, ours is also the first theoretical or empirical study to show that PPS might have been associated with an overall increase in technology adoption.

\section{Data and Descriptive Statistics}

\subsection{The AHA Data}

Our analysis of the impact of PPS uses seven years of panel data from the American Hospital Association's (AHA) annual census of U.S. hospitals. PPS took effect at the start of each hospital's fiscal year on or after October 1, 1983. Our data consist of four years prior to PPS (fiscal years 1980 - 1983) and three years post PPS (fiscal years 1984 - 1986). We interpret the year of the data as corresponding to the hospital's fiscal year. ${ }^{19}$

We restrict our analysis to the first three years of PPS, during which the treatment of capital was specified in advance (in particular, we do not use data from the subsequent period when there was uncertainty concerning the treatment of capital, see footnote 18). We also exclude

\footnotetext{
${ }^{19}$ In practice, the data may consist of somewhat less than three years post PPS since only about one quarter of hospitals begin their fiscal year on October 1. In addition not all hospitals report data for the 12-month period corresponding to their fiscal year. We discuss these issues in more detail in the interpretation of the empirical results below.
} 
from the analysis the four states (MA, NY, MD and NJ) that received waivers exempting them from the federal PPS legislation. Because these four states also experienced their own idiosyncratic changes in hospital reimbursement policy during our period of analysis (often right around the time of the enactment of federal PPS), the states are not useful for us as controls (Health Care Financing Administration, 1986, Health Care Financing Administration, 1987, Antos, 1993, MHA, 2002). These four states contain about 10 percent of the nation's hospitals, leaving us with a sample of about 6,200 hospitals per year. ${ }^{20}$

The data contain information on total input expenditures and its components, employment and its components, and a series of binary indicator variables for whether the hospital has a variety of different technologies. All of these input and employment data refer to the total amounts for the hospital, and therefore are unaffected by any potential reallocation of factor usage within the hospital, e.g., to nursing home or outpatient units that may be affiliated with the hospital. In addition, we also observe inpatient hospital utilization, specifically admissions and patient days. The expenditure and utilization data for year $t$ are in principle measured for the twelve-month reporting period from October 1, t-1 through September 30, $t$; the employment and technology variables are in principal measured as of September 30, $t$. Note that hospital employment and payroll consist of nurses, technicians, therapists, administrators, and other support staff; most doctors are not included as they are not directly employed or paid by the hospital. With the exception of patient days, none of the variables are reported separately for Medicare. We use Medicare's share of patient days in the hospital as the key source of our cross-sectional variation in the impact of PPS across hospitals (see below).

Medicare explicitly defines a hospital's reimbursable capital costs to include interest and depreciation expenses (GAO, 1986, OTA, 1984, Cotterill, 1991), each of which we can identify in the AHA data. ${ }^{21}$ Since changes in interest expenses may reflect financing changes rather than real input changes, we focus on depreciation expenses (which are about two-thirds of combined interest and depreciation expenses). Medicare uses straight-line depreciation to reimburse hospitals for the depreciation costs of structures and equipment (CBO, 1988). The estimated life of an asset is determined by the American Hospital Association; during the time

\footnotetext{
${ }^{20}$ Cutler (1995) uses MA as a control state relative to other New England states in his study of the impact of PPS on health outcomes, as PPS was only introduced in MA in FY 1986. Because Medicare and Medicaid experimented with alternative forms of rate setting in MA between FY 1982 and FY 1985 (Health Care Financing Administration, 1987), MA is not suitable as a control state for our analysis of the effect of relative factor price changes resulting from PPS (although these do not necessarily pose a problem for Cutler's analysis of the impact of PPS on health outcomes).

${ }^{21}$ Capital-related insurance costs, property taxes, leases, rents, and return on equity (for investor-owned hospitals) are also included in capital costs. In practice, however, capital costs are primarily interest and depreciation expenses, which are also the items reported separately in the AHA data and used by the overseers of Medicare to study Medicare capital costs (e.g. CBO, 1988, Prospective Payment Assessment Commission, 1992, Medicare Payment Advisory Commission, 1999).
} 
period we study, it ranged from 4 to 40 years depending on the asset; lives of 5 and 10 year tend to be the most common (AHA, 1983). Depreciation expenses therefore measure past and current capital expenditures rather than the capital stock (which would have been the ideal measure). Since the cost of capital and equipment prices should not vary systematically across hospitals with different Medicare shares, depreciation expenses should be a good proxy for the capital stock.

Our baseline measure of the capital-labor ratio, $K_{i} / L_{i}$ in terms of the model, is therefore the "depreciation share" defined as depreciation expenses divided by operating expenses. We define operating expenses as total input expenses net of interest and depreciation expenses. Just under two-thirds of operating expenses are payroll expenses (including employee benefits), with the remainder consisting of supplies and purchased services. Depreciation expenses are on average about 4.5 percent of operating expenses (see Table 1), indicating that the hospital sector is much less capital intensive than many other regulated industries. ${ }^{22}$

\subsection{Descriptive Statistics and Time Series Evidence}

Table 1 gives the basic descriptive statistics for our key variables over the entire sample. Changes in these variables over time are depicted in Figures 1-3.

Figure 1 shows the simple time-series average of hospital capital-labor ratio (depreciation share). Consistent with Proposition 1, the time-series displays a striking increase in the average capital-labor ratio at the time of PPS's introduction (FY 1984) both in absolute terms and relative to the pre-existing time-series pattern. Proposition 2 suggests that if the level of the price cap $\theta$ is sufficiently low, labor inputs should fall, but even in this case, capital inputs may rise or remain unchanged. Consistent with this, the time-series shows a pronounced decrease in labor inputs (real operating expenditures) relative to the pre-existing trends (Figure 2). They also show no evidence of a deviation in capital inputs (real depreciation expenditures) from the pre-existing time-series trend (Figure 3$).{ }^{23}$

The time-series evidence is only suggestive, however, since it may be driven by other secular changes in the hospital sector or the macro economy more generally. Our empirical work below exploits the within-variation for hospitals, in particular, focusing on the interaction between the introduction of PPS and the pre-PPS Medicare share (the empirical counterpart of $m_{i}$ in the model). It is nonetheless interesting that this very different empirical strategy will show patterns quite similar to those visible in Figures 1-3.

\footnotetext{
${ }^{22}$ The National Income Product Accounts indicate that the share of capital in value added in health services is $12.8 \%$ during the period of our data. In contrast, the share of capital in electric, gas and sanitary services is $64.1 \%$ and in telephone and telegraph, it is $49 \%$. We are grateful to Veronica Guerrieri for help with the National Income Product Accounts

${ }^{23}$ To match the empirical work below, the time series in Figures 2 and 3 are presented on a log scale; in practice, the pattern is similar if we look at absolute levels.
} 


\section{Econometric Framework}

The motivating theory developed in Section 2 suggests an empirical strategy for detecting the effects of PPS reform based on variation across hospitals in their (pre-PPS) Medicare share, $m_{i}$. Proposition 1 indicates that the regulatory change should be associated with an increase in the capital-labor ratio for all affected hospitals (i.e., for all hospitals with $m_{i}>0$ ), but with a larger effect in hospitals with a higher $m_{i}$ (see equation (12)). Based on this reasoning, our basic estimating equation is

$$
y_{i t}=\alpha_{i}+\gamma_{t}+\mathbf{X}_{i t}^{\prime} \cdot \boldsymbol{\eta}+\beta \cdot\left(P O S T_{t} \cdot m_{i}\right)+\varepsilon_{i t},
$$

where $y_{i t}$ is the outcome variable of interest in hospital $i$ at time $t$. In our first empirical models, $y_{i t}$ will represent the capital-labor ratio (measured as the depreciation share) to investigate the predictions in Proposition 1. We will later use the same framework to investigate the responses of a number of other outcomes.

In our estimating equation $(24), \alpha_{i}$ represents a full set of hospital fixed effects, $\gamma_{t}$ stands for a full set of year dummies, and $\mathbf{X}_{i t}$ is a vector of other covariates, which are not included in the baseline regressions, but will be added in several of the robustness checks below. Finally, $\varepsilon_{i t}$ is a random disturbance term capturing all omitted influences.

The main variable of interest is the interaction term $\left(P O S T_{t} \cdot m_{i}\right)$ with coefficient $\beta$. Here $P O S T_{t}$ is a dummy variable which takes the value equal to 1 for the three post-PPS years (1984-1986). A useful variant of this equation is

$$
y_{i t}=\alpha_{i}+\gamma_{t}+\mathbf{X}_{i t}^{\prime} \cdot \boldsymbol{\eta}+\beta \cdot\left(P O S T_{t} \cdot m_{i}\right)+\phi \cdot\left(d_{1983} \cdot m_{i}\right)+\varepsilon_{i t},
$$

where $d_{1983}$ is a dummy for the year 1983 . The interaction term $\left(d_{1983} \cdot m_{i}\right)$ acts as a prespecification test; it will be informative on whether there are any differential trends in the variables of interest by Medicare share before the introduction of PPS.

We will also estimate a more flexible version of these equations of the form

$$
y_{i t}=\alpha_{i}+\gamma_{t}+\mathbf{X}_{i t}^{\prime} \cdot \boldsymbol{\eta}+\sum_{t \geq 1981} \beta_{t} \cdot m_{i}+\varepsilon_{i t} .
$$

Relative to (24) or (25), the model in (26) allows both time-varying post-PPS effects and also a more flexible investigation of whether there are any differential trends in the variables of interest by Medicare share in any of the pre-PPS years.

In all models, to account for potential serial correlation of the observations from the same hospital, we adjust the standard errors by allowing for an arbitrary variance-covariance matrix within each hospital over time (see Wooldridge, 2002, p. 275). In practice, this does not have much effect on the standard errors. 
A key question is how to measure $m_{i}$ empirically. Because reimbursement in the pre-PPS regime was based on Medicare's share of patient days in the hospital (Newhouse, 2002, p. 22), we define $m_{i}$ as the share of Medicare inpatient days. Since, as discussed in the motivating theory, the Medicare share $m_{i}$ is likely to respond endogenously to the regulatory change, we measure $m_{i}$ in 1983, the year prior to the implementation of PPS.

Figure 4 shows the considerable variation across hospitals in their Medicare share in 1983. The average hospital's Medicare share is almost two-fifths (38 percent), with a standard deviation of over one fifth (21 percent). The mass point of almost 15 percent of hospitals which we have coded as having zero Medicare share reflects that fact that certain types of hospitalsspecifically federal, long-term, psychiatric, children's, and rehabilitation hospitals - were exempt from Medicare PPS (OTA, 1985, Newhouse, 2002, p. 27). The exemption stems from the extremely low Medicare share of these hospitals. For our purposes, we code their $m_{i}$ as 0 since they would not be affected by the reform. In the robustness analysis below, we show that the main results can be obtained when we identify the effect of PPS using only the variation between zero share and non-zero share hospitals, or using only the variation in $m_{i}$ among hospitals coded with a non-zero $m_{i}$.

The identifying assumption in estimating equations (24), (25), and (26) is that, absent the introduction of PPS, hospitals with different $m_{i}$ 's would not have experienced differential changes in their outcomes in the post-PPS period. However, $m_{i}$ is not randomly assigned. Indeed, in the cross-section prior to PPS, a larger $m_{i}$ is correlated with a smaller size (as measured, for example, by input expenditures) and higher depreciation share. ${ }^{24}$ Any fixed differences across hospitals will be absorbed by the hospital fixed effects, the $\alpha_{i}$ 's. However, such systematic differences raise concerns about whether, absent the introduction of PPS in FY 1984, hospitals with different $m_{i}$ would have experienced similar changes in the outcomes of interest. Equations (25) and (26) allow us to use the pre-PPS data to investigate the validity of this identifying assumption by looking for differential trends prior to PPS. The results below will show little evidence of such pre-existing trends, supporting our identifying assumption.

Motivated by the theoretical predictions, we estimate equations (24), (25), and (26) for various dependent variables: capital-labor ratio (depreciation share), log labor inputs (log operating expenditures), log capital inputs (log depreciation expenditures), Medicare share of patient days, log average length of hospital stay, and the share of nurse employment that is high-skill. When the dependent variable is not already a share, we estimate the equation in $\operatorname{logs}{ }^{25}$

\footnotetext{
${ }^{24}$ These and other results mentioned in the paper but not shown in the tables are available upon request from the authors.

${ }^{25}$ A level specification would constrain the outcomes of each hospital to grow by the same absolute amount within a year, which is inappropriate given the considerable variation in size across hospitals.
} 


\section{Main Results}

\subsection{Results on Capital-Labor Ratio}

Proposition 1 suggests that the move from full cost to partial cost reimbursement should increase the capital-labor ratio. We investigate this in Table 2, which shows that the introduction of Medicare PPS is associated with a statistically and economically significant increase in the capital-labor ratio (depreciation share).

Column (1) shows the estimation of our most parsimonious equation, (24). The POST variable is simply a dummy for the three years in which PPS is in effect in our sample (19841986). In this specification, the coefficient $\beta$ on the key interaction term $\left(m_{i} \cdot P O S T_{t}\right)$, is estimated as 1.129 (standard error $=0.108$ ). This is both a highly statistically significant and economically large effect. Given that the average hospital has a 38 percent Medicare share prior to PPS, this estimate suggests that in its first three years, the introduction of PPS was associated with an increase in the depreciation share of about $0.42(\simeq 1.129 \times 0.38)$ for the average hospital. Since the average depreciation share is about 4.5, this corresponds to a sizable 10 percent increase in the capital-labor ratio of the average Medicare share hospital. ${ }^{26}$

Column (2) investigates whether the differential growth in the capital-labor ratio between high and low Medicare share hospitals was present before the introduction of PPS by estimating equation (25). The estimate of the key parameter, $\beta$, is essentially unchanged, while the coefficient $\phi$ on the interaction between the 1983 dummy and the Medicare share, $\left(d_{1983} \cdot m_{i}\right)$, is very small (practically zero) and highly insignificant. This indicates that relative to the years 1980 through 1982, hospitals with a larger $m_{i}$ did not experience a statistically or economically significant change in their capital-labor ratio in 1983 (the year before PPS) relative to hospitals with a smaller $m_{i}$. This is supportive of the identifying assumption that absent the introduction of PPS, hospitals with different Medicare shares would have experienced similar changes in their capital-labor ratios.

Column (3) shows the results from estimating the more flexible equation (26) in which each year dummy is interacted with the hospital's 1983 Medicare share; the omitted year is 1980 . This allows a further investigation of the identifying assumption as well as an examination of the timing of the response to PPS. The results indicate that relative to their 1980 spending,

\footnotetext{
${ }^{26}$ We can use this estimate to derive a back-of-the-envelope estimate of the elasticity of substitution between total capital and labor. Assuming that $s_{L} \approx 1$, the increase in relative labor costs could be estimated to be about $75 \%$ for the average affected hospital (i.e., $\left.1 /\left(1-s_{L} m_{i}\right) \approx 1 /(1-0.4) \approx 0.75\right)$. This would imply that the capital-labor ratio changed by about $10 \%$ in response to a $75 \%$ change in relative labor costs, which would be consistent with an elasticity of substitution of about 0.13. In practice, however, the implied elasticity of substitution is likely to be considerably higher, for 0.75 is likely to be a significant overestimate of the change in the relative costs of labor, since the fungibility between Medicare and non-Medicare costs is likely to apply at the margin, but not on average, and because $s_{L} \approx 1$ is likely to be an overestimate.
} 
hospitals with a larger Medicare share did not experience a significant change in their capitallabor ratio relative to hospitals with a smaller Medicare share in the pre-PPS years 1981 or 1983, but there is a one-time downward blip in $1982 .{ }^{27}$ Thus, the pattern over all four pre-PPS years suggests that, if anything, the capital-labor ratio may have been declining in hospitals with a larger Medicare share relative to hospitals with a smaller Medicare share. There is a pronounced shift in this pattern starting in 1984, the first year that PPS is in place. In this year, hospitals with a larger Medicare share experience a statistically significant increase in the capital-labor ratio relative to hospitals with a smaller Medicare share, confirming the results in the previous two columns.

In a pattern that will repeat itself for many of the other dependent variables that we analyze, the results in column (3) also indicate that the magnitude of the increase in the capital-labor ratio associated with PPS grows from 1984 to 1985 and again from 1985 to 1986. This likely reflects, at least in part, lags in the implementation of PPS both in actuality and as measured in our data. PPS was effective at the beginning of the hospital's fiscal year starting on or after October 1, 1983. Hospitals were therefore added to the new regime throughout its first year in operation, with some not entering the new system until midway or late in the 1984 calendar year (OTA, 1985). Moreover, not all hospitals follow the AHA instructions to report data for year $t$ for the twelve month period from October $1, t-1$ to September $30, t$; in any given year, about half appear to instead report data for the twelve-month period corresponding to their fiscal year. This also contributes to a staggered implementation of PPS in the data. However, the fact that the increase in the size of the effect from 1984 to 1985 (i.e., from a year in which only some hospitals were fully under the system to a year in which all were) is quite similar to the increase in the size of the effect from 1985 to 1986 (two years in which all affected hospitals were under the system) suggests that lags in implementation alone cannot fully account for the time pattern we observe. Lags in the hospital response to the new reimbursement regime (perhaps due to adjustment costs) may have also played a role.

Whatever its underlying cause, the empirical evidence in column (3) that the impact of PPS appears to grow over time suggests that a more appropriate parameterization of the postPPS period may be a trend rather than a single post-PPS dummy. This motivates yet another slight variation on our estimating equation,

$$
y_{i t}=\alpha_{i}+\gamma_{t}+\mathbf{X}_{i t}^{\prime} \cdot \boldsymbol{\eta}+\tilde{\beta} \cdot\left(\sum_{t \geq 1984}(t-1983) \cdot m_{i}\right)+\phi \cdot\left(d_{1983} \cdot m_{i}\right)+\varepsilon_{i t}, .
$$

\footnotetext{
${ }^{27}$ This one-year blip in 1982 is not a major concern for our results. We show in Section 7 that our results are robust to numerous alterantive specifications that deal flexibly with potential mean reversion and to including a linear trend interacted with Medicare share. Moreover, our results are also robust to excluding the 1982 data from the analysis, with or without including a linear trend interacted with Medicare share (not shown).
} 
which imposes a linear structure on the post-PPS effects. This equation has the advantage of summarizing the post-PPS patterns more parsimoniously than equation (26).

Columns (4) and (5) estimate equation (27) with and without the pre-specification test term, $\left(d_{1983} \cdot m_{i}\right)$. In both cases, there is a very precisely estimated coefficient of $\tilde{\beta}$ of about 0.53 (standard error approximately 0.05). In column (5) as in column (2), there is no evidence of a pre-PPS differential effect. With a similar calculation to above, the estimate of 0.53 suggests that, in its first three years, PPS was associated, on average, with an approximately 4 percent per year increase in hospitals' capital-labor ratio.

\subsection{Results on Labor and Capital Inputs and Medicare Share}

Proposition 2 suggests that if the price cap $\theta$ is low, labor inputs should decline in response to the move to partial cost reimbursement. Table 3 investigates the differential change in (log) labor inputs (log operating expenses) across hospitals with different pre-PPS Medicare shares; it reports results from estimating equations (24), through (27) with this alternative dependent variable. Consistent with Proposition 2, the results suggest that the move from full cost to partial cost reimbursement was associated with a decline in labor inputs. Once again, the estimates are quite precise. For example, the estimate of $\beta$, the coefficient on the interaction term $\left(m_{i} \cdot P O S T_{t}\right)$, in column (1) is -0.141 (standard error $=0.016$ ). Column (2) shows no evidence of a pre-existing trend. The estimates suggest that during the first three years of PPS, there was a decline of about 5 percent $(\simeq 0.141 \times 0.38)$ in labor inputs for an average Medicare share hospital.

The estimates in column (3) again suggest that the impact of PPS was increasing over the first three years in which it was in place. ${ }^{28}$ Correspondingly, the linear trend specifications in columns (4) and (5) also fit the data very well and produce precise estimates of about -0.07. This implies that, during its first three years, the PPS reform was associated, on average, with an approximately 3 percent $(\simeq 0.07 \times 0.38)$ per year decline in labor inputs. The specifications also show some evidence of a small and marginally statistically significant increase in labor inputs in more affected hospitals in some of the pre-PPS years. Although this may raise concerns about the potential for mean reversion that may contaminate our estimate of the impact of PPS, Section 7 will show that the results are highly robust to a number of specifications that flexibly deal with potential mean reversion issues.

Table 4 estimates our baseline models for log capital inputs (log depreciation expenses). The results indicate essentially no statistical or substantive effect on capital inputs. These results

\footnotetext{
${ }^{28}$ Another potential explanation for the time pattern in the adjustment of labor inputs to PPS, besides the possible explanations discussed above, is that the level of the price cap $\theta$ was tightened after the first year of PPS (Coulam and Gaumer, 1991), which would naturally lead to further declines in labor inputs.
} 
suggest that the decline in labor inputs was not associated with a corresponding decline in capital inputs. This is consistent with the theoretical result in Proposition 2 that even when the price cap $\theta$ is low enough that labor inputs decline, capital inputs need not decrease and may in fact increase when there is sufficient substitutability between capital and labor. ${ }^{29}$

We have interpreted the results for labor and capital inputs as corresponding to the predictions of the theoretical model when the price cap $\theta$ is relatively low. As discussed in footnote 13, the existing evidence is suggestive of a low price cap. In addition, recall from Section 2.2 that when the price cap is low, the move to partial cost reimbursement should be associated with a decline in the Medicare share $m_{i}$. Consistent with this, Table 5 shows that PPS is associated with a decline in Medicare's share of patient days. ${ }^{30}$ The point estimate in our preferred specification (column 5) is -0.032 (standard error $=0.003)$, and suggests that, for its first three years, PPS was associated with about a 1 percentage point $(\simeq 0.032 \times 0.38)$ per year decline in the Medicare share of patient days, or a 2 - 3 percent per year decline relative to the baseline.

\subsection{Technology Adoption}

The AHA data contain a series of binary indicators for whether the hospital has various "facilities", such as a blood bank, open heart surgery facilities, CT scanner, occupational therapy, genetic counseling, and neonatal intensive care. These data have been widely used to study technology adoption decisions in hospitals (e.g. Cutler and Sheiner, 1998, Baker and Phibbs, 2002, Finkelstein, 2005). Since they contain only indicator variables for the presence or absence of various facilities, we cannot study upgrading of existing technology or the intensity of technology use, but we can study the total number of facilities, which provides one proxy for the $A_{i}$ variable in the theoretical model

Overall, during our time period, the AHA collects information on the presence of 113 different facilities. These are listed, together with their sample means and the years in which they are available, in Appendix Table A. On average, a given facility is reported in the data for 4.6 out of the possible 7 years; only one-quarter of the technologies are in the data for all seven years. Moreover, as is readily apparent from Appendix Table A, the list encompasses

\footnotetext{
${ }^{29}$ Recall that the value of the elasticity of substitution between capital and labor necessary for capital inputs not to decline depends on the level of the price cap, $\theta$. If $\theta$ were zero, the elasticity of substitution would have to exceed 1 (cfr., Proposition 2). However, if $\theta$ is positive (but small), even when the elasticity of substitution is less than 1, labor inputs would decline while capital inputs may not.

${ }^{30}$ To prevent a mechanical correlation between the cross-sectional variation, $m_{i}$, and the dependent variable, in this table we define $m_{i}$ based on the hospital's Medicare share in 1980, and exclude 1980 from the analysis. All of our previous results are robust to this alternative specification. Also, while we code the regressor $m_{i}$ to be zero for the approximately 15 percent of hospitals that are exempt from PPS, we allow the dependent variable in this case to take its actual value for all hospitals. On average over 1981 - 1986, the dependent variable is 0.38 ; it is $0.09(0.43)$ for exempt (non-exempt) hospitals.
} 
a range of very different types of facilities. Given these two features of the data, we pursue two complementary approaches to analyzing the impact of the change from full to partial cost reimbursement on technology adoption.

Our first approach (consistent with the perfect substitutability across different technologies in the model) treats all facilities equally and estimates equations (24)-(27) using the (unweighted) number of facilities that hospital $i$ has in year $t$ as the dependent variable (in this specification, year fixed effects take care of the unbalanced panel nature of the data). Our second approach estimates separate hazard models of the time to adoption for specific technologies that are in the data for all of the years of our sample.

\subsubsection{Number of Facilities}

In our first approach, the dependent variable is the raw count of the number of facilities of each hospital. This dependent variable ranges from 0 to 77 with an average of 25. Approximately 10 percent of the hospital-years in the sample have zero facilities. Table 6 shows the results. Panel A reports the OLS estimates. Since there are a large number of zero's, we cannot estimate this equation in logs, nor is there a natural scaling factor to use in the denominator to turn this into a share estimate. Instead Panel B reports the analogous results from the conditional fixed effects Poisson model (Hausman et al., 1984). For the model corresponding to equation (25) above, this approach amounts to assuming the following conditional expectation for the number of facilities for hospital $i$ at time $t, N_{i t}$, given the sample mean of the vector of covariates $\mathbf{X}_{i}$, $\overline{\mathbf{X}}_{i}$, for hospital $i:^{31}$

$$
E\left[N_{i t} \mid \alpha_{i}, \overline{\mathbf{X}}_{i}\right]=\exp \left(\alpha_{i}+\gamma_{t}+\mathbf{X}_{i t}^{\prime} \cdot \boldsymbol{\eta}+\beta \cdot\left(P O S T_{t} \cdot m_{i}\right)+\phi \cdot\left(d_{1983} \cdot m_{i}\right)\right)
$$

Because this equation is nonlinear and cannot be estimated consistently with fixed effects, we follow Hausman et al. (1984), and estimate the conditional logit transformation:

$$
E\left[N_{i t} \mid \alpha_{i}, \overline{\mathbf{X}}_{i}, \bar{N}_{i}\right]=\frac{\exp \left(\gamma_{t}+\mathbf{X}_{i t}^{\prime} \cdot \boldsymbol{\eta}+\beta \cdot\left(P O S T_{t} \cdot m_{i}\right)+\phi \cdot\left(d_{1983} \cdot m_{i}\right)\right)}{\sum_{\tau=1}^{T} \exp \left(\gamma_{\tau}+\mathbf{X}_{i \tau}^{\prime} \cdot \boldsymbol{\eta}+\beta \cdot\left(P O S T_{\tau} \cdot m_{i}\right)+\phi \cdot\left(d_{1983} \cdot m_{i}\right)\right)} \bar{N}_{i},
$$

where $\bar{N}_{i}$ is the average number of facilities for hospital $i$ over the sample. This transformation removes the unobserved hospital effects, the $\alpha_{i}$ 's, and enables consistent estimation. We estimate equation (29) with quasi-maximum likelihood and calculate the fully-robust variancecovariance matrix (see Wooldridge, 2002, pp. 674-676).

In practice, the results are not sensitive to whether we use OLS or the conditional fixed effect Poisson model. In either case, the estimates suggest that the change from full to partial

\footnotetext{
${ }^{31}$ The analogs of our other estimating equations, (26) and (27), are obtained by replacing the $\beta \cdot\left(P O S T_{t} \cdot m_{i}\right)$ term with a full set of interactions between $m_{i}$ and post-1981 year dummies, or with $\tilde{\beta} \cdot\left(\sum_{t \geq 1984}(t-1983) \cdot m_{i}\right)$.
} 
cost reimbursement is associated with a statistically and economically significant increase in the number of facilities of affected hospitals.

The point estimate from the OLS specification in column (1) is 2.621, suggesting that, on average, the regulatory change is associated with an increase of about one new facility $(\simeq 2.621 \times 0.38)$ in a hospital over its first three years; this corresponds to about a 4 percent increase over the average number of facilities in a hospital (which is about 25). The magnitude of the estimated effect is quite similar in the conditional fixed effect Poisson specification in column (6); the point estimate of 0.12 suggests that the introduction of PPS is associated with an approximately 5 percent $(\simeq 0.120 \times 0.38)$ increase in the number of new facilities for the average Medicare share hospital over its first three years.

The results in Table 6 are also broadly supportive of our identifying assumption of no differential trends across hospitals in the number of facilities prior to PPS. Columns (3) and (8) show some evidence of a differential decline in the number of facilities in higher Medicare share hospitals in 1981 relative to 1980, but reassuringly, there is no similar pattern among any of the other pre-PPS years 1981, 1982 or 1983. Although the results in columns (3) and (8) may raise concerns about mean reversion, Section 7 will show that the results are robust to several different checks against mean reversion.

One difference with the previous set of findings is the time pattern of the impact of PPS in the flexibly estimated specification (columns 3 or 8); rather than the approximately linear growth for the other variables studied so far, the number of facilities in the affected hospitals shows a statistically significant increase from 1983 to 1984, and again from 1984 to 1985, but the effect then appears to decline somewhat from 1985 to 1986 (OLS specification) or at least not rise further from 1985 to 1986 (Poisson specification).

\subsubsection{Hazard Models}

A drawback to the preceding analysis is that it treats all technologies as perfect substitutes. As an alternative, we estimate separate hazard models of the time to adoption for specific technologies that are in the data for all of the years of our sample. We focus on 10 technologies that were identified as "high tech" by previous researchers (Cutler and Sheiner, 1998, Baker, 2001, and Baker and Phibbs, 2002), and that are present in our data in all years. Two of these are cardiac technologies (cardiac catheterization and open heart surgery), two are diagnostic technologies (CT scanner and diagnostic radioisotope facility), four are radiation therapies used in cancer treatment (megavoltage radiation therapy, radioactive implants, therapeutic radioisotope facility, and x-ray radiation) and the remaining two are the neonatal intensive care unit and organ transplant. Figure 5 plots the diffusion pattern over our sample period of each of these 10 technologies; they differ in both their initial diffusion level and in whether 
and how rapidly they are diffusing over our sample period.

In the hazard model analysis, we exclude hospitals that have a given technology in 1980 (since they are not "at risk" of failure -i.e., of adoption), and treat hospitals that have still not adopted the technology by 1986 (the end of our sample period) as censored. Our first model is an exponential (i.e., constant baseline) proportional hazard model of the form:

$$
\lambda_{t}=\alpha \exp \left(\gamma_{t}+\phi \cdot d_{1983} \cdot m_{i}+\beta \cdot\left(P O S T_{t} \cdot m_{i}\right)+\mathbf{X}_{i}^{\prime} \cdot \boldsymbol{\eta}\right)
$$

where $\lambda_{t}$ denotes the conditional probability that the hospital adopts the technology in question at time $t$, given that it has not yet adopted the technology, and $\alpha$ denotes the constant baseline hazard parameter (which we estimate). The assumption of the proportional hazard model is that the covariates shift the baseline hazard proportionally. Our second model is a Cox semiparametric proportional hazard model, which allows for a fully flexible, non-parametric baseline hazard $\lambda_{0}$, and is estimated by a transformation similar to that in equation (29) - see Kiefer (1988). In the Cox model, we do not include year fixed effects, since the fully flexible baseline hazard is also specified with respect to calendar time.

Since we have at most a single transition (adoption) for each hospital, we cannot include hospital fixed effects in the hazard model analysis. Instead, we control for a range of timeinvariant hospital characteristics (denoted by $\mathbf{X}_{i}$ ). These are $m_{i}$ (i.e., the hospital's 1983 Medicare share), the square of $m_{i}$, the number of beds in 1983, and dummy variables for whether the hospital is a general (non-speciality) hospital, whether it is short term, whether it is federal, whether it is located in an urban area, and a complete set of state fixed effects. ${ }^{32}$

Table 7 reports the results from both models. ${ }^{33}$ To conserve space, we report results only from a specification similar to equation (25), which includes a single interaction between the Medicare share, $m_{i}$, and the post-PPS period dummy, $P O S T_{t}$ as well as the pre-specification test with the interaction between $m_{i}$ and the dummy for the year $1983 .{ }^{34}$ Panel A of Table 7 reports the results from the exponential proportional hazard model, while Panel B reports results from the Cox proportional hazard model. For each technology in each panel, we report the coefficient and the standard error on $P O S T_{t} \cdot m_{i}$ and $d_{1983} \cdot m_{i}$. To illustrate the magnitude of our estimates, we also translate the hazard model coefficient on $P O S T_{t} \cdot m_{i}$ into

\footnotetext{
${ }^{32}$ Our previous results are very similar if we estimate the models controlling for these covariates instead of hospital fixed effects.

${ }^{33}$ We also estimated (but do not report) extended hazard models allowing for unobserved hospital heterogeneity parameterized by a gamma distribution using the discrete time nonparametric baseline proportional hazard framework of Han and Hausman (1990). Our results are not sensitive to this extension, though there was evidence of statistically significant hospital heterogeneity (estimates from the Han-Hausman model without heterogeneity were very similar to the Cox model). For computational reasons, the Han-Hausman models were estimated without the state fixed effects (results from the exponential hazard or Cox models are not sensitive to whether or not state fixed effect are included).

${ }^{34} \mathrm{As}$ with the results for the total number of facilities, the results from hazard model estimates of individual technologies do not indicate that the impact of PPS grows continually over the three PPS years in our sample.
} 
the implied change in the proportion of hospitals that adopt the technology between 1981 and 1986 associated with changing $m_{i}$ from zero to its mean value.

Since we look at 10 different technologies, the per-technology p-values will be lower than when each technology is viewed as part of a "family of hypotheses" that PPS had no effect on any of the 10 technologies. We therefore also report the family-wise error rate adjusted p-value [in square brackets]. This p-value corresponds to the probability of rejecting the null hypothesis of no effect on a given technology under the null family of hypotheses of no effect on any of the technologies. ${ }^{35}$ The family-wise adjusted p-values are about 5 times larger than the standard p-values.

Both panels of Table 7 show similar results and suggest that the shift from full cost to partial cost reimbursement was associated with increased technology adoption. At a 5 percent cutoff, the results from the exponential (Cox) model using the standard p-values suggest that PPS is associated with increased adoption of 7 (6) of the 10 specific technologies. The results using the family-wise adjusted p-values suggest that PPS is associated with an increased adoption of 3 of the 10 technologies. Two of these three technologies, open heart surgery and CT scan, are likely to be used disproportionately by Medicare patients. Our interpretation of the increase in adoption following the PPS is thus along the lines of Proposition 3, and relies on technology-labor substitution. ${ }^{36}$

While we cannot definitively pinpoint the mechanism for this technology-labor substitution, we can provide some evidence of one natural mechanism, the use of technology to reduce the length of stay. The typical hospital day is relatively nurse- or custodial care-intensive. By increasing the intensity of treatment up front, hospitals may be able to reduce length of stay on the margin. Consistent with this, Table 8 presents evidence that Medicare PPS is associated with declines in log average length of stay, defined as $\log$ (patient days/admissions). ${ }^{37}$

It is also noteworthy that the other technology for which the family-wise adjusted p-values (as well as the standard p-values) show a statistically significant increase in adoption is the neonatal intensive care unit (NICU), which is likely to be used almost exclusively by nonMedicare patients. Although an effect of the PPS on NICU may at first appear puzzling (or

\footnotetext{
${ }^{35}$ We calculate these family-wise error rate adjusted p-values based on 10,000 iterations of the free step-down resampling method of Westfall and Young (1993). This is more powerful than the standard Bonferroni correction because it does not assume independence across the 10 outcomes and sequentially removes hypotheses from the family after they are rejected; see Kling and Liebman (2004) for an application and a more detailed discussion of this method.

${ }^{36}$ As noted before, hospital labor consists of nurses, orderlies, administrators, and custodial staff but does not include doctors (who are neither employed by nor paid by the hospitals). Thus the technologies may well be complementary with physicians (or particular physician specialties) but still substitutes for hospital labor.

${ }^{37}$ Because the dependent variable is mechanically related to the cross-sectional variation of Medicare share of patient days in 1983, we again drop 1980 from the sample and re-define the cross-sectional variation as Medicare share of patient days in 1980.
} 
even concerning), it is consistent with the growing body of evidence of "spillovers" from the nature of health insurance of one group of patients to the treatment of another group. ${ }^{38}$ Such spillovers could be incorporated into the framework in Section 2 by relaxing the assumption that $z_{i}$ in the production function (1) is constant. A change from full cost to partial cost reimbursement would then encourage a firm to switch its managerial efforts (a component of $z_{i}$ ) from Medicare-related activities to non-Medicare activities, potentially inducing the adoption of non-Medicare related technologies. ${ }^{39}$ Another reason for such spillovers is the presence of complementarities in the operation or adoption of new technologies; adopting a number of new Medicare-related technologies may reduce the costs (and/or increase the benefits) of adopting other, non-Medicare, technologies. Finally, in practice, Medicare's cost-based reimbursement rules permitted hospitals considerable latitude in determining which costs to assign to Medicare (OTA, 1984, CBO, 1988), allowing some degree of fungibility in the reimbursement of capital expenses. In light of all these considerations, we do not find it surprising that there is evidence of some effect of PPS on adoption of non-Medicare technologies.

\subsection{Changes in Skill Composition}

Finally, Proposition 4 suggests that when technology (or capital) is more complementary to skilled than to unskilled labor, the induced increase in technology (or in the capital-labor ratio) should cause a change in the composition of the workforce towards more skilled employees. We can identify full-time equivalent employment of two types of nurses in the data, Registered Nurses (RN's) and Licensed Practitioner Nurses (LPN's); together these constitute about onequarter of total hospital employment. ${ }^{40}$ RN's are considerably more skilled than LPN's. ${ }^{41}$

Table 9 shows that the introduction of PPS appears to be associated with an increase in the proportion of nurses that are relatively more skilled nurses (the RN's). These results are somewhat weaker than our previous findings; for example, in one specification, there is evidence

\footnotetext{
${ }^{38}$ For example, Baicker and Staiger (2005) find that increases in the hospital reimbursement rate of Medicaidwhich primarily reimburses for childbirth and pediatrics - is associated with declines not only in infant mortality but also in heart attack mortality among the elderly Medicare population. Similarly, Baker (1997) finds that higher managed care penetration in private insurance is associated with decreased hospital spending on fee-forservice Medicare patients. Most closely related to our findings, Dafny (2005) finds that in response to increases in average reimbursement rates for Medicare patients with specific diagnoses, hospitals spread the increased revenue uniformly across the treatment of all patients.

${ }^{39}$ Note that this is a distinct effect on technology adoption from that highlighted in Proposition 3, which focuses on the technologies directly substituting for the tasks previously performed by the labor that was being subsidized under the full cost reimbursement regime.

${ }^{40}$ The total amount of hospital employment accounted by nurses is about one-third, but the other nursing categories do not have consistent names across years, making it impossible for us to use them in this exercise.

${ }^{41} \mathrm{RN}$ certification requies about twice as many years of training as LPN certification, which is reflected in the approximately 50 percent higher hourly wage of RN's relative to LPN's. We are grateful to Doug Staiger for providing us with the estimates of hourly wages by occupation from the 2000 Merged Outgoing Rotation Groups of the CPS.
} 
of a marginally statistically significant effect prior to PPS in the same direction as the PPS (column 2). In our preferred specification (column 5), the pre-PPS effect is not statistically significant, but is still of the same sign as the main effect and about half the magnitude. Overall, we interpret these findings as broadly suggestive of a potential increase in the skill content of employment associated with the induced increase in technology adoption. Since, as discussed in the Introduction, the existing view in the literature is that capital and technology are more complementary to skilled labor than unskilled labor, evidence that PPS is associated with increases in the skill composition of hospitals' workforces provides indirect support for our results concerning the effect of PPS on capital-labor ratios and technology adoption.

\subsection{Alternative Interpretations}

We have so far offered our preferred interpretation that the observed changes in factor demands and technology are a response to the change in relative factor prices induced by PPS. There are a number of alternative interpretations for our results, however the evidence suggests that they are less compelling than our preferred interpretation.

One potential alternative is that the increase in the depreciation share, documented in Table 2, may be a mechanical effect. Depreciation is a backward looking measure, and thus the ratio of depreciation to operating expenses may mechanically increase in response to a proportional scaling back of capital and labor inputs. But in practice, we see no scaling back of capital includes, and moreover, this alternative explanation would suggest that the effect should attenuate over time, whereas the results in column (3) of Table 2 indicate that the effect appears to grow over time. Another related concern would be that the PPS-induced reduction in hospitals' Medicare share (see Table 5) could mechanically cause an increase in the capital-labor ratio if Medicare patients are treated in a less capital-intensive manner than nonMedicare patients. Empirically, however, Medicare patients appear to be more capital-intensive than non-Medicare patients; in the 1983 cross-section, hospitals with a higher Medicare share have a statistically significantly higher depreciation share, with or without controlling for a rich set of covariates. In addition, neither of these two "mechanical" explanations is consistent with the evidence of PPS-induced changes in technology adoption and skill composition.

Another possible interpretation is that the increase in the capital-labor ratio may partly reflect a strategic response by hospitals to the possibility that capital reimbursement may be made prospective in the future; if so, hospitals may wish to build up their historical capital costs to increase their future prospective capital reimbursement rates. The incentive for such a strategic response is not obvious, however, since it was not a priori clear if and when capital reimbursement would be made prospective, nor how or whether own historical costs would affect any prospective reimbursement rates (see e.g., GAO, 1986, CBO, 1988). Moreover, 
to the extent that the response reflects the results from such "gaming", we might expect it to occur predominantly - or at least disproportionately - on the more easily manipulatable financing dimension (e.g., interest expenditures, or leveraging) rather than on the depreciation share per se. However, in Table 12 below, we find no evidence that PPS is associated with an increase in debt financing of capital expenditures ("leveraging up"). Finally, this type of gaming response should also not translate into effects on other margins, such as technology adoption or the skill composition of the workforce. ${ }^{42}$

Turning to the technology adoption results, one potential concern is the presence of secular increases in medical technology during this time period. Since the elderly are among the most intensive users of medical technology, there may be a spurious association between Medicare share and technology adoption trends. The evidence of an impact of PPS on the adoption of the NICU (a non-Medicare technology) is reassuring in this regard. Moreover, several of the technologies for which we find an impact of PPS are in fact not diffusing over our sample period (see Figure 5). Most importantly, the results from our pre-specification test $\left(d_{1983} \cdot m_{i}\right)$ in Tables 6 and 7 show no systematic evidence of differential trends in technology adoption across hospitals with different Medicare share before the introduction of PPS.

An alternative interpretation for our technology findings is that PPS reimbursement on the price cap (i.e., output) side is not fully prospective (McClellan, 1996, 1997); the reimbursement a hospital receives for a Medicare patient varies not only based on the patient's diagnosis, but also, in some cases, on the type of treatment he or she receives, particularly the type of surgery, if any. These features may have increased hospitals' incentives to perform these surgeries, and consequently induced them to adopt the technologies needed to perform them. However, the evidence suggests that this type of incentive effect is unlikely to be the driving factor behind our technology adoption results. For we find equally strong results for procedures which are not reimbursed more generously after PPS. As noted by McClellan (1996), for ad hoc reasons, there are separate reimbursement rates for patients who have a heart attack if they undergo percutaneous transluminal coronary angioplasty (PCTA) or coronary artery bypass graft (CABG), but not if they spend time in the cardiac care unit (CCU). Hazard models estimated for adoption of the CCU show that the introduction of PPS is associated with an increased rate of adoption of the CCU even though this was not a technology whose

\footnotetext{
${ }^{42}$ Even if the effect is not merely a strategic one, the magnitude of the input response may be affected by hospitals' expectations that continued reimbursement of capital costs might be temporary. A priori, however, it is not clear how such expectations (even if they were important) would affect magnitudes. On the one hand, the response might be larger because the relative subsidy to capital is expected to be temporary and hospitals may attempt to incur and pass through their capital costs while they still can. On the other hand, if there are adjustment costs, the response may be smaller than the case in which the change in the regulatory regime is expected to be permanent.
} 
use was associated with any increased reimbursement rate. ${ }^{43}$ Moreover, there is no evidence that hospitals vary resources per patient in response to the subsequent changes in Medicare's relative reimbursement rates of various health services (though there is evidence of nominal responses, so-called "upcoding," see, e.g., Dafny, 2005).

Finally, since PPS applied only to hospital inpatient expenditures, it may have encouraged a real or nominal reallocation of some inpatient hospital activity to outpatient or nursing home units of the hospital. Previous empirical evidence suggests that PPS was, in fact, associated with re-allocation of some inpatient hospital activity to hospital outpatient units, although there is no evidence of re-allocation to nursing homes (Coulam and Gaumer, 1991). However, any such reallocations within the hospital can not explain our findings regarding the impact of PPS on input and technology choices, as our input and technology measures are inclusive of hospital-based outpatient units and hospital-based nursing home facilities. ${ }^{44}$ Of course, if some activities were spun off out of the hospital completely, these could potentially contribute to our estimated decline in labor inputs; they could not, however, explain the estimated increase in technology adoption. Moreover, the empirical evidence is not suggestive of such spin-off behavior. We find no evidence that the introduction of PPS is associated with an increased probability of having a hospital-based nursing home unit (results not reported), and although we cannot use our empirical strategy to investigate the impact of PPS on the creation of freestanding nursing home facilities, there is no evidence in the time series of an increase in total nursing home use over our time period (HCFA, 1999 p.178).

\section{Robustness Checks}

\subsection{Alternative Specifications}

We present robustness results for our main dependent variables: depreciation share (capitallabor ratio), log labor inputs, log capital inputs, and the number of facilities. ${ }^{45}$ In line with the pattern of results shown in Tables 2, 3, 4 and 6, we report results with the post-PPS period parameterized by a linear trend as in equation (27) for all outcomes except the number of facilities, for which we report results with the post-PPS period parameterized by a single indicator post-PPS dummy variable as in equation (25).

Column (1) of Table 10 reproduces the baseline results. To investigate the concern that

\footnotetext{
${ }^{43}$ Information on whether a hospital has a CCU is available from 1980-1985 (see Appendix Table A). The other technology adoption results in Table 7 are robust to excluding 1986 from the data.

${ }^{44}$ The estimated impact of PPS on the capital-labor ratio looks quite similar if we instead use measures of capital and labor that exclude any inputs used in a hospital-based nursing home (results not reported).

${ }^{45}$ To save space, we only report the robustness analysis of the number of facilities in the OLS specification. Results from the conditional fixed effect Poisson model were similar, except that we did not estimate the first-differenced specification (column 4) since this specification cannot be consistently estimated within the conditional fixed effects Poisson model.
} 
our results may be spuriously picking up underlying differential trends by hospitals with different pre-PPS Medicare shares, our first robustness exercise adds an interaction between the Medicare share (in 1983), $m_{i}$, and a linear trend (i.e., in terms of our estimating equations above, the vector of covariates $\mathbf{X}_{i t}$ now includes $\left.m_{i} \cdot t\right)$. The estimates in column (2) show that our main results are generally robust to the inclusion of this linear trend. ${ }^{46}$

A related but different concern is that of mean reversion. In particular, if high Medicare share hospitals are adjusting back to some hospital-specific equilibrium level, this may be picked up by our post-PPS times Medicare share interaction. To investigate this issue, column (3) interacts the value of the dependent variable for each hospital in 1982 with a full set of year dummies. This specification thus flexibly controls for any mean-reverting dynamics as well as any potential differential trends that depend on hospital baseline characteristics (e.g., based on technology levels). The estimates are remarkably similar to the baseline and show no evidence that mean reversion or differential trends based on pre-treatment characteristics had any significant effect on our results.

As another check on the serial correlation properties of the error term and patterns of mean reversion, column (4) estimates the model in first differences rather than in levels. This specification is also useful as a check on the strict exogeneity assumption necessary for consistency of the fixed effects estimator (Wooldridge, 2002, p. 284), and on the potential importance of measurement error in the data (Griliches and Hausman, 1986). The first-differenced results in column (4) are very similar to the baseline results. ${ }^{47}$

Column (5) deals with concerns about measurement error in our key variable, the Medicare share, by instrumenting for the 1983 Medicare share with past values. The results are again similar to the baseline estimates. The only exception is in Panel $\mathrm{C}$ where now there is a small and marginally significant negative effect on log capital inputs. Since the baseline estimate in column (1) is also negative (but insignificant) for this variable, this evidence might suggest that there might have been a small decline in log capital inputs following the introduction of PPS, though this result is not robust across specifications (see especially column 8). Whether or not this is the case is not essential for the interpretation of the rest of our results.

Several other specification checks investigated the sensitivity of our findings to differences

\footnotetext{
${ }^{46}$ The only exception is in Panel $\mathrm{C}$ for $\log$ capital inputs, where we now find a significant pre-PPS effect. We find a similar significant pre-PPS positive effect on log capital inputs in the first-differenced specification in column (4) and the specification excluding small regional hospitals in column (7) as well. Nevertheless, since neither here nor in our base specifications is there any evidence of an impact of PPS on total log capital inputs, these results are not a major problem for our approach and simply show that the capital input results are in general less precisely estimated.

${ }^{47}$ The one exception is for the number of facilities (Panel D), which now show a pre-PPS effect of the same sign as the estimated PPS effect that is significant at 5\%. However, since this is the only specification among many where we find a same-signed significant pre-PPS effect for the number of facilities, we interpret this as partly driven by sampling variability.
} 
across areas and groups of hospitals. Since the price cap of Medicare PPS was phased in over a four-year period as a combination of hospital-specific historical rates, regional average rates and national rates (CBO, 1998, Gaumer and Staiger, 1990), regional differences in the level of the price cap might contribute to differential regional effects of PPS. Column (6) includes a full set of interactions between the (nine) census region dummies and year effects. In addition, exceptions to PPS for some small rural hospitals made the reimbursement of operating costs potentially not as prospective for these hospitals, which constitute about 20 percent of all hospitals, although obviously a much smaller proportion of hospital beds (Staiger and Gaumer, 1990, Newhouse, 2002, p. 31). Column (7) therefore excludes the approximately 20 percent of hospitals that are outside an MSA and had fewer than 50 beds in 1983. The results in column (6) and (7) are again very similar to the baseline estimates in column (1).

We also looked at results weighted by hospital size (measured as the number of beds in 1983). Hospital size is highly right skewed; while the 90th percentile is only four times bigger than the median, the 99th percentile is more than double the 90th percentile (and the largest hospitals are over twice as big as the 99th percentile). Consequently, a regression weighted by hospital size effectively only compares the behavior of the hospitals within the top 5th percentile or so. To avoid this, while still weighting by hospital size, we exclude the top ventile (i.e., the top 5\%) of hospitals. ${ }^{48}$ The weighted results, shown in column (8), are on the whole very similar to those in column (1).

The evidence in Table 7 of an impact of PPS on the adoption of non-Medicare technologies such as NICU raises the concern that there may be differential trends across hospitals related to other demographic differences of their patient-bases, which may be confounding our estimates. To check for this possibility, column (9) includes $d_{1983} \cdot b_{i}$ and POSTTREN $D_{t} \cdot b_{i}$ (i.e., $\left(\sum_{t \geq 1984}(t-1983) \cdot b_{i}\right)$ as in equation $\left.(27)\right)$ or $P O S T_{t} \cdot b_{i}$ in Panel $\mathrm{D}$, where $b_{i}$ is the newborn share of non-Medicare patient days (defined analogously to $m_{i}$ ). The inclusion of these variables has no major effect on any of our results. In addition, the coefficients on $d_{1983} \cdot b_{i}$ and POSTTREND $D_{t} \cdot b_{i}\left(\right.$ or $P O S T_{t} \cdot b_{i}$ in Panel D) are economically and statistically insignificant (not shown in column 9). ${ }^{49}$

Looking across hospital ownership types, we find that the estimated impact of PPS is generally quite similar across publicly-owned, for-profit, and non-profit hospitals. The one exception is the technology adoption effects of PPS which appears to be more pronounced in

\footnotetext{
${ }^{48}$ Excluding the top or the bottom ventile or the top or the bottom decile of hospitals from the unweighted regressions has no perceptible effect on the results (not shown). Moreover, regressions weighted by log of hospital size without excluding the top 5\% also produce very similar results (again not shown to save space).

${ }^{49}$ Including these additional interactions also has no effect on the hazard model estimates. We only find significant effects of $P O S T_{t} \cdot b_{i}$ for NICU, where it has the expected sign, but the magnitude is much smaller than those of the changes in response to relative factor prices induced by PPS.
} 
publicly-owned hospitals (results not shown).

Finally, we explored the heterogeneity in the estimated effect of PPS based on the type of variation in $m_{i}$ used to identify its effects. Recall that federally-owned hospitals, long-term hospitals, and certain speciality hospitals - together totalling 15 percent of all hospitals - were exempted from PPS, and were coded as having a zero Medicare share (see Figure 4). Table 11 explores how the estimated effect of PPS varies depending on whether we use the variation in Medicare share provided by these exempt hospitals to identify the effect of PPS. Column (1) replicates the baseline findings. In column (2), we add a full set of year dummies interacted with each of the three categories that provide an exemption from PPS to equations (25) and (27). As a result, identification of the effect of PPS comes only from within-hospital type variation in $m_{i}$ and the three types of hospitals that are exempt from Medicare PPS are not used to estimate its impact. Column (3) presents the complementary approach in which identification of PPS comes only from between-hospital type variation in $m_{i}$; here, we instrument the interaction terms $d_{1983} \cdot m_{i}$ and POSTTREND $D_{t} \cdot m_{i}$ with the full set of year dummies interacted with each of the three exemption categories. The results indicate that the basic findings are robust to using either the within or between variation. Most of the estimated effects of quite similar in size using either source of variation, although the estimated impact of PPS on the capital-labor ratio is substantially larger using the between variation than the within variation.

In summary, a wide variety of alternative specifications (some of them reported in Tables 10 and 11) suggest that the PPS-related increase in capital-labor ratio and decline in log labor inputs are robust to a battery of checks. The results on the number of facilities are also robust; although a number of specifications produced opposite-signed and statistically significant pre-PPS results (in particular, columns 4, 6, 7, and 8), which might raise concerns about mean reversion, the estimated effects on facilities are highly robust to several checks for mean reversion. The results on log capital inputs are on the whole less precise, but they are consistent with our interpretation of no effect of PPS on overall capital inputs.

\subsection{Alternative Dependent Variables}

Table 12 investigates the robustness of our results to alternative measures of various dependent variables. Once again, the first column repeats the baseline regressions for comparison. Panel A shows that the results for log labor inputs are robust to using alternative measures of labor inputs, such as log payroll expenditures rather than log operating expenditures (see column 2). Log payroll expenditures (which are just under two-thirds of log operating costs) are a more direct measure of labor costs, but they are not our preferred measure, since they do not include the full set of costs that experienced the relative price change under PPS. It is also interesting to consider the impact of PPS on the non-payroll portion of operating expenses. This may 
include elements of capital (or variable, non-labor costs more generally) such as pills, lab tests, and needles; it may also include capital equipment that hospitals lease and therefore treat as operating expenses for an accounting purposes. The results in column (3) suggest that the PPS-induced increase in the price of operating expenditures relative to capital expenditures was associated with a similar decline in log non-payroll operating expenses as in log payroll expenses. Columns (4) and (5) show that our results for log labor inputs are also generally robust to using log employment or using log nurses, defined as RN's plus LPN's, though with both of these dependent variables, there is some evidence of pre-PPS effects, in one case of the same sign as the main effect, and in the other of the opposite sign.

Panels B and $\mathrm{C}$ show that the results for log capital inputs and the capital-labor ratio are robust to using interest expenses as well as (or instead of) depreciation expenses to measure capital inputs. In particular, in all cases, the PPS effect is qualitatively similar, though in some specifications there is evidence of an opposite-signed pre-PPS effect. The results in Panel B suggest that PPS is not associated with any substantive or statistical change in either log depreciation or log interest expenditures. Consistent with this, the results in Panel $\mathrm{C}$ suggest that the (proportional) increase in the capital-labor ratio is quite similar when depreciation expenses or interest expenses are used to proxy for capital inputs.

\section{Conclusions}

This paper has investigated the impact of regulatory change on firm input mix and technology choices. We presented a simple neoclassical framework that emphasizes changes in relative factor prices faced by regulated firms under different regimes and how this may affect input mix and technology choices. We then investigated this possibility empirically by studying the impact of the introduction of the Medicare Prospective Payment System (PPS) in the United States. This reform changed the reimbursement for Medicare-related inpatient hospital expenses from a full cost reimbursement system for both labor and capital inputs to a partial cost reimbursement system, and thereby raised the relative price of labor.

Consistent with the framework we developed, the empirical results suggest that the PPS reform is associated with an increase in the capital-labor ratio. This decline stems mainly from a decline in labor inputs. We also found that the introduction of PPS is associated with a significant increase in the adoption of a range of new health care technologies. Within our theoretical framework, this would be the case when there is a relatively high degree of substitutability between technology and hospital labor. We presented suggestive evidence of technology-labor substitution working through declines in the length of stay. We also found an increase in the skill composition of these hospitals, which is consistent with technology-skill 
(or capital-skill) complementarities.

Our empirical findings suggest that relative factor prices are an important determinant of technology diffusion in the hospital sector and perhaps in other sectors as well. They raise an interesting question for further research of whether other factors that increase the relative price of labor for hospitals, such as labor unions or the tax treatment of capital expenditures, also encourage capital deepening and technology adoption.

Our findings do not address the efficiency and welfare consequences of the increase in relative labor prices associated with a move to PPS. These depend in part on the relative generosity of labor and capital reimbursement under the previous full cost reimbursement system, and also on other pre-existing distortions in the health care sector. However, the evidence that the move to PPS was not associated with substantial adverse health outcomes (Cutler, 1995, Staiger and Gaumer, 1990) suggests that at least on the health dimension there were no substantial adverse welfare effects.

It is also worth emphasizing that our findings regarding technology adoption run counter to the general expectation that PPS would likely reduce the pace of technology adoption (Sloan et al., 1988, Coulam and Gaumer, 1991, Weisbrod, 1991). Such expectations were formed by considering PPS as a full price cap system, and hence overlooked the associated relative factor price changes. This highlights the potential importance of the details of regulation policy in determining its ultimate impact. The particular detail we have focused on - the exemption of capital costs from a price cap - appears to be quite common in practice. For example, the subsequent Medicare prospective payment reimbursement system for home health care also excluded capital-related costs (in particular, "durable medical equipment" such as hospital beds or oxygen equipment) from the price cap (Federal Register, 2000).

Naturally, our empirical results directly speak only to the impact of regulatory change in the hospital sector. It is possible that the health care sector is not representative of regulatory effects in other sectors, for example because most hospitals are non-profit or public entities or because the health care sector is significantly less capital intensive than many other regulated industries (recall footnote 22). Nevertheless, the theoretical framework we develop should be applicable to other regulated industries, many of which operate under some form of partial cost reimbursement (see Joskow, 2005). An investigation of the response of input and technology choices to similar regulatory changes in other industries is another interesting area for future research and would be particularly useful for understanding the extent to which the results presented here generalize to other industries. 


\section{Appendix A: Proofs from Section 2}

Proof of Proposition 1: Taking the ratio of (10) to (6), we obtain

$$
\frac{F_{K}\left(A_{i}, L_{i}^{p}, K_{i}^{p}\right) / F_{L}\left(A_{i}, L_{i}^{p}, K_{i}^{p}\right)}{F_{K}\left(A_{i}, L_{i}^{f}, K_{i}^{f}\right) / F_{L}\left(A_{i}, L_{i}^{f}, K_{i}^{f}\right)}=\left(1-m_{i} s_{L}\right) .
$$

When $F\left(A_{i}, L_{i}, K_{i}\right)$ is homothetic in $L_{i}$ and $K_{i}$, the left-hand side is a decreasing function of $\left(K_{i}^{p} / L_{i}^{p}\right) /\left(K_{i}^{f} / L_{i}^{f}\right)$, which immediately establishes $(11)$, since $\left(1-m_{i} s_{L}\right)<1$, and $(12)$, since $\left(1-m_{i} s_{L}\right)$ is decreasing in $m_{i}$. QED

Proof of Proposition 2: To prove this proposition, totally differentiate the first-order conditions (4) and (5) with respect to $L_{i}, K_{i}$ and $s_{L}$, and write the resulting system as

$$
\left(\begin{array}{ll}
F_{L L} & F_{L K} \\
F_{L K} & F_{K K}
\end{array}\right)\left(\begin{array}{c}
d L \\
d K
\end{array}\right)=\left(\begin{array}{c}
-m_{i} \\
0
\end{array}\right) d s_{L}
$$

Applying Cramer's rule immediately gives (13), and the fact that $F_{L L} F_{K K}-\left(F_{L K}\right)^{2}>0$ and $F_{K K}<0$ follows from the concavity of $F$, thus establishing the fact that $d L_{i}\left(s_{L}\right) / d s_{L}>0$ as stated in (13). Similarly, from Cramer's rule

$$
\frac{d K_{i}\left(s_{L}\right)}{d s_{L}}=\frac{m_{i} F_{L K}}{F_{L L} F_{K K}-\left(F_{L K}\right)^{2}} .
$$

Therefore, this will be positive when $F_{L K}>0$ and negative when $F_{L K}<0$. When $F$ is homogeneous of degree $\alpha$, i.e., $F\left(A_{i}, L_{i}, K_{i}\right)=H_{1}\left(A_{i}\right) \phi\left(L_{i}, K_{i}\right)^{\alpha}$, it is easy to verify that

$$
F_{L K} \propto(\alpha-1) \phi_{L} \phi_{K}+\phi_{L K} \phi
$$

Recall that when $\phi$ exhibits constant returns to scale, the elasticity of substitution is given by

$$
\sigma_{\phi} \equiv \frac{\phi_{L} \phi_{K}}{\phi_{L K} \phi}
$$

This implies that $F_{L K}<0$ if and only if $1 /(1-\alpha)<\sigma_{\phi}$ and positive if and only if $1 /(1-\alpha)>\sigma_{\phi}$, thus establishing (14). QED

Proof of Proposition 3: Using the form in (16), the first-order necessary and sufficient conditions (under full cost reimbursement) are

$$
\begin{aligned}
q \beta \psi_{L}\left(A_{i}, L_{i}\right) \psi\left(A_{i}, L_{i}\right)^{\beta-1} H_{s}\left(K_{s, i}\right) & =\left(1-m_{i} s_{L}\right) w \\
q \beta \psi_{A}\left(A_{i}, L_{i}\right) \psi\left(A_{i}, L_{i}\right)^{\beta-1} H_{s}\left(K_{s, i}\right) & =\left(1-m_{i} s_{K}\right) R \kappa_{i}\left(A_{i}\right) \\
q \psi\left(A_{i}, L_{i}\right)^{\beta} H_{s}^{\prime}\left(K_{s, i}\right) & =\left(1-m_{i} s_{K}\right) R .
\end{aligned}
$$

Taking logs and totally differentiating with respect to $A_{i}, L_{i}, K_{s, i}$ and $s_{L}$, we obtain the system of equations

$$
\left(\begin{array}{ccc}
\frac{\psi_{L L}\left(A_{i}, L_{i}\right)}{\psi_{L}\left(A_{i}, L_{i}\right)} & \frac{\psi_{A L}\left(A_{i}, L_{i}\right)}{\psi_{L}\left(A_{i}, L_{i}\right)} & \\
-(1-\beta) \frac{\psi_{L}\left(A_{i}, L_{i}\right)}{\psi\left(A_{i}, L_{i}\right)} & -(1-\beta) \frac{\eta}{\psi\left(A_{i}, L_{i}\right)} & \frac{\eta}{K_{s, i}} \\
\frac{\psi_{A L}\left(A_{i}, L_{i}\right)}{\psi_{A}\left(A_{i}, L_{i}\right)} & -\frac{\kappa_{i}^{\prime}\left(A_{i}\right)}{\kappa_{i}\left(A_{i}\right)} \frac{\psi_{A A}\left(A_{i}, L_{i}\right)}{\psi_{A}\left(A_{i}, L_{i}\right)} & \\
-(1-\beta) \frac{\psi_{L}\left(A_{i}, L_{i}\right)}{\psi\left(A_{i}, L_{i}\right)} & -(1-\beta) \frac{\eta}{\psi\left(A_{i}, L_{i}\right)} & \frac{\eta}{K_{s, i}} \\
\beta \frac{\psi_{L}\left(A_{i}, L_{i}\right)}{\psi\left(A_{i}, L_{i}\right)} & \beta \frac{\psi_{A}\left(A_{i}, L_{i}\right)}{\psi\left(A_{i}, L_{i}\right)} & \frac{\eta-1}{K_{s, i}}
\end{array}\right)\left(\begin{array}{c}
d L_{i} \\
d A_{i} \\
d K_{s, i}
\end{array}\right)=\left(\begin{array}{c}
\frac{-m_{i}}{1-m_{i} s_{L}} \\
0 \\
0
\end{array}\right) d s_{L} .
$$

Applying Cramer's rule again, and using the fact that (16) is strictly concave, we immediately obtain $d L_{i}\left(s_{L}\right) / d s_{L}>0, d K_{s, i}\left(s_{L}\right) / d s_{L}>0$ and that $d A_{i}\left(s_{L}\right) / d s_{L}$ is proportional to

$$
(1-\eta) \psi_{A L} \psi+(1-\beta)(\eta-1) \psi_{A} \psi_{L}+\beta \eta \psi_{A} \psi_{L} .
$$


Again using the definition of the elasticity of substitution with constant returns to scale, i.e., $\varepsilon_{\psi} \equiv$ $\psi_{A} \psi_{L} / \psi_{A L} \psi$, and the fact that $K_{a, i}$ is a monotonic transformation of $A_{i}$ yields (18). QED

Proof of Proposition 5: The first-order conditions with respect to capital and labor imply

$$
\frac{F_{K}\left(A_{i}, L_{i}^{p}, K_{i}^{p}\right) / F_{L}\left(A_{i}, L_{i}^{p}, K_{i}^{p}\right)}{F_{K}\left(A_{i}, L_{i}^{f}, K_{i}^{f}\right) / F_{L}\left(A_{i}, L_{i}^{f}, K_{i}^{f}\right)}=\frac{\left(1-m_{i}^{f} s_{L}\right)\left(1-m_{i}^{p} s_{K}\right)}{\left(1-m_{i}^{f} s_{K}\right)} .
$$

The right hand side of this equation being less than 1 is sufficient for (23), which is in turn guaranteed by assumption (22). QED

\section{Appendix B: Cost Plus Reimbursement Without Fungibil- ity}

The analysis in the text was simplified by the fact that we allowed the hospital to substitute labor (and capital) between the Medicare and non-Medicare products, and focused on the case where $s_{L} m_{i}<1$ and $s_{K} m_{i}<1$. The combination of these two assumptions implied that that the hospital always faced positive marginal costs of hiring more labor, capital and technology.

An alternative model would be one in which there is cost plus reimbursement, in the sense that for every dollar spent on capital or labor, the hospital receives more than one dollar back, that is, $s_{L}>1$ and $s_{K}>1$, and there is no fungibility. In this case, the model developed in 2.1 needs to be modified, since it would imply that the hospital would like to choose infinite amounts of capital and labor (unless $F_{L}$ and $F_{K}$ become negative). This would not only be unrealistic, but would also run into regulatory constraints. This Appendix briefly discusses how the analysis is modified once these regulatory constraints are incorporated. In particular, Medicare stipulates that hospitals can charge for "reasonable and customary" costs for Medicare services. We interpret this as implying that the amount of reimbursement required by the hospitals has to be less than a fraction of the average productivity of each factor that is being reimbursed under Medicare.

Let us simply focus on the Medicare services provided by the hospital and ignore technology choices (which, as before, can be incorporated in a straightforward manner). Moreover, assume throughout that $s_{L}>1$ and $s_{K}>1$. This implies that the profits of the hospital $i$ are

$$
\pi^{f}(i)=q F\left(L_{i}, K_{i}\right)+s_{L} w \tilde{L}_{i}+s_{K} R \tilde{K}_{i}-w L_{i}-R K_{i}
$$

where $L_{i}$ and $K_{i}$ are the total amounts of capital and labor hired by the hospital, while $\tilde{L}_{i}$ and $\tilde{K}_{i}$ are the total amounts of labor and capital for which the hospital requests reimbursement from Medicare. Although we have assumed that there is no fungibility, in the sense that the hospital cannot demand reimbursement for labor and capital used for other purposes, it can always use additional labor and capital for Medicare-related activities even if it does not ask for reimbursement. We will see that this might be useful depending on how tight the reimbursement constraints imposed by Medicare are.

In particular, we model these constraints as follows:

$$
\begin{gathered}
s_{L} w \tilde{L}_{i} \leq B_{L} F\left(L_{i}, K_{i}\right) \\
s_{K} R \tilde{K}_{i} \leq B_{K} F\left(L_{i}, K_{i}\right) .
\end{gathered}
$$

Simply put, these constraints require the reimbursement received from Medicare for labor and capital not to exceed a certain fraction of the health services provided to Medicare patients. To clarify this interpretation, for example, (33) can be expressed as $s_{L} w / B_{L} \leq F\left(L_{i}, K_{i}\right) / \tilde{L}_{i}$, which shows that this constraint equivalently requires the average product of labor (used for reimbursement) not to exceed a certain threshold. 
All the other assumptions from the main model, in particular, that $F$ is increasing, strictly concave and twice continuously differentiable in both of its arguments, still apply. The constraints (33) and (34) also explain why we had to allow for the hospital to be able to choose more labor and capital than the amounts for which it demands reimbursement from Medicare. In particular, imagine that $B_{L}$ is very small (in the limit, $B_{L} \rightarrow 0$ ). If we had imposed that $\tilde{L}_{i}=L_{i}$ and labor were an essential factor of production, then the hospital would have to shutdown; but with our formulation, and in reality, it can function profitably by choosing $\tilde{L}_{i}<L_{i}$. This discussion also shows that if the reimbursement constraints (33) and (34) are not too binding, the solution will typically have $\tilde{L}_{i}=L_{i}$ and $\tilde{K}_{i}=K_{i}$.

Consequently, under full cost (plus) reimbursement, the firm chooses $\tilde{L}_{i}, L_{i}, \tilde{K}_{i}$ and $K_{i}$ to maximize (32) subject to (33), (34) and the natural constraints arising from non-fungibility that $\tilde{L}_{i} \leq L_{i}$ and $\tilde{K}_{i} \leq K_{i}$ (so that the amount of labor and capital reimbursed are less than the total amount of labor and capital used in Medicare-related activities).

Lemma 1 Profit maximization implies that with full cost reimbursement, both (33) and (34) will be binding.

Proof. Suppose not, and that for example, (33) is slack. Since $F$ is increasing in $L_{i}$ and $s_{L}>1$, the hospital can set $\tilde{L}_{i}=L_{i}$ and increase $L_{i}$ until (33) binds, which will increase the value of profits in (32), yielding a contradiction. The same argument applies to (34), proving the lemma.

This lemma enables us to substitute for constraints (33) and (34) and write the maximization problem under full cost reimbursement regulation as follows:

$$
\max _{\tilde{L}_{i}, L_{i}, \tilde{K}_{i}, K_{i}}\left(q+B_{L}+B_{K}\right) F\left(L_{i}, K_{i}\right)-w L_{i}-R K_{i}
$$

subject to $\tilde{L}_{i} \leq L_{i}$ and $\tilde{K}_{i} \leq K_{i}$. Intuitively, if the hospital will hire more labor or capital than what it demands reimbursement for, the marginal cost of this labor and capital will be given by the factor market prices, $w$ and $R$, and the amounts $B_{L} F\left(L_{i}, K_{i}\right)$ and $B_{K} F\left(L_{i}, K_{i}\right)$ will be perceived by the hospital as lump-sum transfers. Alternatively, the firm will hire exactly $\tilde{L}_{i}$ and $\tilde{K}_{i}$.

The first-order conditions of this problem are

$$
\begin{gathered}
\left(q+B_{L}+B_{K}\right) F_{L}\left(L_{i}^{f}, K_{i}^{f}\right) \geq w \text { and } \tilde{L}_{i}^{f} \leq L_{i}^{f} \\
\left(q+B_{L}+B_{K}\right) F_{K}\left(L_{i}^{f}, K_{i}^{f}\right) \geq R \text { and } \tilde{K}_{i}^{f} \leq K_{i}^{f},
\end{gathered}
$$

both holding with complementary slackness and $f$ denoting full cost reimbursement.

Lemma 1 has another important implication for our analysis. If the solution to the maximization problem of the hospital involves $\tilde{L}_{i}^{f}=L_{i}^{f}$ and $\tilde{K}_{i}^{f}=K_{i}^{f}$, then (33) and (34) define two equations in two unknowns $\tilde{L}_{i}^{f}$ and $\tilde{K}_{i}^{f}$, and moreover, decreasing returns to capital and labor implies that there exists a unique tuple $\left(L^{*}, K^{*}\right)$ satisfying these two equations. Therefore, if we have the second inequalities in (36) and (37) hold as equality, we must have $\tilde{L}_{i}^{f}=L_{i}^{f}=L^{*}$ and $\tilde{K}_{i}^{f}=K_{i}^{f}=K^{*}$. The above discussion then suggests that as long as (33) and (34) are not very restrictive (i.e., are sufficiently generous), we will be in a situation in which the firm hires the levels of labor and capital that will exactly satisfy these two constraints, $\left(L^{*}, K^{*}\right)$.

Next let us turn to the partial cost reimbursement regime, where there is no reimbursement for labor, so the constraint (33), as well as $s_{L}$, are removed, and the firm now receives $q+B_{P}$ per unit of Medicare health services where $B_{P} \geq 0$. The maximization problem then becomes

$$
\pi^{f}(i)=\left(q+B_{P}\right) F\left(L_{i}, K_{i}\right)+s_{K} R \tilde{K}_{i}-w L_{i}-R K_{i}
$$

subject to (34) and $\tilde{K}_{i} \leq K_{i}$. We then immediately have the following result which parallels Lemma 1 (proof omitted):

Lemma 2 Profit maximization implies that with partial cost reimbursement, (34) will be binding. 
Consequently, the maximization problem of the firm can be written as:

$$
\max _{\tilde{L}_{i}, L_{i}, \tilde{K}_{i}, K_{i}}\left(q+B_{P}+B_{K}\right) F\left(L_{i}, K_{i}\right)-w L_{i}-R K_{i}
$$

subject to $\tilde{K}_{i} \leq K_{i}$. In this case, we have the following first-order conditions:

$$
\begin{gathered}
\left(q+B_{P}+B_{K}\right) F_{L}\left(L_{i}^{p}, K_{i}^{p}\right)=w, \text { and } \\
\left(q+B_{P}+B_{K}\right) F_{K}\left(L_{i}^{p}, K_{i}^{p}\right) \geq R \text { and } \tilde{K}_{i}^{p} \leq K_{i}^{p},
\end{gathered}
$$

with the second condition holding with complementary slackness.

The difficulty in the analysis in this case stems from the fact that either of (33) or (34) could be very tight, with correspondingly large Lagrange multipliers. For example, this would be the case when $B_{L} \rightarrow 0$, so that there was effectively no reimbursement of labor because of the tightness of the "reasonable and customary" constraint. Nevertheless, the following proposition can be established:

Proposition 6 Suppose that under full cost reimbursement $L_{i}^{f}=L^{*}$ and $K_{i}^{f}=K^{*}$. Consider a change to partial cost reimbursement with $B_{P}<B_{L}$, then we have

$$
L_{i}^{p}<L_{i}^{f}
$$

Moreover, if $F$ is homogeneous of degree $\beta<1$ in $L_{i}$ and $K_{i}$, then

$$
\frac{K_{i}^{f}}{L_{i}^{f}}<\frac{K_{i}^{p}}{L_{i}^{p}}
$$

Proof. The first-order conditions for (35) imply that $\left(q+B_{L}+B_{K}\right) F_{L}\left(L^{*}, K^{*}\right) \geq w$ and $\left(q+B_{L}+B_{K}\right) F_{K}\left(L^{*}, K^{*}\right) \geq R$, while the first-order conditions for $(38)$ imply $\left(q+B_{P}+B_{K}\right) F_{L}\left(L_{i}^{p}, K_{i}^{p}\right)=$ $w$ and $\left(q+B_{P}+B_{K}\right) F_{K}\left(L_{i}^{p}, K_{i}^{p}\right) \geq R$. To obtain a contradiction suppose that $L_{i}^{p} \geq L_{i}^{f}$. Lemma 2 implies that (34) holds as equality. Since $L_{i}^{p} \geq L_{i}^{f}=L^{*}$, (34) then implies $K_{i}^{p} \geq K_{i}^{f}=K^{*}$. First, suppose that $K_{i}^{p}=K^{*}$. Then diminishing returns to labor implies that $\left(q+B_{L}+B_{K}\right) F_{L}\left(L^{*}, K^{*}\right) \geq w$ is inconsistent with $\left(q+B_{P}+B_{K}\right) F_{L}\left(L_{i}^{p}, K^{*}\right)=w, L_{i}^{p} \geq L^{*}$ and $B_{P}<B_{L}$, yielding a contradiction. Second, suppose that $K_{i}^{p}>K^{*}$. Then (37) implies $\left(q+B_{P}+B_{K}\right) F_{K}\left(L_{i}^{p}, K_{i}^{p}\right)=R$. Then, $B_{P}<B_{L}$ implies that

$$
\begin{aligned}
\left(q+B_{P}+B_{K}\right) F_{L}\left(L_{i}^{p}, K_{i}^{p}\right) & >\left(q+B_{L}+B_{K}\right) F_{L}\left(L^{*}, K^{*}\right) \\
\left(q+B_{P}+B_{K}\right) F_{K}\left(L_{i}^{p}, K_{i}^{p}\right) & >\left(q+B_{L}+B_{K}\right) F_{K}\left(L^{*}, K^{*}\right),
\end{aligned}
$$

which is inconsistent with $K_{i}^{p}>K^{*}$ and $L_{i}^{p} \geq L^{*}$ given decreasing returns, yielding another contradiction, and establishing that we must have $L_{i}^{p}<L^{*}$, i.e., (39).

To obtain (40), first note that if $K_{i}^{p} \geq \tilde{K}_{i}^{f}=K^{*}$, given (39), (40) would apply immediately. Therefore, we only have to show that it also holds when $K_{i}^{p}<\tilde{K}_{i}^{f}=K^{*}$. Suppose this is the case. Then, use Lemma 2 and the homogeneity assumption on $F$, to reexpress (34) as

$$
s_{K} R \tilde{K}_{i}^{p}\left(K_{i}^{p}\right)^{\beta} \leq B_{K} F\left(\frac{L_{i}^{p}}{K_{i}^{p}}, 1\right) .
$$

Since $\tilde{K}_{i}^{p} \leq K_{i}^{p}<\tilde{K}_{i}^{f}=K^{*}$, it must be that $L_{i}^{p} / K_{i}^{p}<L_{i}^{f} / K_{i}^{f}$, establishing (40).

This proposition generalizes the results from our basic analysis with fungibility in subsection 2.1 to the case without fungibility, though the results are weaker since they hold under some additional conditions. Most importantly, the main results apply as long as the full cost reimbursement is sufficiently generous to start with so as to ensure $L_{i}^{f}=\tilde{L}_{i}^{f}=L^{*}$ and $K_{i}^{f}=\tilde{K}_{i}^{f}=K^{*}$, and partial cost reimbursement is less generous than full cost reimbursement as captured by the condition that $B_{P}<B_{L}$. Both of these appear as plausible conditions in the context of the PPS reform. 


\section{References}

Acemoglu, Daron. 2002. "Technical Change, Inequality and the Labor Market", Journal of Economic Literature, XL, 7-72.

Acemoglu, Daron. 2003. "Factor Prices and Technical Change: From Induced Innovations to Recent Debates" in Philippe Aghion, Roman Frydman, Joseph Stiglitz and Michael Woodford (editors) Knowledge, Information and Expectations in Modern Macroeconomics: in Honor of Edmund S. Phelps, New Jersey, Princeton University Press, 464-491.

Acemoglu, Daron and Joshua Linn. 2004. "Market Size in Innovation: Theory and Evidence from the Pharmaceutical Industry." Quarterly Journal of Economics, 119, 1049-1090.

American Hospital Association. 1983. Estimated Useful Lives of Depreciable Hospital Assets. American Hospital Association, Chicago IL.

Antos, Joseph. 1993. "Waivers, Research, and Health System Reform." Health Affairs: $179-183$

Armstrong, Mark, Simon, Cowen and John, Vickers. 1994. Regulatory Reform: Economic Analysis and British Experience, Cambridge, Massachusetts, MIT Press.

Averech, Harvey and Leland Johnson. 1962. "Behavior of the Firm under Regulatory Constraint." American Economic Review 52: 1053-1069.

Baicker, Katherine and Douglas Staiger. 2005. "Fiscal Shenanigans, Targeted Federal Health Care Funds, and Patient Mortality." Quarterly Journal of Economics 120(1).

Baker, Laurence, "HMOs and Fee for Service Health Care Expenditures: Evidence from Medicare." Journal of Health Economics, XVI (1997), 453-481.

Baker, Laurence. 2001. "Managed Care and Technology Adoption in Health Care: Evidence from Magnetic Resonance Imaging." Journal of Health Economics, 20: 395-421.

Baker, Laurence and Ciaran Phibbs. 2002. "Managed care, technology adoption, and health care: the adoption of neonatal intensive care." Rand Journal of Economics 33: 524-548.

Baumol, William and Alvin Klevorick. 1970. "Input Choices and Rate of Return Regulation: An Overview of the Discussion" Bell Journal of Economics and Management Science, 1:162-190.

Binswanger, Hans and Vernon Ruttan. 1978. Induced Innovation: Technology, Institutions and Development, Baltimore, Johns Hopkins University Press.

Congressional Budget Office. 1988. "Including Capital Expenses in the Prospective Payment System."

Cotterill, Philip. 1991. "Prospective payment for Medicare hospital capital: Implications of the research." Health Care Financing Review, Annual Supplement: 79-86.

Coulam, Robert and Gary Gaumer. 1991. "Medicare's prospective payment system: A 
critical appraisal." Health Care Financing Review, Annual Supplement: 45 -77.

Cutler, David. 2003. Your Money or Your Life: Strong Medicine for America's Health Care System. Oxford University Press.

Cutler, David. 1995. "The Incidence of Adverse Medical Outcomes Under Prospective Payment." Econometrica 63(1): 29-50.

Cutler, David and Louise Sheiner. 1998. Managed Care and the Growth of Medical Expenditures." In Alan Garber (ed). Frontiers in Health Policy Research.

Cutler, David and Richard Zeckhauser. 2000. "The Anatomy of Health Insurance" in A. Culyer and J. Newhouse, eds. Handbook of Health Economics, Volume IA, Amsterdam: Elsevier.

Dafny, Leemore. 2005. "How Do Hospitals Respond to Price Changes?" American Economic Review 95(5): 1525-1547.

David, Paul. 1975. Technical Choice, Innovation and Economic Growth: Essays on American and British Experience in the Nineteenth Century, London, Cambridge University Press.

Feder, Judith, Jack Hadley, and Stephen Zuckerman. 1987. "How did Medicare's Prospective Payment System Affect Hospitals?" New England Journal of Medicine 317(14): 867-873.

Federal Register. 2000. U.S. Government Printing Office, Washington, D.C. July 3.

Finkelstein, Amy. 2004. "Static and Dynamic Effects of Health Policy: Evidence from the Vaccine Industry." Quarterly Journal of Economics 527-564.

Finkelstein, Amy. 2005. "The Aggregate Effects of Health Insurance: Evidence from the Introduction of Medicare." NBER Working Paper 11619.

Fuchs, Victor. 1996. "Economics, Values, and Health Care Reform." Presidential Address of the American Economic Association, American Economic Review, March 1996.

GAO. 1986. "Medicare: Alternative for Paying Hospital Capital Costs."

GAO. 2000. "Medicare Hospital Payments: PPS Includes Several Policies Intended to Help Rural Hospitals."

Greenstone, Michael. 2002. "The Impacts of Environmental Regulation on Industrial Activity: Evidence from the 1970 and 1977 Clean Air Act Amendments and the Census of Manufacturers." Journal of Political Economy 110(6).

Griliches, Zvi. 1956. "Capital-Skill Complementarity" Review of Economics and Statistics, LI, 465-68.

Griliches, Zvi and Jerry Hausman. 1986. "Errors in Variables in Panel Data." Journal of Econometrics 31: 93-118.

Habakkuk, H. J. 1962. American and British Technology in the Nineteenth Century: Search for Labor Saving Inventions, Cambridge University Press. 
Han, Aaron and Jerry Hausman. 1990. "Flexible Parametric Estimation of Duration and Competing Risk Models." Journal of Applied Econometrics 5:1-28.

Health Care Financing Administration. 1986. Status Report: Research and Demonstrations in Health Care Financing. U.S. Department of Health and Human Services: Baltimore MD.

Health Care Financing Administration. 1987. Status Report: Research and Demonstrations in Health Care Financing. U.S. Department of Health and Human Services: Baltimore MD.

Health Care Financing Administration. 1999. Statistical Supplement. U.S. Department of Health and Human Services: Baltimore MD.

Hausman, Jerry, Bronwyn Hall, and Zvi Griliches. 1984. "Econometric models for count data with an application to the patents-R\&D relationship." Econometrica 52(4): 909-938.

Hicks, John. 1932. The Theory of Wages, Macmillan, London.

Joskow, Paul. 2005. "Incentive Regulation in Theory and Practice: Electricity Distribution and Transmission Networks." Mimeo.

Kiefer, Nicholas. 1988. "Economic Duration Data and Hazard Functions." Journal of Economic Literature 26(2): 646-679.

Kling, Jeffrey and Jeffrey Liebman. 2004. "Experimental Analysis of Neighborhood Effects on Youth." Unpublished mimeo.

Krusell, Per, Lee Ohanian, Victor Rios-Rull and Giovanni Violante. 2000. "Capital Skill Complementary and Inequality" Econometrica, 68, pp. 1029-1053.

Laffont, Jean-Jacques and Jean Tirole. 1993. A Theory of Incentives in Procurement and Regulation. MIT Press, Cambridge MA.

McClellan, Mark. 1996. "Medicare Reimbursement and Hospital Cost Growth." in David Wise (ed) Advances in the Economics of Aging. Chicago: University of Chicago Press.

McClellan, Mark. 1997. "Hospital Reimbursement Incentives: An Empirical Analysis." Journal of Economics 63 Management Strategy 6 (1): 91-128.

Medicare Payment Advisory Commission (MedPAC). 1999. "Report to Congress: Medicare Payment Policy." March. Available on line at http://www.medpac.gov.

Newell, Richard, Adam Jaffe and Robert Stavins. 1999. "The induced innovation hypothesis and energy-saving technological change." Quarterly Journal of Economics, August, pp.941-975.

Newhouse, Joseph. 1992. "Medicare Care Costs: How Much Welfare Loss?" Journal of Economic Perspectives, 6(3): 3-21.

Newhouse, Joseph. 2002. Pricing the Priceless: A Health Care Conundrum. MIT Press: Cambridge, MA.

Office of Technology Assessment (OTA). 1984. "Medical Technology and the Costs of the Medicare Program." Government Printing Office, Washington DC. 
Office of Technology Assessment (OTA). 1985. "Medicare's Prospective Payment System: Strategies for Evaluating Cost, Quality, and Medical Technology." Government Printing Office: Washington DC.

Prospective Payment Assessment Commission. 1988. "Medicare Prospective Payment and the American Health Care System: Report to the Congress." Washington DC

Prospective Payment Assessment Commission. 1990. "Medicare Prospective Payment and the American Health Care System: Report to the Congress." Washington DC

Prospective Payment Assessment Commission. 1992. "Medicare Prospective Payment and the American Health Care System: Report to the Congress." Washington DC

Sloan, Frank, Michael Morrissey and Joseph Valvona. 1988. "Medicare Prospective Payment and the Use of Medical Technologies in Hospitals." Medical Care 26(9): 837-853.

Sloan, Frank. 2000. "Not-for-profit ownership and hospital behavior." Handbook of Health Economics, Volume 1B, Anthony Culyer and Joseph Newhouse (eds). Elsevier.

Staiger, Douglas and Gary Gaumer. 1990. "The Impact of Financial Pressure on Quality of Care in Hospitals: Post-Admission Mortality Under Medicare's Prospective Payment System" Abt Associates Inc.

Staiger, Douglas, Joanne Spetz and Ciaran Phibbs. 1999. "Is there monopsony in the labor market? Evidence from a natural experiment." National Bureau of Economic Research Working Paper 7258.

Weisbrod. Burton. 1991. "The Health Care Quadrilemma: An Essay on Technological Change, Insurance, Quality of Care, and Cost Containment." Journal of Economic Literature 29(2): 523-552.

Westfall, Peter H. and Young, Stanley S. 1993. Resampling-Based Multiple Testing: Examples and Methods for P-value Adjustment. New York: Wiley.

Wooldridge, Jeffrey. 2002. Econometric Analysis of Cross Section and Panel Data. MIT Press, Cambridge, MA.

Yin, Wesley. 2005. "Do Market Incentives Generate Innovation or Balkanization? Evidence from the Market for Rare Disease Drugs." University of Chicago mimeo. 
Figure 1: Capital Labor Ratio average (depreciation expenses / operating expenses)

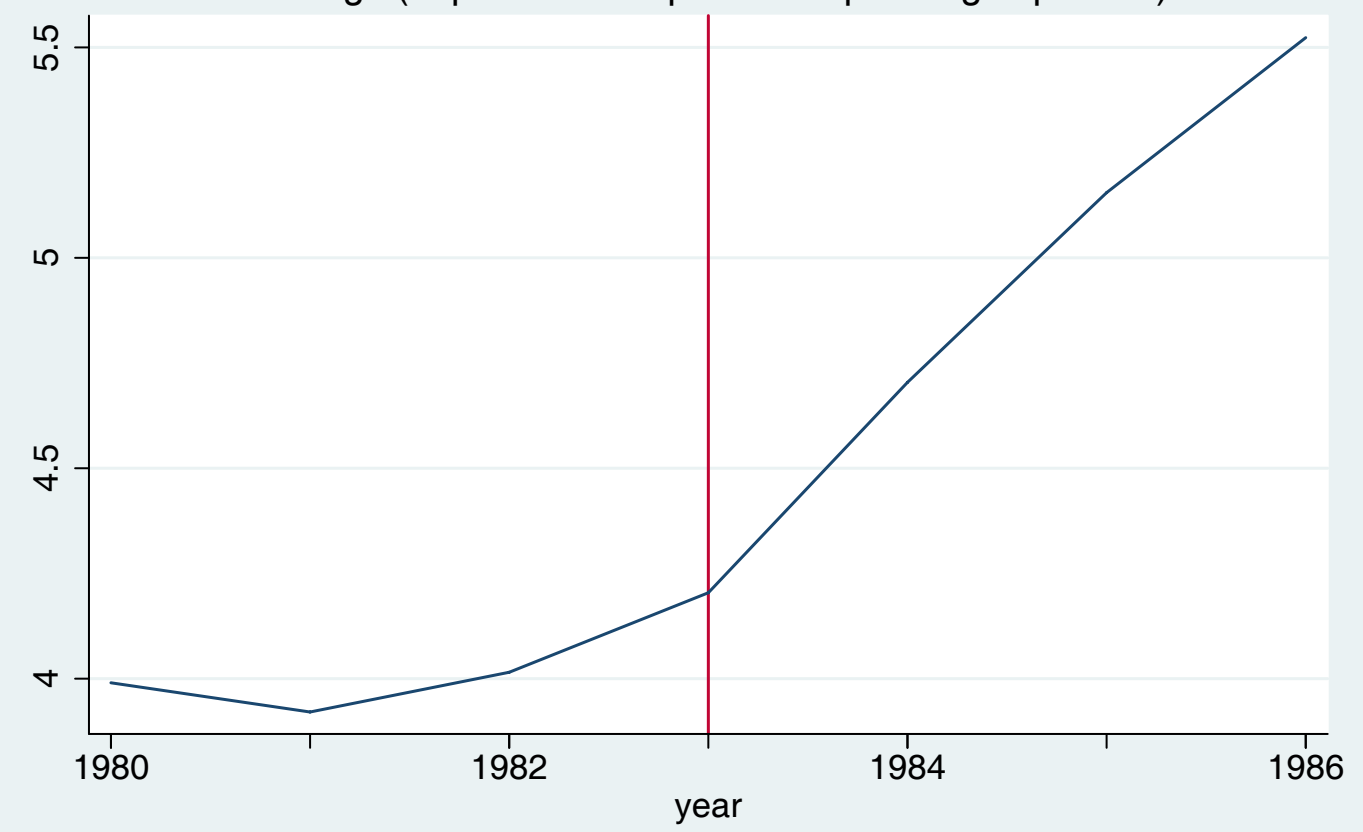

Capital-labor ratio is shown in units per 100.

Figure 2: log Labor Inputs

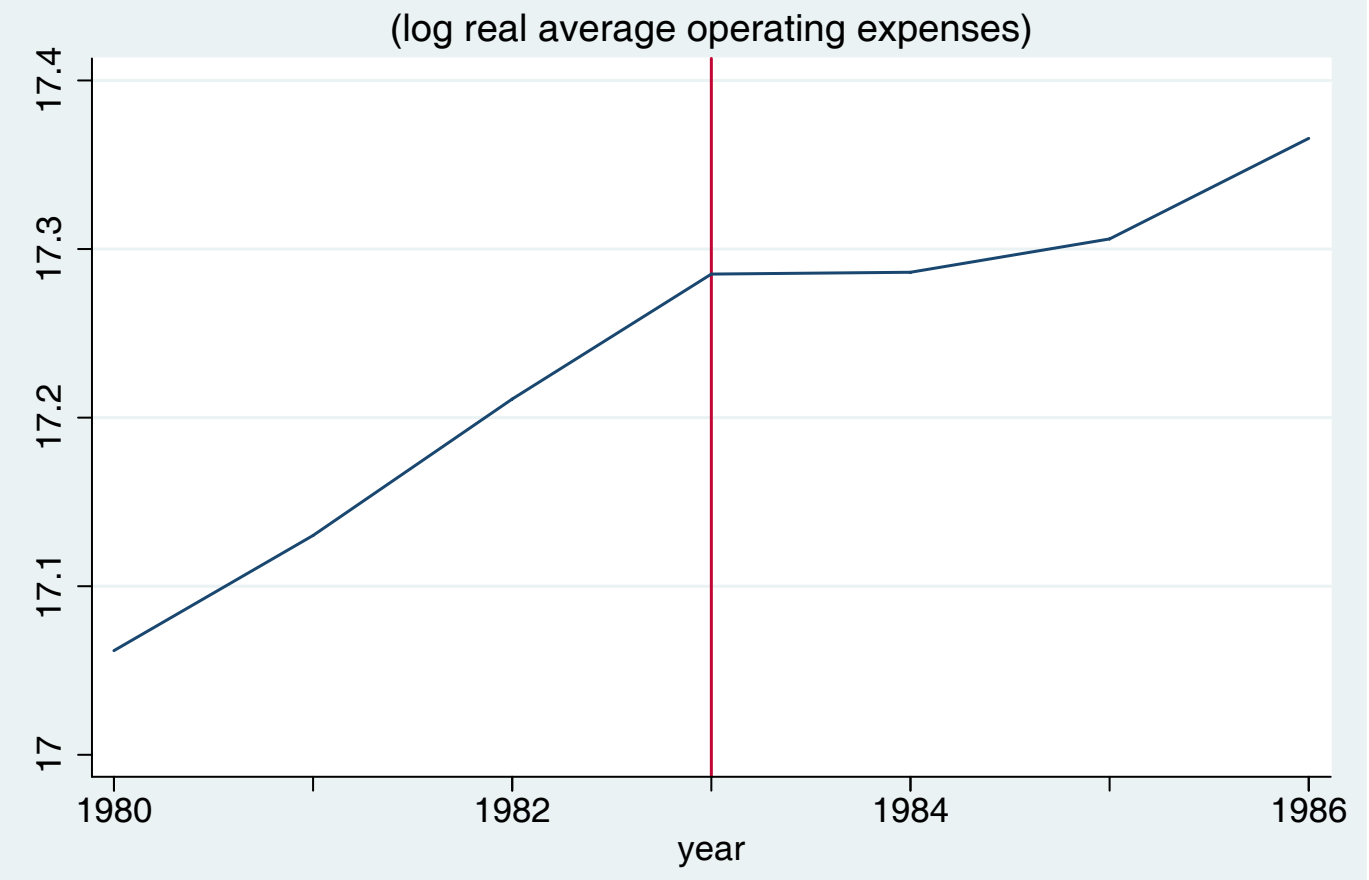

Dollar amounts are measured in 2004 dollars. 
Figure 3: log Capital Inputs

(log real average depreciation expenses)

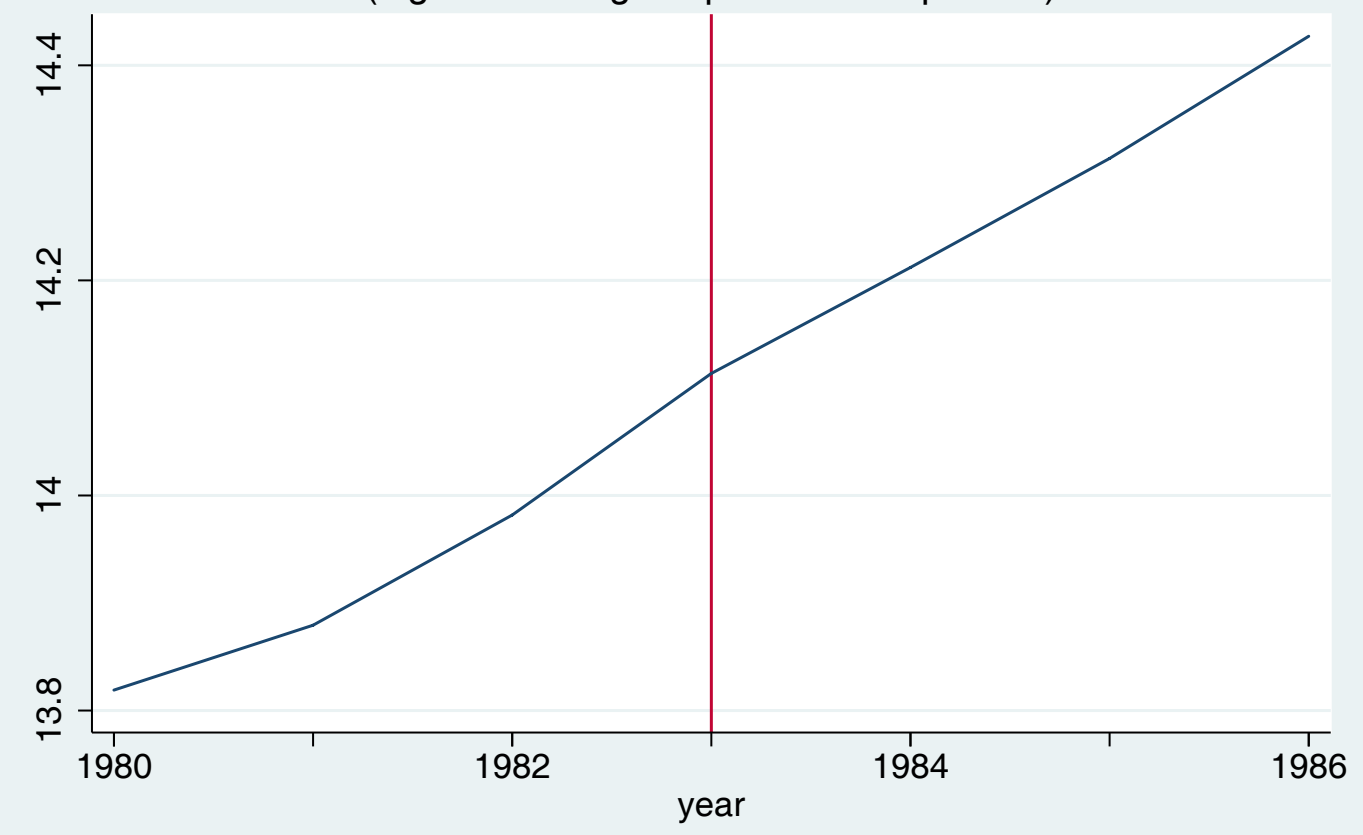

Dollar amounts are measured in 2004 dollars.

Fiqure 4: Distrib'n of Hospitals by Medicare Share in 1983

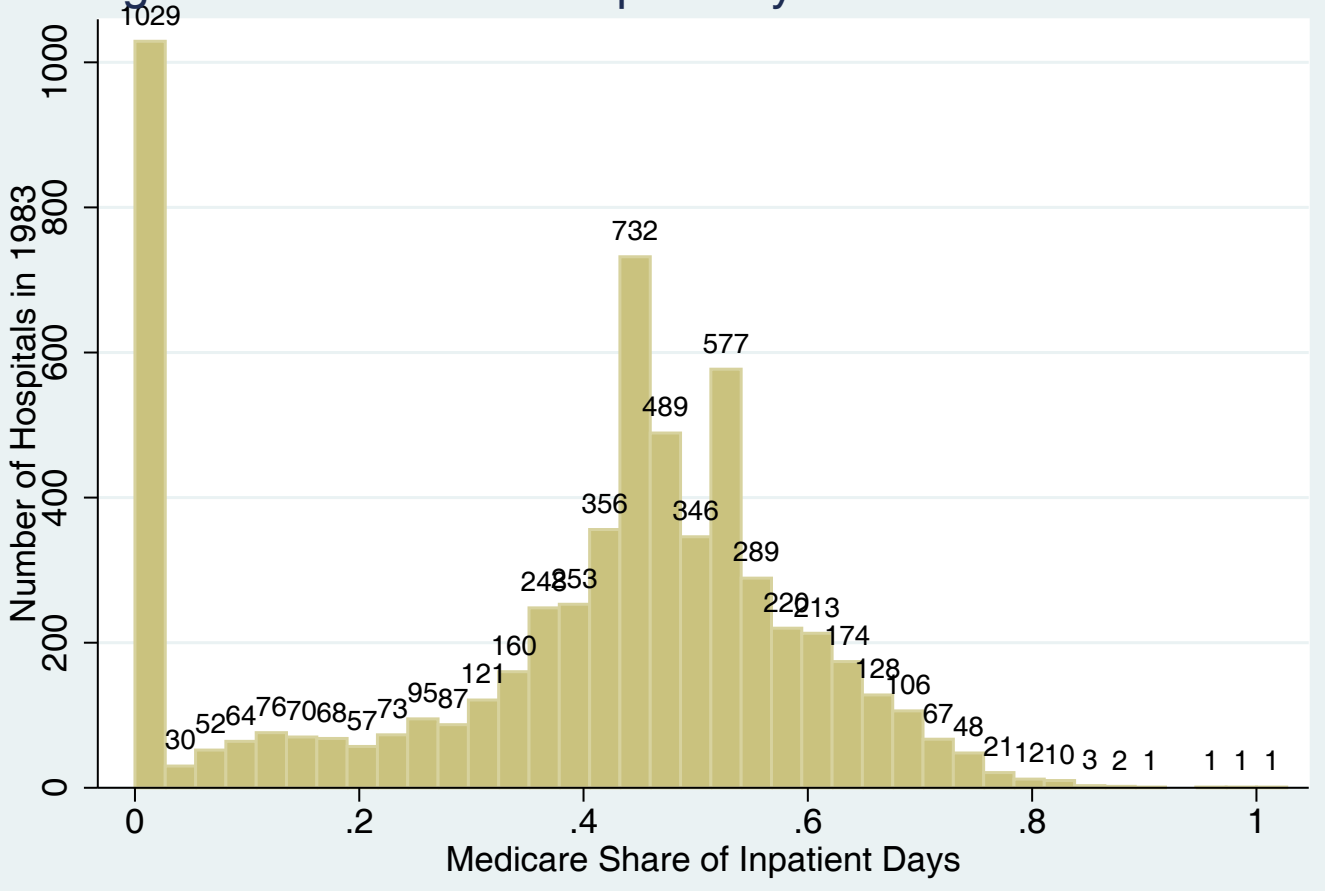




\section{Figure 5: Technology Diffusion}
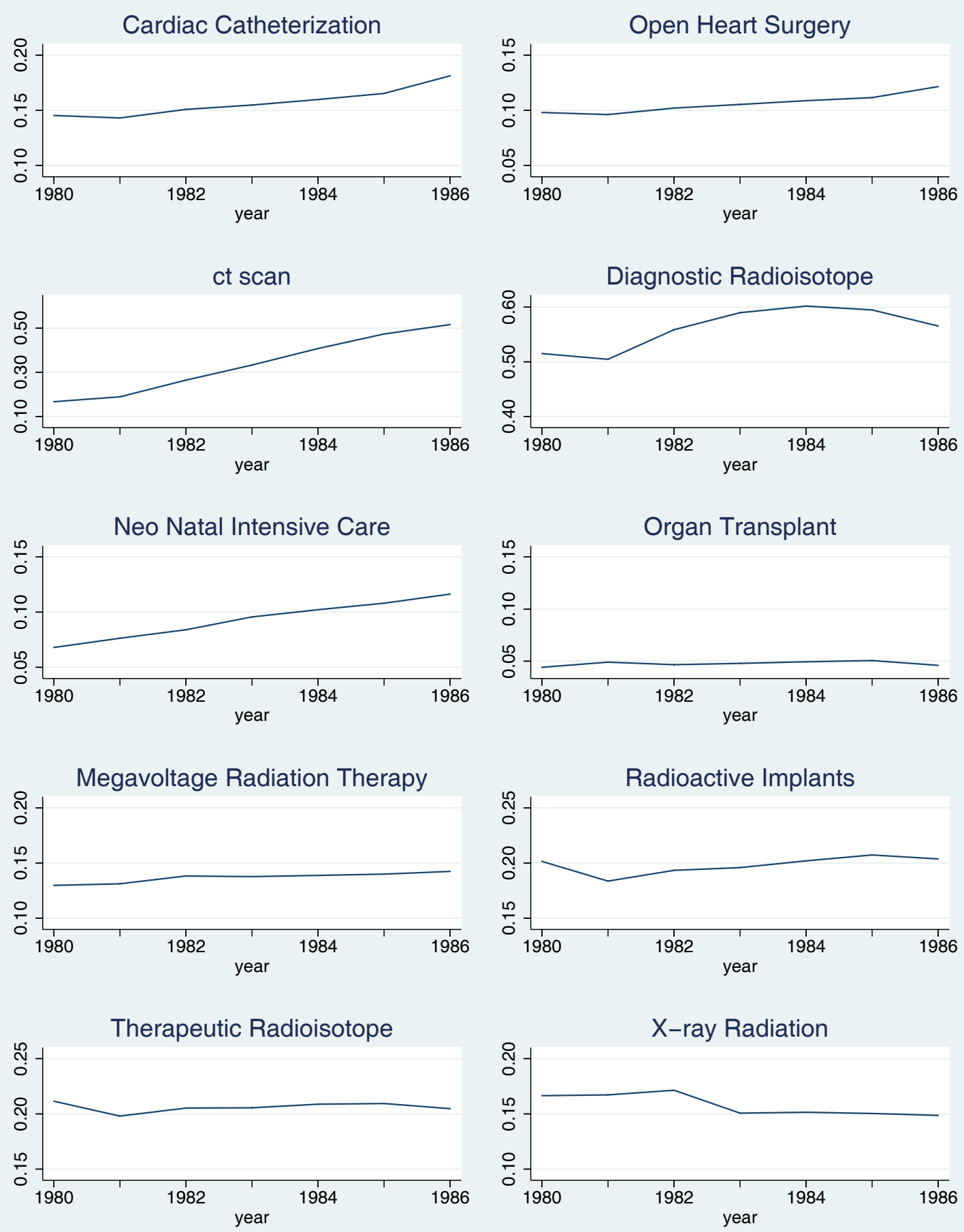

Note: Figures show share of hospitals with given technology in each year. 
Table 1: Summary Statistics

\begin{tabular}{lll}
\hline \hline & & Standard \\
Variable & Average & Deviation \\
\hline Medicare Share of Inpatient Days in 1983 & 0.38 & 0.21 \\
Real Operating Expenditures ('000) & $\$ 31,300$ & $\$ 44,500$ \\
Real Capital Expenditures (Interest plus Depreciation) ('000) & $\$ 2,156$ & $\$ 3,459$ \\
Real Depreciation Expenditures ('000) & $\$ 1,379$ & $\$ 2,224$ \\
Capital Share (Capital Expenditures / Operating Expenditures) & $7.09 \%$ & $4.90 \%$ \\
Depreciation Share (Depreciation / Operating) & $4.50 \%$ & $2.50 \%$ \\
Skill Ratio (Registered Nurses / Registered Nurses + Licensed Nurse Practitioners) & $70 \%$ & $16 \%$ \\
\hline \hline
\end{tabular}

Note: Table reports averages for the various hospital characteristics. All dollar estimates are in thousands of 2004 dollars. All share estimates are multiplied by $100 . \mathrm{N}=43,188$, except for skill composition where $N=43,162$. Data consist of a total of 6,280 hospitals, of which 5,881 (94 percent) are in the data for all seven years, and all are in the data for at least two years. All hospitals in the sample have information on Medicare share in 1983.

Table 2: The Impact of PPS on the Capital-Labor Ratio

\begin{tabular}{|c|c|c|c|c|c|}
\hline & $(1)$ & $(2)$ & (3) & (4) & (5) \\
\hline $\mathrm{POST}^{*} m_{i}$ & $\begin{array}{l}1.129 \\
(0.108)\end{array}$ & $\begin{array}{l}1.122 \\
(0.121)\end{array}$ & & & \\
\hline POSTTREND* $m_{i}$ & & & & $\begin{array}{l}0.538 \\
(0.050)\end{array}$ & $\begin{array}{l}0.532 \\
(0.053)\end{array}$ \\
\hline $\mathrm{d}_{81} * m_{i}$ & & & $\begin{array}{l}0.153 \\
(0.114)\end{array}$ & & \\
\hline $\mathrm{d}_{82} * m_{i}$ & & & $\begin{array}{l}-0.388 \\
(0.131)\end{array}$ & & \\
\hline $\mathrm{d}_{83} * m_{i}$ & & $\begin{array}{l}-0.028 \\
(0.098)\end{array}$ & $\begin{array}{l}-0.109 \\
(0.136)\end{array}$ & & $\begin{array}{l}-0.060 \\
(0.088)\end{array}$ \\
\hline $\mathrm{d}_{84} * m_{i}$ & & & $\begin{array}{l}0.601 \\
(0.163)\end{array}$ & & \\
\hline $\mathrm{d}_{85} * m_{i}$ & & & $\begin{array}{l}1.068 \\
(0.172)\end{array}$ & & \\
\hline $\mathrm{d}_{86} * m_{i}$ & & & $\begin{array}{l}1.474 \\
(0.189)\end{array}$ & & \\
\hline
\end{tabular}

Notes: Dependent variable is depreciation share. Table reports results from estimating equations (24) - (27) by OLS. All regressions include hospital and year fixed effects. Mean dependent variable is 4.5. POST is an indicator variable for the years 1984 - 1986. POSTTREND is 0 through 1983 and then takes the values 1, 2, and 3 in 1984, 1985, and 1986 respectively. $d_{t}$ is an indicator variable for year $t . m_{i}$ measures the Medicare share of the hospital's inpatient days in 1983. Standard errors are in parentheses. Standard errors are adjusted to allow for an arbitrary covariance matrix within each hospital over time. $\mathrm{N}=43,188$. In column (3), omitted category is $\mathrm{d}_{80} * m_{i}$. To interpret the magnitudes, recall that the average Medicare share in 1983 is about two-fifths. 
Table 3 The Impact of PPS on Log Labor Inputs

\begin{tabular}{|c|c|c|c|c|c|}
\hline & $(1)$ & $(2)$ & (3) & (4) & (5) \\
\hline $\mathrm{POST}^{*} m_{i}$ & $\begin{array}{l}-0.141 \\
(0.016)\end{array}$ & $\begin{array}{l}-0.135 \\
(0.018)\end{array}$ & & & \\
\hline POSTTREND* $m_{i}$ & & & & $\begin{array}{l}-0.070 \\
(0.007)\end{array}$ & $\begin{array}{l}-0.068 \\
(0.008)\end{array}$ \\
\hline $\mathrm{d}_{81} * m_{i}$ & & & $\begin{array}{l}0.003 \\
(0.016)\end{array}$ & & \\
\hline $\mathrm{d}_{82} * m_{i}$ & & & $\begin{array}{l}0.034 \\
(0.020)\end{array}$ & & \\
\hline $\mathrm{d}_{83} * m_{i}$ & & $\begin{array}{l}0.021 \\
(0.015)\end{array}$ & $\begin{array}{l}0.034 \\
(0.021)\end{array}$ & & $\begin{array}{l}0.022 \\
(0.013)\end{array}$ \\
\hline $\mathrm{d}_{84} * m_{i}$ & & & $\begin{array}{l}-0.052 \\
(0.023)\end{array}$ & & \\
\hline $\mathrm{d}_{85} * m_{i}$ & & & $\begin{array}{l}-0.138 \\
(0.025)\end{array}$ & & \\
\hline $\mathrm{d}_{86} * m_{i}$ & & & $\begin{array}{l}-0.184 \\
(0.026)\end{array}$ & & \\
\hline
\end{tabular}

Notes: Dependent variable is log operating expenditures. Table reports results from estimating equations (24)- (27) by OLS. All regressions hospital and year fixed effects. POST is an indicator variable for the years $1984-1986$. POSTTREND is 0 through 1983 and then takes the values 1, 2, and 3 in 1984, 1985, and 1986 respectively. $d_{t}$ is an indicator variable for year $t . m_{i}$ measures the Medicare share of the hospital's inpatient days in 1983. Standard errors are in parentheses. Standard errors are adjusted to allow for an arbitrary covariance matrix within each hospital over time. $\mathrm{N}=43,188$. In column (3), omitted category is $\mathrm{d}_{80}{ }^{*} m_{i}$. To interpret the magnitudes, recall that the average Medicare share in 1983 is about two-fifths. 
Table 4 The Impact of PPS on Log Capital Inputs

\begin{tabular}{|c|c|c|c|c|c|}
\hline & (1) & $(2)$ & (3) & $(4)$ & (5) \\
\hline $\mathrm{POST}^{*} m_{i}$ & $\begin{array}{l}-0.011 \\
(0.035)\end{array}$ & $\begin{array}{l}0.010 \\
(0.040)\end{array}$ & & & \\
\hline POSTTREND $^{*} m_{i}$ & & & & $\begin{array}{l}-0.028 \\
(0.015)\end{array}$ & $\begin{array}{l}-0.023 \\
(0.016)\end{array}$ \\
\hline $\mathrm{d}_{81} * m_{i}$ & & & $\begin{array}{l}0.011 \\
(0.042)\end{array}$ & & \\
\hline $\mathrm{d}_{82} * m_{i}$ & & & $\begin{array}{l}-0.282 \\
(0.048)\end{array}$ & & \\
\hline $\mathrm{d}_{83} * m_{i}$ & & $\begin{array}{l}0.077 \\
(0.043)\end{array}$ & $\begin{array}{l}-0.016 \\
(0.053)\end{array}$ & & $\begin{array}{l}0.049 \\
(0.039)\end{array}$ \\
\hline $\mathrm{d}_{84} * m_{i}$ & & & $\begin{array}{l}0.012 \\
(0.053)\end{array}$ & & \\
\hline $\mathrm{d}_{85} * m_{i}$ & & & $\begin{array}{l}-0.073 \\
(0.055)\end{array}$ & & \\
\hline $\mathrm{d}_{86} * m_{i}$ & & & $\begin{array}{l}-0.192 \\
(0.059)\end{array}$ & & \\
\hline
\end{tabular}

Notes: Dependent variable is log depreciation expenditures. Table reports results from estimating equations (24) (27) by OLS. All regressions hospital and year fixed effects. POST is an indicator variable for the years $1984-$ 1986. POSTTREND is 0 through 1983 and then takes the values 1, 2, and 3 in 1984, 1985, and 1986 respectively. $d_{t}$ is an indicator variable for year $t . m_{i}$ measures the Medicare share of the hospital's inpatient days in 1983. Standard errors are in parentheses. Standard errors are adjusted to allow for an arbitrary covariance matrix within each hospital over time. $\mathrm{N}=40,888$. In column (3), omitted category is $\mathrm{d}_{80}{ }^{*} m_{i}$. To interpret the magnitudes, recall that the average Medicare share in 1983 is about two-fifths. 
Table 5: The Impact of PPS on the Medicare share

\begin{tabular}{llllll}
\hline & $(1)$ & $(2)$ & $(3)$ & $(4)$ & $(5)$ \\
\hline POST $^{*} m_{i}$ & -0.064 & -0.065 & & & \\
POSTTREND* $m_{i}$ & $(0.006)$ & $(0.007)$ & & -0.031 & -0.032 \\
& & & & $(0.003)$ & $(0.003)$ \\
$\mathrm{d}_{82}{ }^{*} m_{i}$ & & & -0.009 & & \\
$\mathrm{~d}_{83}{ }^{*} m_{i}$ & & & $(0.008)$ & & -0.002 \\
& & -0.004 & -0.008 & & $(0.006)$ \\
$\mathrm{d}_{84}{ }^{*} m_{i}$ & & $(0.007)$ & $(0.008)$ & & \\
$\mathrm{d}_{85} * m_{i}$ & & & -0.034 & & \\
& & & $(0.008)$ & & \\
$\mathrm{d}_{86} * m_{i}$ & & & -0.085 & & \\
& & & $-0.009)$ & & \\
\hline \hline
\end{tabular}

Notes: Dependent variable is Medicare share of inpatient days. Table reports results from estimating equations (24) - (27) by OLS. All regressions include hospital and year fixed effects. Data from 1980 is excluded from the analysis and for the cross-sectional variation, Medicare share of inpatient days $m_{\mathrm{i}}$ is measured in 1980 (instead of in 1983 as in other analyses). Mean dependent variable is 0.38. POST is an indicator variable for the years $1984-1986$.

POSTTREND is 0 through 1983 and then takes the values 1, 2, and 3 in 1984, 1985, and 1986 respectively. $d_{t}$ is an indicator variable for year $t$. Standard errors are adjusted to allow for an arbitrary covariance matrix within each hospital over time. $\mathrm{N}=36,611$. In column (3), omitted category is $\mathrm{d}_{81}{ }^{*} m_{i}$. Note that while we code the regressor $m_{i}$ to be zero for the approximately 15 percent of hospitals that are exempt from PPS (see Figure 4), we allow the dependent variable "Medicare share" to take its actual value for all hospitals. On average, the dependent variable is 0.09 (0.43) for exempt (non-exempt) hospitals. 
Table 6: The Impact of PPS on Technology Adoption I: Number of Facilities

\begin{tabular}{|c|c|c|c|c|c|c|c|c|c|c|}
\hline & \multicolumn{5}{|c|}{ Panel A: OLS } & \multicolumn{5}{|c|}{ Panel B: Conditional Fixed Effect Poisson } \\
\hline & (1) & $(2)$ & (3) & $(4)$ & (5) & $(6)$ & $(7)$ & $(8)$ & (9) & $(10)$ \\
\hline $\mathrm{POST}^{*} m_{i}$ & $\begin{array}{l}2.621 \\
(0.357)\end{array}$ & $\begin{array}{l}.501 \\
(0.401)\end{array}$ & & & & $\begin{array}{l}0.120 \\
(0.015)\end{array}$ & $\begin{array}{l}0.114 \\
(0.004)\end{array}$ & & $\begin{array}{l}0.061 \\
(0.007)\end{array}$ & $\begin{array}{l}0.058 \\
(0.004)\end{array}$ \\
\hline POSTTREND* $m_{i}$ & & & & $\begin{array}{l}1.156 \\
(0.134)\end{array}$ & $\begin{array}{l}1.093 \\
(0.178)\end{array}$ & & & & & \\
\hline $\mathrm{d}_{81} * m_{i}$ & & & $\begin{array}{l}-2.423 \\
(0.526)\end{array}$ & & & & & $\begin{array}{l}-0.106 \\
(0.020\end{array}$ & & \\
\hline $\mathrm{d}_{82} * m_{i}$ & & & $\begin{array}{l}-2.965 \\
(0.541)\end{array}$ & & & & $\begin{array}{l}-0.023 \\
(0.017)\end{array}$ & $\begin{array}{l}-0.138 \\
(0.023\end{array}$ & & \\
\hline $\mathrm{d}_{83} * m_{i}$ & & $\begin{array}{l}-0.467 \\
(0.354)\end{array}$ & $\begin{array}{l}-2.281 \\
(0.517)\end{array}$ & & $\begin{array}{l}-0.631 \\
(0.326)\end{array}$ & & & $\begin{array}{l}-0.105 \\
(0.022\end{array}$ & & $\begin{array}{l}-0.025 \\
(0.008)\end{array}$ \\
\hline $\mathrm{d}_{84} * m_{i}$ & & & $\begin{array}{l}-0.496 \\
(0.567)\end{array}$ & & & & & $\begin{array}{l}-0.027 \\
(0.023)\end{array}$ & & \\
\hline $\mathrm{d}_{85} * m_{i}$ & & & $\begin{array}{l}1.894 \\
(0.634)\end{array}$ & & & & & $\begin{array}{l}0.065 \\
(0.025\end{array}$ & & \\
\hline $\mathrm{d}_{86} * m_{i}$ & & & $\begin{array}{l}0.696 \\
(0.619)\end{array}$ & & & & & $\begin{array}{l}0.067 \\
(0.030\end{array}$ & & \\
\hline
\end{tabular}

Notes: Dependent variable is number of facilities. All regressions include hospital and year fixed effects. Mean dependent variable is 25 . Left hand panel shows results from estimating equations (24) - (27) by OLS. Right hand side panel shows results from estimating the conditional fixed effect Poisson model in equation (29) with quasi maximum likelihood. POST is an indicator variable for the years $1984-1986$. POSTTREND is 0 through 1983 and then takes the values 1 , 2, and 3 in 1984 , 1985, and 1986 respectively. $d_{t}$ is an indicator variable for year $t . m_{i}$ measures the Medicare share of the hospital's inpatient days in 1983. Standard errors are in parentheses. Standard errors are adjusted to allow for an arbitrary covariance matrix within each hospital over time. $\mathrm{N}=43,188$. In column (3), omitted category is $\mathrm{d}_{80} * m_{i}$. To interpret the magnitudes, recall that the average Medicare share in 1983 is about two-fifths. 
Table 7: The Impact of PPS on Technology Adoption II: Hazard models of technology adoption

\begin{tabular}{|c|c|c|c|c|c|c|c|c|c|c|}
\hline & \multicolumn{2}{|c|}{ Cardiac Technologies } & \multicolumn{2}{|c|}{ Diagnostic Radiology } & \multicolumn{2}{|c|}{ Other technologies } & \multicolumn{4}{|c|}{ Radiation Therapy (Cancer Treatment) } \\
\hline & $\begin{array}{l}\text { Cardiac } \\
\text { Catheter- } \\
\text { ization }\end{array}$ & $\begin{array}{l}\text { Open } \\
\text { Heart } \\
\text { Surgery }\end{array}$ & $\begin{array}{l}\text { CT } \\
\text { scan }\end{array}$ & $\begin{array}{l}\text { Diagnostic } \\
\text { Radio- } \\
\text { isotope }\end{array}$ & $\begin{array}{l}\text { Neo-natal } \\
\text { intensive } \\
\text { care }\end{array}$ & $\begin{array}{l}\text { Organ } \\
\text { Transplant }\end{array}$ & $\begin{array}{l}\text { Megavoltage } \\
\text { Radiation } \\
\text { Therapy }\end{array}$ & $\begin{array}{l}\text { Radio- } \\
\text { active } \\
\text { Implants }\end{array}$ & $\begin{array}{l}\text { Therapeutic } \\
\text { Radioisotope } \\
\text { Facility }\end{array}$ & $\begin{array}{l}\text { X-ray } \\
\text { Radia- } \\
\text { tion }\end{array}$ \\
\hline \multicolumn{11}{|c|}{ Panel A: Exponential Proportional Hazard Model } \\
\hline $\mathrm{POST}^{*} m_{i}$ & $\begin{array}{l}1.23 \\
(0.481) \\
{[0.071]}\end{array}$ & $\begin{array}{l}2.61 \\
(0.683) \\
{[0.001]}\end{array}$ & $\begin{array}{l}0.928 \\
(0.259) \\
{[0.003]}\end{array}$ & $\begin{array}{l}0.666 \\
(0.265) \\
{[0.072]}\end{array}$ & $\begin{array}{l}3.83 \\
(0.663) \\
{[<0.0001]}\end{array}$ & $\begin{array}{l}1.74 \\
(0.785) \\
{[0.116]}\end{array}$ & $\begin{array}{l}1.76 \\
(0.782) \\
{[0.116]}\end{array}$ & $\begin{array}{l}-0.74 \\
(0.508) \\
{[0.383]}\end{array}$ & $\begin{array}{l}-0.096 \\
(0.490) \\
{[0.975]}\end{array}$ & $\begin{array}{l}-0.081 \\
(0.601) \\
{[0.975]}\end{array}$ \\
\hline $\mathrm{d}_{83} * m_{i}$ & $\begin{array}{l}0.24 \\
(0.692) \\
{[0.978]}\end{array}$ & $\begin{array}{l}1.48 \\
(1.054) \\
{[0.745]}\end{array}$ & $\begin{array}{l}0.769 \\
(0.343) \\
{[0.218]}\end{array}$ & $\begin{array}{l}-0.024 \\
(0.312) \\
{[0.996]}\end{array}$ & $\begin{array}{l}1.14 \\
(0.843) \\
{[0.745]}\end{array}$ & $\begin{array}{l}1.07 \\
(1.30) \\
{[0.885]}\end{array}$ & $\begin{array}{l}-1.397 \\
(1.026) \\
{[0.745]}\end{array}$ & $\begin{array}{l}-0.72 \\
(0.769) \\
{[0.883]}\end{array}$ & $\begin{array}{l}0.008 \\
(0.738) \\
{[0.996]}\end{array}$ & $\begin{array}{l}1.70 \\
(1.01) \\
{[0.584]}\end{array}$ \\
\hline 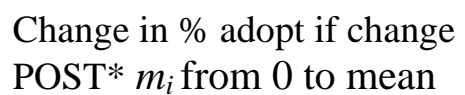 & 0.025 & 0.004 & 0.086 & 0.054 & 0.008 & 0.003 & 0.004 & -0.021 & -0.003 & -0.001 \\
\hline \multicolumn{11}{|c|}{ Panel B: Cox Proportional Hazard Model } \\
\hline $\mathrm{POST}^{*} m_{i}$ & $\begin{array}{l}1.13 \\
(0.480) \\
{[0.129]}\end{array}$ & $\begin{array}{l}2.48 \\
(0.680) \\
{[0.002]}\end{array}$ & $\begin{array}{l}0.783 \\
(0.259) \\
{[0.024]}\end{array}$ & $\begin{array}{l}0.577 \\
(0.266) \\
{[0.165]}\end{array}$ & $\begin{array}{l}3.69 \\
(0.659) \\
{[<0.0001]}\end{array}$ & $\begin{array}{l}1.61 \\
(0.783) \\
{[0.165]}\end{array}$ & $\begin{array}{l}1.69 \\
(0.786) \\
{[0.165]}\end{array}$ & $\begin{array}{l}-0.826 \\
(0.511) \\
{[0.281]}\end{array}$ & $\begin{array}{l}-0.183 \\
(0.490) \\
{[0.921]}\end{array}$ & $\begin{array}{l}-0.188 \\
(0.601) \\
{[0.921]}\end{array}$ \\
\hline $\mathrm{d}_{83} * m_{i}$ & $\begin{array}{l}-0.795 \\
(0.510) \\
{[0.511]}\end{array}$ & $\begin{array}{l}-0.086 \\
(0.657) \\
{[0.984]}\end{array}$ & $\begin{array}{l}0.204 \\
(0.300) \\
{[0.932]}\end{array}$ & $\begin{array}{l}-0.659 \\
(0.253) \\
{[0.070]}\end{array}$ & $\begin{array}{l}0.205 \\
(0.641) \\
{[0.982]}\end{array}$ & $\begin{array}{l}0.023 \\
(0.894) \\
{[0.984]}\end{array}$ & $\begin{array}{l}-2.54 \\
(0.725) \\
{[0.003]}\end{array}$ & $\begin{array}{l}-1.598 \\
(0.568) \\
{[0.040]}\end{array}$ & $\begin{array}{l}-1.160 \\
(0.513) \\
{[0.145]}\end{array}$ & $\begin{array}{l}-0.562 \\
(0.556) \\
{[0.838]}\end{array}$ \\
\hline $\begin{array}{l}\text { Change in \% adopt if change } \\
\text { POST }^{*} m_{i} \text { from } 0 \text { to mean }\end{array}$ & 0.053 & 0.053 & 0.090 & 0.088 & 0.12 & 0.016 & 0.061 & -0.029 & -0.002 & -0.004 \\
\hline $\begin{array}{l}\text { Mean adoption rate } \\
\mathrm{N}\end{array}$ & $\begin{array}{l}0.066 \\
4,861\end{array}$ & $\begin{array}{l}0.033 \\
5,130\end{array}$ & $\begin{array}{l}0.41 \\
4,739\end{array}$ & $\begin{array}{l}0.36 \\
2,758\end{array}$ & $\begin{array}{l}0.066 \\
5,301\end{array}$ & $\begin{array}{l}0.040 \\
5,437\end{array}$ & $\begin{array}{l}0.036 \\
4,950\end{array}$ & $\begin{array}{l}0.082 \\
4,542\end{array}$ & $\begin{array}{l}0.092 \\
4,485\end{array}$ & $\begin{array}{l}0.073 \\
4,741\end{array}$ \\
\hline
\end{tabular}

Notes: Tables show coefficients from proportional hazard models. Censoring occurs if have not adopted by 1986 . All estimates include covariates for the following hospital characteristics in 1983: Medicare share of patient days, Medicare share of patient days squared, number of beds, and indicator variables for state, whether in an MSA, whether a general hospital, whether a short term hospital, and whether a federal hospital. Estimates using the exponential model also include year fixed effects. POST is an indicator variable for the years $1984-1986 . \mathrm{d}_{83}$ is an indicator variable for year 1983 . $m_{i}$ measures the Medicare share of the hospital's inpatient days in 1983. "Change in \% adopt if change POST* $m_{i}$ from mean to 0" denotes the difference in the average hospital adoption (by 1986) rate if all variables are set to their mean except for POST* $m_{i}$ which is set to 0 , relative to if all variables (including POST* $m_{i}$ ) are set to their mean. Heteroskedasticity-robust standard errors are in parentheses. Familywise adjusted p-values based on 10,000 iterations are in square brackets (see text for more details); these tend to be about 5 times larger than the

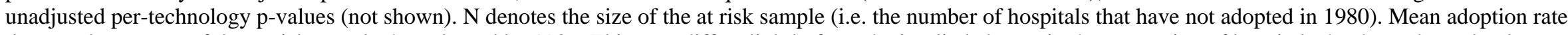
denotes the percent of the at-risk sample that adopted by 1986. This may differ slightly from the implied change in the proportion of hospitals that have the technology between 1980 and 1986 in Figure 5 because Figure 5 is done in a cross-section while the estimates in the table are done in a panel, and hospitals occasionally change their report from having to not having a technology; we have verified that the results in Table 7 are robust to alternative ways of treating this measurement error. 
Table 8: The Impact of PPS on Log Length of Stay

\begin{tabular}{llllll}
\hline \hline & $(1)$ & $(2)$ & $(3)$ & $(4)$ & $(5)$ \\
\hline POST $m_{i}$ & -0.100 & -0.102 & & & \\
POSTTREND* $m_{i}$ & $(0.022)$ & $(0.024)$ & & -0.032 & -0.030 \\
& & & & $(0.010)$ & $(0.011)$ \\
$\mathrm{d}_{82} * m_{i}$ & & & 0.049 & & \\
$\mathrm{~d}_{83} * m_{i}$ & & & $(0.021)$ & & 0.019 \\
& & -0.006 & 0.019 & & $(0.015)$ \\
$\mathrm{d}_{84} * m_{i}$ & & $(0.017)$ & $(0.022)$ & & \\
$\mathrm{d}_{85} * m_{i}$ & & & -0.078 & & \\
& & & $(0.028)$ & & \\
$\mathrm{d}_{86} * m_{i}$ & & & -0.120 & & \\
& & & $-0.032)$ & & \\
\hline \hline
\end{tabular}

Notes: Dependent variable is log length of stay; length of stay is defined as patient days / admissions. Table reports results from estimating equations (24) - (27) by OLS. All regressions include hospital and year fixed effects. Data from 1980 is excluded from the analysis and for the cross-sectional variation, Medicare share of inpatient days $m_{\mathrm{i}}$ is measured in 1980 (instead of in 1983 as in other analyses). POST is an indicator variable for the years $1984-1986$. POSTTREND is 0 through 1983 and then takes the values 1, 2, and 3 in 1984, 1985, and 1986 respectively. $d_{t}$ is an indicator variable for year $t$. Standard errors are in parentheses. Standard errors are adjusted to allow for an arbitrary covariance matrix within each hospital over time. $\mathrm{N}=36,609$. In column (3), omitted category is $\mathrm{d}_{81} * m_{\mathrm{i}}$ 
Table 9: The Impact of PPS on the Share of Nurse Employment that is Skilled Nurses

\begin{tabular}{|c|c|c|c|c|c|}
\hline & (1) & (2) & (3) & (4) & (5) \\
\hline $\mathrm{POST}^{*} m_{i}$ & $\begin{array}{l}3.46 \\
(0.578)\end{array}$ & $\begin{array}{l}3.74 \\
(0.647)\end{array}$ & & & \\
\hline POSTTREND* $m_{i}$ & & & & $\begin{array}{l}1.58 \\
(0.254)\end{array}$ & $\begin{array}{l}1.67 \\
(0.272)\end{array}$ \\
\hline $\mathrm{d}_{81} * m_{i}$ & & & $\begin{array}{l}-0.280 \\
(0.676)\end{array}$ & & \\
\hline $\mathrm{d}_{82} * m_{i}$ & & & $\begin{array}{l}-0.575 \\
(0.775)\end{array}$ & & \\
\hline $\mathrm{d}_{83} * m_{i}$ & & $\begin{array}{l}1.09 \\
(0.612)\end{array}$ & $\begin{array}{l}0.805 \\
(0.819)\end{array}$ & & $\begin{array}{l}0.876 \\
(0.567)\end{array}$ \\
\hline $\mathrm{d}_{84} * m_{i}$ & & & $\begin{array}{l}2.40 \\
(0.899)\end{array}$ & & \\
\hline $\mathrm{d}_{85} * m_{i}$ & & & $\begin{array}{l}3.56 \\
(0.917)\end{array}$ & & \\
\hline $\mathrm{d}_{86} * m_{i}$ & & & $\begin{array}{l}4.44 \\
(0.942)\end{array}$ & & \\
\hline
\end{tabular}

Notes: Dependent variable is RN/(RN+LPN). Table reports results from estimating equations (24) - (27) by OLS. All regressions include hospital and year fixed effects. Mean dependent variable is 70. POST is an indicator variable for the years 1984 - 1986. POSTTREND is 0 through 1983 and then takes the values 1, 2, and 3 in 1984, 1985, and 1986 respectively. $d_{t}$ is an indicator variable for year $t . m_{i}$ measures the Medicare share of the hospital's inpatient days in 1983. Standard errors are in parentheses. Standard errors are adjusted to allow for an arbitrary covariance matrix within each hospital over time. $\mathrm{N}=$ 43,162. In column (3), omitted category is $d_{80} * m_{i}$. To interpret the magnitudes, recall that the average Medicare share in 1983 is about two-fifths. 
Table 10: Robustness Analysis I: Alternative Specifications

\begin{tabular}{|c|c|c|c|c|c|c|c|c|c|}
\hline & $\begin{array}{l}\text { Base } \\
\text { Case } \\
(1)\end{array}$ & $\begin{array}{l}\text { Add linear } \\
\text { trend } * m_{i} \\
\text { (2) }\end{array}$ & $\begin{array}{l}\text { Add year } \\
\text { dummies * } \\
\text { dep var in } 82 \\
\text { (3) }\end{array}$ & $\begin{array}{l}\text { First } \\
\text { Differences } \\
(4)\end{array}$ & $\begin{array}{l}\text { Instrument } \\
\text { for } m_{i} \text { with } \\
\text { past values } \\
(5)\end{array}$ & $\begin{array}{l}\text { Add year * } \\
\text { region } \\
\text { dummies } \\
\text { (6) }\end{array}$ & $\begin{array}{l}\text { Exclude } \\
\text { small rural } \\
\text { hospitals } \\
\text { (7) }\end{array}$ & $\begin{array}{l}\text { Weighted } \\
\text { (8) }\end{array}$ & $\begin{array}{l}\text { Add POSTTREND* } \\
\text { birthshare and } \\
d_{83} * \text { birthshare } \\
\text { (9) }\end{array}$ \\
\hline \multicolumn{10}{|c|}{ Panel A: Dependent Variable is Capital Labor Ratio (depreciation share) } \\
\hline POSTTREND* $m_{i}$ & $\begin{array}{l}0.532 \\
(0.053)\end{array}$ & $\begin{array}{l}0.633 \\
(0.114)\end{array}$ & $\begin{array}{l}0.657 \\
(0.097)\end{array}$ & $\begin{array}{l}0.532 \\
(0.059)\end{array}$ & $\begin{array}{l}0.511 \\
(0.052)\end{array}$ & $\begin{array}{l}0.532 \\
(0.052)\end{array}$ & $\begin{array}{l}0.684 \\
(0.054)\end{array}$ & $\begin{array}{l}0.682 \\
(0.057)\end{array}$ & $\begin{array}{l}0.531 \\
(0.054)\end{array}$ \\
\hline $\mathrm{d}_{83} * m_{i}$ & $\begin{array}{l}-0.060 \\
(0.088)\end{array}$ & $\begin{array}{l}0.040 \\
(0.110)\end{array}$ & $\begin{array}{l}-0.068 \\
(0.182)\end{array}$ & $\begin{array}{l}0.064 \\
(0.079)\end{array}$ & $\begin{array}{l}-0.131 \\
(0.087)\end{array}$ & $\begin{array}{l}-0.034 \\
(0.088)\end{array}$ & $\begin{array}{l}0.061 \\
(0.010)\end{array}$ & $\begin{array}{l}-0.015 \\
(0.104)\end{array}$ & $\begin{array}{l}-0.098 \\
(0.092)\end{array}$ \\
\hline $\mathrm{N}$ & 43,188 & 43,188 & 43,041 & 36,900 & 42,428 & 43,188 & 35,339 & 41,024 & 43,181 \\
\hline \multicolumn{10}{|c|}{ Panel B: Dependent Variable is Log Labor Inputs (log operating expenses) } \\
\hline POSTTREND* $m_{i}$ & $\begin{array}{l}-0.068 \\
(0.008)\end{array}$ & $\begin{array}{l}-0.084 \\
(0.014)\end{array}$ & $\begin{array}{l}-0.066 \\
(0.008)\end{array}$ & $\begin{array}{l}-0.067 \\
(0.007)\end{array}$ & $\begin{array}{l}-0.067 \\
(0.007)\end{array}$ & $\begin{array}{l}-0.061 \\
(0.008)\end{array}$ & $\begin{array}{l}-0.052 \\
(0.008)\end{array}$ & $\begin{array}{l}-0.030 \\
(0.010)\end{array}$ & $\begin{array}{l}-0.071 \\
(0.008)\end{array}$ \\
\hline $\mathrm{d}_{83} * m_{i}$ & $\begin{array}{l}0.022 \\
(0.013)\end{array}$ & $\begin{array}{l}0.006 \\
(0.013)\end{array}$ & $\begin{array}{l}0.023 \\
(0.013)\end{array}$ & $\begin{array}{l}0.007 \\
(0.010)\end{array}$ & $\begin{array}{l}0.034 \\
(0.012)\end{array}$ & $\begin{array}{l}0.024 \\
(0.013)\end{array}$ & $\begin{array}{l}0.044 \\
(0.014)\end{array}$ & $\begin{array}{l}0.054 \\
(0.014)\end{array}$ & $\begin{array}{l}-0.021 \\
(0.013)\end{array}$ \\
\hline $\mathrm{N}$ & 43,188 & 43,188 & 43,041 & 36,900 & 42,428 & 43,188 & 35,339 & 41,024 & 43,181 \\
\hline \multicolumn{10}{|c|}{ Panel C: Dependent Variable is Log Capital Inputs (log depreciation expenses) } \\
\hline POSTTREND* $m_{i}$ & $\begin{array}{l}-0.023 \\
(0.016)\end{array}$ & $\begin{array}{l}0.040 \\
(0.033)\end{array}$ & $\begin{array}{l}-0.013 \\
(0.016)\end{array}$ & $\begin{array}{l}-0.019 \\
(0.017)\end{array}$ & $\begin{array}{l}-0.031 \\
(0.017)\end{array}$ & $\begin{array}{l}-0.015 \\
(0.016)\end{array}$ & $\begin{array}{l}0.024 \\
(0.018)\end{array}$ & $\begin{array}{l}0.041 \\
(0.022)\end{array}$ & $\begin{array}{l}-0.028 \\
(0.017)\end{array}$ \\
\hline $\mathrm{d}_{83} * m_{i}$ & $\begin{array}{l}0.049 \\
(0.039)\end{array}$ & $\begin{array}{l}0.111 \\
(0.042)\end{array}$ & $\begin{array}{l}0.057 \\
(0.039)\end{array}$ & $\begin{array}{l}0.096 \\
(0.034)\end{array}$ & $\begin{array}{l}0.028 \\
(0.039)\end{array}$ & $\begin{array}{l}0.059 \\
(0.040)\end{array}$ & $\begin{array}{l}0.091 \\
(0.042)\end{array}$ & $\begin{array}{l}0.045 \\
(0.044)\end{array}$ & $\begin{array}{l}0.035 \\
(0.039)\end{array}$ \\
\hline $\mathrm{N}$ & 40,888 & 40,888 & 40,079 & 34,468 & 40,169 & 40,888 & 33,418 & 39,273 & 40,883 \\
\hline \multicolumn{10}{|c|}{ Panel D: Dependent Variable is Number of Facilities: } \\
\hline $\mathrm{POST}^{*} m_{i}$ & $\begin{array}{l}2.501 \\
(0.401)\end{array}$ & $\begin{array}{l}4.254 \\
(0.731)\end{array}$ & $\begin{array}{l}2.267 \\
(0.378)\end{array}$ & $\begin{array}{l}2.478 \\
(0.427)\end{array}$ & $\begin{array}{l}3.010 \\
(0.383)\end{array}$ & $\begin{array}{l}2.041 \\
(0.406)\end{array}$ & $\begin{array}{l}1.260 \\
(0.463)\end{array}$ & $\begin{array}{l}1.560 \\
(0.613)\end{array}$ & $\begin{array}{l}2.50 \\
(0.411)\end{array}$ \\
\hline $\mathrm{d}_{83} * m_{i}$ & $\begin{array}{l}-0.467 \\
(0.354)\end{array}$ & $\begin{array}{l}0.410 \\
(0.459)\end{array}$ & $\begin{array}{l}-0.566 \\
(0.347)\end{array}$ & $\begin{array}{l}0.688 \\
(0.333)\end{array}$ & $\begin{array}{l}-0.204 \\
(0.353)\end{array}$ & $\begin{array}{l}-0.737 \\
(0.360)\end{array}$ & $\begin{array}{l}-1.521 \\
(0.416)\end{array}$ & $\begin{array}{l}-1.777 \\
(0.507)\end{array}$ & $\begin{array}{l}-0.453 \\
(0.363)\end{array}$ \\
\hline $\mathrm{N}$ & 43,188 & 43,188 & 43,041 & 36,900 & 42,428 & 43,188 & 35,339 & 41,024 & 43,181 \\
\hline
\end{tabular}

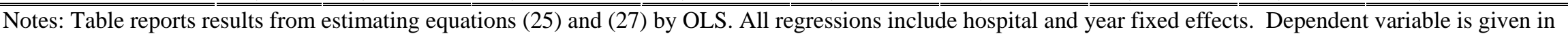
panel heading POST is an indicator variable for the years 1984 - 1986. POSTTREND is 0 through 1983 and then takes the values 1, 2, and 3 in 1984, 1985, and 1986 respectively. $d_{83}$ is an indicator variable for year 1983. $m_{i}$ measures the Medicare share of the hospital's inpatient days in 1983 . Base case includes year and hospital fixed effects. Column 2 adds linear time trend interacted with Mcrshare_83 to base case. Column 3 adds year dummies interacted with log total expenditures in 82 to base case. Column 4 redoes base case in first differences instead of fixed effects. Column 5 instruments for Medicare share in 1983 with past values of the hospital's Medicare share (specifically, the values in 1980, 1981, and 1982). Column 6 adds year dummies interacted with census region dummies (nine) to base case. Column 7 excludes hospitals that are not in an MSA and that have less than 50 beds in 1983. Column 8 weights each hospital by its size (number of beds) in 1983 while excluding the top ventile by size. Column 9 adds POSTTREND*birthshare and $\mathrm{d}_{83}$ *birthshare, where birthshare is the share of non-Medicare patient days accounted for by newborns in 1983. Standard errors are in parentheses and are adjusted to allow for an arbitrary covariance matrix within each hospital over time. 
Table 11: Robustness Analysis II: Estimation using within vs. between variation

\begin{tabular}{|c|c|c|c|}
\hline & $\begin{array}{l}\text { Base Case } \\
(1)\end{array}$ & $\begin{array}{l}\text { Using only within } \\
\text { variation } \\
\text { (2) }\end{array}$ & $\begin{array}{l}\text { Using only between } \\
\text { variation } \\
\text { (3) }\end{array}$ \\
\hline \multicolumn{4}{|c|}{ Panel A: Dependent Variable is Capital Labor Ratio (depreciation share) } \\
\hline POSTTREND* $m_{i}$ & $\begin{array}{l}0.532 \\
(0.053)\end{array}$ & $\begin{array}{l}0.176 \\
(0.092)\end{array}$ & $\begin{array}{l}0.787 \\
(0.044)\end{array}$ \\
\hline $\mathrm{d}_{83} * m_{i}$ & $\begin{array}{l}-0.060 \\
(0.088)\end{array}$ & $\begin{array}{l}0.041 \\
(0.146)\end{array}$ & $\begin{array}{l}-0.129 \\
(0.139)\end{array}$ \\
\hline $\mathrm{N}$ & 43,188 & 43,188 & 43,188 \\
\hline \multicolumn{4}{|c|}{ Panel B: Dependent Variable is Log Labor Inputs (log operating expenses) } \\
\hline POSTTREND* $m_{i}$ & $\begin{array}{l}-0.068 \\
(0.008)\end{array}$ & $\begin{array}{l}-0.076 \\
(0.010)\end{array}$ & $\begin{array}{l}-0.062 \\
(0.005)\end{array}$ \\
\hline $\mathrm{d}_{83} * m_{i}$ & $\begin{array}{l}0.022 \\
(0.013)\end{array}$ & $\begin{array}{l}-0.059 \\
(0.018)\end{array}$ & $\begin{array}{l}0.079 \\
(0.014)\end{array}$ \\
\hline $\mathrm{N}$ & 43,188 & 43,188 & 43,188 \\
\hline \multicolumn{4}{|c|}{ Panel C: Dependent Variable is Log Capital Inputs (log depreciation expenses) } \\
\hline POSTTREND* $m_{i}$ & $\begin{array}{l}-0.023 \\
(0.016)\end{array}$ & $\begin{array}{l}-0.030 \\
(0.022)\end{array}$ & $\begin{array}{l}-0.015 \\
(0.012)\end{array}$ \\
\hline $\mathrm{d}_{83} * m_{i}$ & $\begin{array}{l}0.049 \\
(0.039)\end{array}$ & $\begin{array}{l}0.031 \\
(0.050)\end{array}$ & $\begin{array}{l}0.067 \\
(0.039)\end{array}$ \\
\hline $\mathrm{N}$ & 40,888 & 40,888 & 40,888 \\
\hline \multicolumn{4}{|c|}{ Panel D: Dependent Variable is Number of Facilities } \\
\hline $\mathrm{POST}^{*} m_{i}$ & $\begin{array}{l}2.501 \\
(0.401)\end{array}$ & $\begin{array}{l}2.418 \\
(0.632)\end{array}$ & $\begin{array}{l}2.561 \\
(0.404)\end{array}$ \\
\hline $\mathrm{d}_{83} * m_{i}$ & $\begin{array}{l}-0.467 \\
(0.354)\end{array}$ & $\begin{array}{l}0.135 \\
(0.553)\end{array}$ & $\begin{array}{l}-0.896 \\
(0.561)\end{array}$ \\
\hline $\mathrm{N}$ & 43,188 & 43,188 & 43,188 \\
\hline
\end{tabular}

Notes: Table reports results from estimating equations (25) and (27) by OLS. All regressions include hospital and year fixed effects. Dependent variable is given in panel heading POST is an indicator variable for the years $1984-1986$. POSTTREND is 0 through 1983 and then takes the values 1, 2, and 3 in 1984, 1985, and 1986 respectively. $d_{83}$ is an indicator variable for year 1983. $m_{i}$ measures the Medicare share of the hospital's inpatient days in 1983. Base case includes year and hospital fixed effects. Column 2 ("using only within variation") adds a full set of year dummies interacted with each of the three categorical variables that can make a hospital exempt from PPS (federal ownership, long-term stays, or specialty hospital) so that the identification of the variables of interest comes only from within hospital type variation in Medicare share. Column 3 ("using only between variation") instruments for the variables shown with a full set of year dummies interacted with the three categorical variables that can make a hospital exempt from PPS, so that the identification of the variables of interest comes only from between hospital type variation in Medicare share. 
Table 12: Robustness Analysis III: Alternative Dependent Variables

\begin{tabular}{|c|c|c|c|c|c|}
\hline & Base Case & $\begin{array}{l}\text { Alternative Dependent } \\
\text { Variable I } \\
(2)\end{array}$ & $\begin{array}{l}\text { Alternative Dependent } \\
\text { Variable II } \\
\text { (3) }\end{array}$ & $\begin{array}{l}\text { Alternative Dependent } \\
\text { Variable III } \\
\text { (4) }\end{array}$ & $\begin{array}{l}\text { Alternative Dependent } \\
\text { Variable IV } \\
\text { (5) }\end{array}$ \\
\hline \multicolumn{6}{|c|}{ Panel A: Alternative Dependent Variables for Log Labor Inputs } \\
\hline & $\begin{array}{l}\text { Log Operating } \\
\text { Expenditures }\end{array}$ & Log payroll expenses & $\begin{array}{l}\text { Log non-payroll } \\
\text { operating expenses }\end{array}$ & Log total employment & Log nurses \\
\hline POSTTREND* $m_{i}$ & $\begin{array}{l}-0.068 \\
(0.008)\end{array}$ & $\begin{array}{l}-0.067 \\
(0.009)\end{array}$ & $\begin{array}{l}-0.098 \\
(0.009)\end{array}$ & $\begin{array}{l}-0.095 \\
(0.007)\end{array}$ & $\begin{array}{l}-0.068 \\
(0.009)\end{array}$ \\
\hline $\mathrm{d}_{83} * m_{i}$ & $\begin{array}{l}0.022 \\
(0.013)\end{array}$ & $\begin{array}{l}0.011 \\
(0.017)\end{array}$ & $\begin{array}{l}0.018 \\
(0.016)\end{array}$ & $\begin{array}{l}-0.044 \\
(0.013)\end{array}$ & $\begin{array}{l}0.040 \\
(0.017)\end{array}$ \\
\hline $\mathrm{N}$ & 43,188 & 43,188 & 43,161 & 43,188 & 43,162 \\
\hline \multicolumn{6}{|c|}{ Panel B: Alternative Dependent Variables for Log Capital Inputs } \\
\hline & $\begin{array}{l}\text { Log } \\
\text { Depreciation }\end{array}$ & $\begin{array}{l}\text { Log (interest }+ \\
\text { depreciation) }\end{array}$ & Log interest & & \\
\hline POSTTREND* $m_{i}$ & $\begin{array}{l}-0.023 \\
(0.016)\end{array}$ & $\begin{array}{l}-0.020 \\
(0.022)\end{array}$ & $\begin{array}{l}0.016 \\
(0.040)\end{array}$ & & \\
\hline $\mathrm{d}_{83} * m_{i}$ & $\begin{array}{l}0.049 \\
(0.039)\end{array}$ & $\begin{array}{l}0.451 \\
(0.071)\end{array}$ & $\begin{array}{l}-0.292 \\
(0.092)\end{array}$ & & \\
\hline $\mathrm{N}$ & 40,888 & 41,150 & 36,286 & & \\
\hline Panel C: Alternat & $\begin{array}{l}\text { ve Dependent I } \\
\text { (Depreciation/ } \\
\text { Operating) }\end{array}$ & $\begin{array}{l}\text { ariables for Capital Lal } \\
\text { (Depreciation / Payroll) }\end{array}$ & $\begin{array}{l}\text { Ratio } \\
\text { (Interest + } \\
\text { Depreciation)/ } \\
\text { Operating }\end{array}$ & Interest / Operating & \\
\hline POSTTREND* $m_{i}$ & $\begin{array}{l}0.532 \\
(0.053)\end{array}$ & $\begin{array}{l}0.546 \\
(0.069)\end{array}$ & $\begin{array}{l}0.921 \\
(0.102)\end{array}$ & $\begin{array}{l}0.389 \\
(0.067)\end{array}$ & \\
\hline $\mathrm{d}_{83}{ }^{*} m_{i}$ & $\begin{array}{l}-0.060 \\
(0.088)\end{array}$ & $\begin{array}{l}-0.272 \\
(0.137)\end{array}$ & $\begin{array}{l}-0.318 \\
(0.184)\end{array}$ & $\begin{array}{l}-0.258 \\
(0.133)\end{array}$ & \\
\hline Mean dep var & 4.50 & 6.91 & 7.12 & 2.62 & \\
\hline $\mathrm{N}$ & 43,188 & 43,188 & 43,188 & 43,188 & \\
\hline
\end{tabular}

Notes: Table reports results from estimating equation (27) by OLS. All regressions include hospital and year fixed effects. Dependent variable is given in column heading; first column always shows results for the dependent variable used in the main specifications above. POST is an indicator variable for the years 1984 - 1986. POSTTREND is 0 through 1983 and then takes the values 1, 2, and 3 in 1984, 1985, and 1986 respectively. $d_{83}$ is an indicator variable for year 1983. $m_{i}$ measures the Medicare share of the hospital's inpatient days in 1983. Base case includes year and hospital fixed effects. Other columns substitute alternative measures of dependent variable, as indicated. Standard errors are in parentheses. Standard errors are adjusted to allow for an arbitrary covariance matrix within each hospital over time. 


\begin{tabular}{|c|c|c|}
\hline Facility Description & Years in Data & $\begin{array}{l}\text { Sample } \\
\text { Mean }\end{array}$ \\
\hline Abortion Services (Inpatient or Outpatient) & $1980-85$ & 0.22 \\
\hline Adult Day Care & 1986 & 0.05 \\
\hline Acquired Immune-Deficiency Syndrome (AIDS) Services & 1986 & 0.28 \\
\hline Alcoholism/Chemical Dependency Acute and Subacute Inpatient Care & $1980-85$ & 0.26 \\
\hline Alcoholism/Chemical Dependency Services (Outpatient) & $1981-86$ & 0.17 \\
\hline Ambulance Services & $1980-81$ & 0.17 \\
\hline Anesthesia Service & $1980-81$ & 0.72 \\
\hline Ambulatory Surgical Services & $1981-86$ & 0.80 \\
\hline Autopsy Services & $1980-81$ & 0.47 \\
\hline Hospital Auxiliary & $1980-86$ & 0.75 \\
\hline Blood Bank & $1980-86$ & 0.64 \\
\hline Burn Care & $1980-85$ & 0.09 \\
\hline Birthing Room & $1985-86$ & 0.44 \\
\hline Cancer Tumor Registry & $1980-81$ & 0.30 \\
\hline Cardiac Intensive Care & $1980-85$ & 0.67 \\
\hline Cardiac Catheterization & $1980-86$ & 0.16 \\
\hline Chaplaincy Services & 1980-85 & 0.55 \\
\hline Clinical Psychology Services & $1980-86$ & 0.33 \\
\hline Community Health Promotion & 1986 & 0.54 \\
\hline Continuing Care Case Management & 1986 & 0.15 \\
\hline Contraceptive Care & 1986 & 0.09 \\
\hline C.T. Scanner (Head or Body Unit) & $1980-86$ & 0.34 \\
\hline Day Hospital & $1981-86$ & 0.17 \\
\hline Dental Services & $1980-85$ & 0.48 \\
\hline Diagnostic Radioisotope Facility & $1980-86$ & 0.56 \\
\hline Diagnostic X-Ray & $1985-86$ & 0.89 \\
\hline Electrocardiography & $1980-85$ & 0.91 \\
\hline Electroencephalography & $1980-81$ & 0.50 \\
\hline Emergency Department & $1981-86$ & 0.85 \\
\hline Electromyography & $1980-81$ & 0.27 \\
\hline Extracorporeal Shock-Wave Lithotripter & $1985-86$ & 0.02 \\
\hline Family Planning & $1980-85$ & 0.10 \\
\hline Pharmacy Service (Full or Part Time) & 1980-85 & 0.91 \\
\hline Pharmacy Unit Dose System & $1980-85$ & 0.71 \\
\hline Fertility Counseling & 1986 & 0.09 \\
\hline Fitness Center & 1986 & 0.09 \\
\hline General Laboratory Services & $1980-81,1984-85$ & 0.88 \\
\hline Genetic Screening & 1986 & 0.06 \\
\hline Genetic Counseling & $1980-86$ & 0.06 \\
\hline Geriatric Acute-Care Unit & 1986 & 0.12 \\
\hline Comprehensive Geriatric Assessment Services & 1982-86 & 0.13 \\
\hline Satellite Geriatric Clinics & 1986 & 0.02 \\
\hline General Surgical Services & $1980-81,1983-85$ & 0.87 \\
\hline Hemodialysis (Home Care/Mobile Unit) & $1980-81$ & 0.04 \\
\hline Histopathology Services & $1980-86$ & 0.56 \\
\hline Hemodialysis Services (Inpatient or Outpatient) & $1980-86$ & 0.21 \\
\hline Home Care Program & $1980-86$ & 0.18 \\
\hline
\end{tabular}




\author{
Hospice \\ Health Promotion \\ Intermediate Care For Mentally Retarded \\ Intermediate Care, Other \\ Intravenous Admixture Services \\ Intravenous Therapy Team \\ Medical Library \\ Megavoltage Radiation Therapy \\ Medical/Surgical Acute Care \\ Medical/Surgical Intensive Care \\ Newborn Nursery \\ Neonatal Intensive Care \\ Neurosurgery \\ Nuclear Magnetic Resonance Facility \\ Obstetrical Care \\ Occupational Health Services \\ Open-Heart Surgery \\ Organ Transplant (Including Kidney) \\ Organized Outpatient Department \\ Optometric Services \\ Organ Bank \\ Occupational Therapy \\ Patient Education \\ Patient Representative Services \\ Pediatric Acute Care \\ Pediatric Intensive Care \\ Percutaneous Lithotripsy \\ Pulmonary Function Laboratory \\ Podiatric Services (Inpatient or Outpatient) \\ Postoperative Recovery Room \\ Premature Nursery \\ Psychiatric Acute Care \\ Psychiatric Consultation And Education \\ Psychiatric Emergency Services \\ Psychiatric Foster An/Or Home Care Program \\ Psychiatric Intensive Care \\ Psychiatric Liason Services \\ Psychiatric Long-Term Care \\ Psychiatric Outpatient Services \\ Psychiatric Services, Pediatric \\ Physical Therapy \\ Radioactive Implants \\ Recreational Therapy \\ Rehabilitation \\ Rehabilitation Services (Outpatient) \\ Residential Care \\ Respit Care \\ Respiratory Therapy \\ Sheltered Care
}

1980-86

0.08

1981-85

0.40

1980-85

0.03

1980-85

0.13

1980-85

0.71

1980

0.25

1980-81

0.84

1980-86

0.14

1980-85

0.91

1980-85

0.74

1980-85

0.70

1980-85

0.09

1980-81

0.29

1983-86

0.04

1980-85

0.70

1986

0.23

1980-86 $\quad 0.11$

1980-86

0.05

1981-86

0.49

1981-85

0.16

1980-81

0.03

1980-86

0.40

1986

0.67

1980-86

0.49

1980-85

0.75

1980-85

0.18

1985

0.11

1980-81

0.58

1980-85

0.31

1980-82

0.83

1980-85

0.26

1980-85

0.36

1980-86

0.29

1981-86

0.32

1980-86

0.03

1980-82

0.13

1983-86

0.16

1980-85

0.06

1981-86

0.18

1981-86

0.14

1980-86

0.13

1980-86

0.79

1980-86

0.20

1980-86

0.30

1980-85

0.30

1981-86

0.32

1980

0.05

1986

0.09

1980-86

0.81

1981-85

0.02 


$\begin{array}{lll}\text { Self Care } & 1980-85 & 0.06 \\ \text { Long Term-Skilled Nursing } & 1980-85 & 0.16 \\ \text { Social Work Services } & 1980-85 & 0.77 \\ \text { Speech Therapy } & 1980-86 & 0.36 \\ \text { Other Special Care } & 1981-85 & 0.22 \\ \text { Sports Medicine Clinic/Service } & 1986 & 0.11 \\ \text { Sterilization } & 1986 & 0.23 \\ \text { Toxicology/Antidote Information } & 1980-81 & 0.38 \\ \text { Tuberculosis And Other Respiratory Diseases } & 1980-86 & 0.34 \\ \text { Therapeutic Radioisotope Facility } & 1980-86 & 0.21 \\ \text { Trauma Center } & 1984-86 & 0.17 \\ \text { Ultrasound } & 1981-86 & 0.69 \\ \text { Volunteer Services } & 1980-86 & 0.65 \\ \text { Women's Center } & 1986 & 0.09 \\ \text { Worksite Health Promotion } & 1986 & 0.35 \\ \text { X-Ray Radiation Therapy } & 1980-86 & 0.16\end{array}$

Note: All facilities are coded directly from a single variable in the data except for Neonatal Intensive Care Unit where we followed the coding procedure of Baker and Phibbs (2002), and the following seven variables which we generated as a consistent series using combinations of different variables in different years:

1. "Abortion Services (Inpatient or Outpatient)": coded 1 in 1980 and 1981 if the hospital reports having either inpatient abortion services or outpatient abortion services or both; coded 1 in $1982-1985$ if the hospital reports having abortion services.

2. “Alcoholism/Chemical Dependency Acute and Subacute Inpatient Care”: coded 1 in 1984 if the hospital reports having alcohol/chemical dependency acute inpatient care or alcohol/chemical dependency subacute inpatient care or both; coded 1 in 1980-1983, 1985 if hospital reports having alcohol/chemical dependency inpatient care.

3. C.T. Scanner (Head or Body Unit): coded 1 in 1980 and 1981 if the hospital reports having either a C.T. Scanner Head Unit or a C.T. Scanner Body Unit or both; coded $11982-1986$ if the hospital reports having a C.T. Scanner.

4. Pharmacy Service (Full or Part Time): coded 1 in 1980 or 1981 if the hospital reports having either a full time or a part time pharmacist or both; coded 1 in 1982-1985 if the hospital reports having pharmacy services.

5. Hemodialysis Services (Inpatient or Outpatient): Coded 1 in 1980 and 1981 if the hospital reports having either hemodialysis inpatient services or hemodialysis outpatient services or both; coded 1 in $1982-1986$ if hospital reports having hemodialysis services.

6. Organ Transplant (Including Kidney): coded 1 in 1980-1985 if the hospital reports having either organ transplant capability (other than kidney) or kidney transplant capability or both; coded 1 in 1986 if hospital reports having organ transplant capability (including kidney).

7. Podiatric Services (Inpatient or Outpatient): Coded 1 in 1981 if the hospital reports having inpatient or outpatient podiatric services or both; coded 1 in 1980,1982-85 if hospital reports having podiatric services. 